\title{
Grey matter pathology in multiple sclerosis
}

\author{
PhD Thesis \\ in partial fulfilment of the requirements \\ for the degree "Doctor of Philosophy $(\mathrm{PhD}) / \mathrm{Dr}$. rer. nat." \\ in the Neuroscience Program \\ at the Georg August University Göttingen, \\ Faculty of Biology
}

Submitted by

Monika Albert

born in

Budapest 
Referees: Prof. Dr. Klaus-Armin Nave and Prof. Dr. Wolfgang Brück Prof. Dr. Harald Neumann

Prof. Dr. Jens Frahm 
Herewith I declare that I prepared the $\mathrm{PhD}$ thesis

'Grey matter pathology in multiple sclerosis' on my own and with no other sources and aids than quoted.

Göttingen, 23. September 2005 


\section{CONTENTS}

1. INTRODUCTION 9

1.1. Hallmarks of histopathology in multiple sclerosis 9

1.2. Immunology of multiple sclerosis 11

1.3. Repair mechanisms 12

1.3.1. Remyelination 12

$\begin{array}{ll}\text { 1.3.2. Adaptive plasticity } & 13\end{array}$

$\begin{array}{ll}\text { 1.4. Grey matter lesions } & 14\end{array}$

1.5. Aim of the study 15

2. MATERIALS AND METHODS 16

2.1. Materials and methods to study cortical de-and remyelination

2.1.1. Brain tissue 16

2.1.2. Neuropathological techniques and immunohistochemistry 17

2.1.3. In situ hybridization 17

$\begin{array}{ll}\text { 2.1.4. Electron microscopy } & 17\end{array}$

$\begin{array}{ll}\text { 2.1.5. Morphometric image analysis } & 18\end{array}$

2.1.6. Quantitative morphometry of immuno-labelled cells 18

$\begin{array}{ll}\text { 2.1.7. Extent of remyelination } & 18\end{array}$

2.2. Materials and methods to study inflammation, $\begin{array}{ll}\text { dendrites and synapses in cortical lesions } & 19\end{array}$

2.2.1. Brain tissue 19

2.2.2. Neuropathological techniques and immunohistochemistry 19

2.2.3. Quantitative morphometry of immuno-labelled structures 20

2.2.4. Image analysis, densitometry 21

2.3. Materials and methods to study synaptic contacts in the cerebellar $\begin{array}{ll}\text { dentate nucleus and in the pontine nuclei } & 21\end{array}$

2.3.1. Brain tissue prepared for histology 21

2.3.2. Brain tissue prepared for electron microscopy 22

2.3.3. Histological techniques 22

2.3.4. Electron microscopy 23

$\begin{array}{ll}\text { 2.3.5. Statistical analysis } & 23\end{array}$ 
3. RESULTS

3.1. PATHOLOGICAL HALLMARKS OF MULTIPLE SCLEROSIS

IN THE GREY MATTER: DEMYELINATION, INFLAMMATION, GLIOSIS AND NEURONAL INJURY 28

3.1.1. Demyelination in cortex of patients with chronic MS 28

3.1.1.1. Demyelinated lesions on average cover $14 \%$ $\begin{array}{ll}\text { of cortical grey matter } & 28\end{array}$

3.1.1.2. Cortical demyelination is mostly located subpially 28

3.1.2. Inflammation in cortex of patients with chronic MS 29

3.1.3. Reactive astrogliosis in chronic cortical plaque 32

3.1.4. Inflammation in cortex of patients with early MS 33

3.1.4.1. Topography of cortical plaques in early MS 34

3.1.4.2. Early cortico-subcortical lesions are highly inflammatory and destructive $\quad 34$

3.1.4.3. Small perivascular cortical lesions are less destructive 41

3.1.5. Neuronal injury 45

3.2. COMPENSATORY MECHANISMS IN THE GREY MATTER IN MULTIPLE SCLEROSIS: REMYELINATION AND ADAPTIVE REMODELLING OF SYNAPTIC CONTACTS 47

3.2.1. Remyelination of cortical lesions in patients with chronic MS 47

3.2.1.1. Remyelination is extensive in cortical MS lesions 47

3.2.1.2. Electron microscopy reveals thin myelin sheaths in remyelinated cortical lesions $\quad 47$

3.2.1.3. Oligodendrocytes are abundant in remyelinated cortical lesions 51

3.2.1.4. Remyelination of cortical lesions is more extensive than remyelination of white matter lesions 53

3.2.2. Synaptic remodelling in the cerebellar dentate nucleus and in the pons in patients with chronic MS 56

3.2.2.1. Regression and remodelling of synapses in the cerebellar dentate nucleus 56

3.2.2.1.1. Elimination of synapses is synapse and neuron specific and occurs irrespective of demyelination 56

3.2.2.1.2. Dissociation of axo-somatic and axo-stem dendritic synapses $\quad 60$

$\begin{array}{ll}\text { 3.2.2.1.3. Lysosomal degradation of synapses } & 60\end{array}$ 
3.2.2.2.1. Preserved density of the synapses

in the demyelinated pons $\quad 65$

3.2.2.2.2. Synaptic reorganisation in the demyelinated lesions of the pons 65

$\begin{array}{lr}\text { 4. DISCUSSION } & 68\end{array}$

4.1. Extensive demyelination and little inflammation

in cortical lesions in chronic MS

68

4.1.1. Humoral immunity may be responsible

for subpial lesions

4.1.2. Minor inflammation may support repair mechanisms $\begin{array}{ll}\text { in cortical lesions } & 69\end{array}$

4.2. Inflammatory demyelination in cortical lesions in early MS 70

4.2.1. Adaptive immune response and pathological heterogeneity $\begin{array}{ll}\text { in cortical lesions } & 70\end{array}$

4.2.2. Macrophages may convey axonal damage in the lesions 71

4.2.3. Grey matter BBB may prevent monocyte extravasation in cortical lesions $\quad 72$

4.2.4. Neurons may provide an "immunosuppressive" milieu 73

4.3. Cortical lesions show a high propensity for remyelination 74

4.3.1. Normal appearing cortical areas may in part be remyelinated 74

4.3.2. Oligodendrocytes are present and express myelin proteins in the majority of cortical plaques $\quad 74$

4.3.3. Cortical microenvironment is permissive for remyelination 74

4.4. Region specific remodelling of synaptic contacts in the dentate nucleus and in the pontine nuclei 75

4.4.1. Region specific synaptic remodelling in the dentate nucleus 76

4.4.2. Displacement of synapses upon postsynaptic induction in the dentate nucleus: synaptic stripping $\quad 76$

4.4.3. Displacement of synapses upon presynaptic induction in the dentate nucleus: autophagy and lysosomal $\begin{array}{ll}\text { degradation of synaptic components } & 77\end{array}$

4.4.4. Preserved synaptic density in the demyelinated pons 78 
4.4.5. Multicellular dynamic synaptic

reorganisation in the demyelinated pons

5. SUMMARY

80

6. REFERENCES

82 


\section{ACKNOWLEDGEMENTS}

I would like to acknowledge all people who supported me during the $\mathrm{PhD}$ period.

I thank Prof. Wolfgang Brück for giving me the highly interesting research project and the opportunity to work with a unique collection of human brain tissue at his well equipped department in exceptionally comfortable circumstances. I am grateful to Prof. Brück for the outstanding training in neuropathology and for the otherwise stimulating scientific atmosphere.

I thank Jun.-Prof. Dr. Christine Stadelmann-Nessler for her professional day-to-day supervision. Dr. Stadelmann introduced me to the field of histopathology with special emphasis on the pathology of multiple sclerosis, performing and interpreting immunohistochemistry, other histopathological techniques and electron microscopy, which we have used for this study. I am grateful to Dr. Stadelmann for the inspiring discussions and for her always kind and ready help in every aspect concerning my scientific career.

Part of this work was generously supported by Prof. Joachim Wolff through active participation and invaluable consultations relating to synaptic changes and a range of other issues, from general concepts to practical advice until the last interpretation of our data.

I thank Prof. Klaus-Armin Nave for his helpful advice, Prof. Harald Neumann and Prof. Jens Frahm for the supportive comments throughout my MSc-PhD years.

Finally, I would like to thank all members of the Institute of Neuropathology for the uniquely friendly working atmosphere. 


\section{INTRODUCTION}

Multiple sclerosis (MS) is the most common chronic disabling neurological disease of young adulthood. MS is a chronic disease of the central nervous system usually manifesting itself as discrete and recurrent attacks of visual impairment, motor, sensory and cognitive dysfunction. In the majority of cases these attacks are followed by remissions of symptoms or even recovery (relapsing-remitting multiple sclerosis, RRMS). Later, however, the relapsingremitting course often blends into a slow, but permanent progression (secondary progressive multiple sclerosis, SPMS). About $10 \%$ of the patients present with an insidious disease onset followed by steady progression (primary progressive multiple sclerosis, PPMS).

The pathology underlying this disorder is the formation of multiple demyelinated plaques. Lesions are typically widely disseminated in the central nervous system (CNS), with the predilection of well myelinated areas: the optic nerve, periventricular white matter, corpus callosum, cerebellum and cervical cord (Carswell, 1838). The demyelinating process is associated with persistent inflammation (Babinski, 1885). Thus, MS has traditionally been considered of as an inflammatory demyelinating disease of the white matter. Therefore, our knowledge concerning the histopathology of MS is derived mainly from studying white matter plaques.

\subsection{Hallmarks of histopathology in multiple sclerosis}

The MS lesion is characterized by demyelination, inflammation, relative axonal preservation, and gliosis (Prineas, 1985; Lassmann, 1998; Allen, 1991). By definition, MS selectively affects the myelin sheaths and the myelin forming oligodendrocytes, but leaves the nerve cells and axons -at least in part- intact. During the disease course new lesions are formed and old lesions persist. Therefore, the inflammatory and demyelinating activity often varies between the plaques.

New lesions typically evolve around small and medium sized vessels (Rindfleisch, 1863). In these early active lesions, the inflammatory process arises by mononuclear cells, which accumulate in the perivascular space and disperse in the adjacent parenchyma. Inflammatory cells in the lesion are composed of subpopulations of invading T-lymphocytes, monocytes, macrophages and resident microglial cells (Gay et al., 1997). Macrophages contain myelin degradation products due to recent myelin phagocytosis and show a foamy phenotype (Brück et al., 1994). B-lymphocytes may be present and may locally produce immunoglobulin (Prineas and Wright, 1978). The blood brain barrier (BBB) is permeable for serum proteins 
(Miller et al., 1988; Grossman et al., 1988; Estes et al., 1990). Ramified microglia cells express major histocompatibility complex (MHC) antigens and surround actively demyelinating lesions (Powell et al., 1992). Activated macrophages and microglial cells secrete high amounts of cytotoxic mediators, which are directly responsible for demyelination and oligodendroglial and neuroaxonal injury (Hallpike et al., 1970; Anthony et al., 1997; Woodroofe and Cruzner 1993).

Recent pioneer work classified four different pathomechanisms that lead to the formation of demyelinated MS plaques (Lucchinetti et al., 1996). All four immune patterns occur on the basis of T-cell and macrophage driven inflammation. The difference between the lesions rests upon the antibody deposition, the complement activation and the loss of oligodendrocytes. In pattern 1 lesions, T-cells and macrophages/microglia cells dominate in the lesion. Demyelination is mediated by the direct cytotoxicity of T-cells and toxic products released by the macrophages. Pattern 2 lesions are B-cell and antibody-mediated demyelinations. Myelin is coated by immunoglobulin and activated complement. The pathology of Pattern 3 lesions is reminiscent of hypoxia-like tissue injury, affecting initially the most distal processes of oligodendrocytes leading to loss of myelin associated glycoprotein (MAG) and to their apoptotic cell death. Pattern 4 lesions involve primary oligodendroglia dysfunction. Such a lesion is characterised by a pronounced loss of oligodendrocytes (Lassmann, 2004).

In lesions without ongoing demyelination, i.e. in chronic inactive lesions demyelinated axons embedded in a dense glial scar transverse the plaque. Oligodendrocytes are scarce. Occasionally, few T-lymphocytes and plasma cells persist in the perivascular space around fibrotic vessels (Prineas and Wright, 1978). Acute exacerbations of chronic lesions (chronic active lesions) manifest themselves as inflammatory activity confined to the lesional edge.

Axons are relatively preserved in MS plaques. However, the reduction of axonal density can reach 60\% in chronic lesions (Lovas et al., 2000; Mews et al., 1988). Axonal integrity depends on the trophic support provided by the insulating myelin sheath. Axonal injury in MS lesions occurs first during active demyelination, when CD8+ T- cells and macrophages release their inflammatory cytokines and cytotoxic substances. This early insult results in massive axonal injury (Ferguson et al., 1997; Trapp et al., 1998). The damage is however variable, by remyelination of the axons may be reversible, lasts few days or weeks. However, axonal degeneration also occurs also later in chronic inactive plaques. This "slow burning", low grade, invariable and steady axonal injury may account for much of the axonal loss and 
explain the progression and cumulative disability in progressive phase of MS (Kornek et al., 2000).

Astrocytes are important cellular components of chronic MS plaques. In actively demyelinating lesions, astrocytes are large, often multinucleated and show strong immunreactivity for glial fibrillary acidic protein (GFAP). These reactive astrocytes may contain myelin debris (Marburg, 1906), may express histocompatibility complex antigens (Lee et al., 1990), and contain lysosomal enzymes (Allen et al., 1979). Reactive astrocytes also engage demyelinated axons, thus substituting in part for the lost myelin sheath (Soffer and Raine, 1980). Reactive changes in astrocytes finally result in the formation of the dense glial scar.

\subsection{Immunology of multiple sclerosis}

MS is considered to be a chronic inflammatory disease, where the immune system is reactive against self CNS antigens (Martin et al., 1992). The inflammatory process begins with an acute phase and blends into a chronic stage employing both T helper 1 (Th1)- and T helper 2 (Th2)-type effector cells and cytokine patterns. According to a generally accepted concept, autoreactive CD4+ T-lymphocytes initiate the inflammatory process in the periphery and the inflammatory focus in the brain.

Cross-reactive antigens, brain resident pathogens or CNS antigens are released and delivered into lymph nodes and the spleen. Presentation of the neural antigen on major histocompatibility complex II (MHC II) by antigen presenting cells, such as dendritic cells leads to activation, priming and clonal expansion of CD4+ T-cells in the blood. Primed CD4+ T-cells migrate through the blood brain barrier (BBB), enter the brain and accumulate at sites where they re-encounter their priming antigen. CD4+ T-cells become re-stimulated upon the secondary recognition of proper epitopes presented on MHCII by microglial and astroglial cells. They secrete the pro-inflammatory (Th 1) cytokines IL-2, TNF- $\alpha$ and INF- $\gamma$, which enhance the up-regulation of endothelial adhesions factors and attract inflammatory effector cells such as CD8+ T-lymphocytes, monocytes, macrophages and B-cells to the brain.

CD8+ T-cells recognise antigens presented on MHC I molecules expressed by virtually all cells in the CNS, in particular by oligodendrocytes and neurons (Höftberger et al., 2004; Neumann et al., 1995). CD8+ T-cells can cause cytolysis of the antigen expressing cell by the release of cytotoxic granules (perforin, granzyme) (Jones et al., 1991 and Scolding et al., 1990) or by Fas/Fas-ligand mediated interaction (Medana et al., 2000). Thus, 
oligodendrocytes and neurons are direct targets of CD8+ cytotoxic T-lymphocytes (Höftberger et al., 2004).

Monocytes mature into phagocytic macrophages. Activated macrophages release oxyradicals, matrix metalloproteinases (MMPs) and TNF- $\alpha$, giving rise to a toxic environment. B-cells in the lesion mature to plasma cells and produce large quantities of immunoglobulin, in particular IgG. In addition, inflammation is associated with the focal BBB leakage (Miller et al., 1988; Grossman et al., 1988; Estes et al., 1990), which allows immunoglobulin and complement components to enter the CNS. Antibodies may bind to membrane bound myelin antigens and antigens on antigen expressing cells. Binding the specific antibody leads to (i) cellular cytotoxicity via Fc-receptors and phagocytosis by activated macrophages, (ii) activation of the complement cascade, formation of the membrane-attacking terminal complement complex and finally to cell death (the inflammatory process in MS is reviewed in detail by Hemmer et al., 2002).

In resolution of the inflammatory process, the T-cell response becomes skewed from CD4+ Th1 to Th2 cells. Th2 cells produce anti-inflammatory cytokines such as IL-4, IL-5, IL-10, IL-13 and transforming growth factor- $\beta$ (TGF- $\beta)$, which silence the inflammatory reaction (Issazadeh et al., 1995). Th2 cytokines support B-lymphocyte differentiation and antibody production and suppress the Th1 response (Sewell and Jolles, 2002).

\subsection{Repair mechanisms}

MS initially runs a relapsing-remitting disease course. Repair mechanisms account for part of clinical remissions. The functional recovery is attributable to resolution of tissue oedema and inflammation, remyelination of axons and compensation of neuronal injury by adaptive reorganisation of the functional neuronal networks.

\subsubsection{Remyelination}

Remyelination has been reported in a large proportion of MS lesions (Barkhof et al. 2003; Bruck et al. 2003; Prineas and Connell 1979). Remyelination occurs early, even when demyelination is still ongoing (Prineas et al. 1993; Raine and Wu 1993; Lassmann et al. 1997). Oligodendrocyte precursor cells (OPCs) enter the lesion, engage naked axons and while myelinating mature into adult oligodendrocytes (Carroll and Jennings, 1994). They form new myelin, which is thinner and forms shorter internodes than expected for the diamater of the axons (Morell et al., 2000; Sim et al., 2000; Capello et al., 1997; Ludwin et al., 1984). Remyelination leads to incomplete or complete repair (shadow plaque) of the 
lesions. Remyelination provides trophic support, restores the conduction velocity and has been shown to prevent axons from "slow burning" axonal injury (Smith and McDonald, 1999).

Specific markers identify precursors, premature and mature oligodendrocytes. Premyelinating oligodendrocytes express high amount of proteolipid protein (PLP) mRNA. Premature myelinating and mature oligodendrocytes express the early differentiation antigen 2'3'cyclic nucleotide 3'phosphodiesterase (CNP), whereas only mature remyelinating oligodendrocytes are characterised by myelin basic protein (MBP) immunreactivity (Chang, 2003; Wolswijk, 2000; Ozawa et al., 1994; Prineas, 1989).

The most noteworthy difference between early and late MS is the propensity to remyelinate the lesions (Ozawa et al., 1994). Oligodendrocytes are preserved in a proportion of patients in early disease, however, in the chronic disease stage, only few oligodendrocytes are detected in the lesions (Ozawa et al. 1994; Lucchinetti et al. 1999). Remyelination of chronic lesions mostly remains incomplete and restricted to the lesional edge (Barkhof et al. 2003). Factors impairing remyelination may include gliosis, a lack of growth factors, a lack of oligodendrocyte progenitors, and axons not permissive for remyelination (Franklin, 2002).

\subsubsection{Adaptive plasticity}

Beside remyelination of axons, compensatory mechanisms may reduce the functional consequences of demyelinated plaques. Plasticity, the intrinsic capacity of the CNS to adapt to the structural damage (Jacobs and Donoghue, 1991), contributes to functional recovery after brain lesion and has been shown in MS (Morgen et al. 2004; Reddy et al., 2000; Pantano et al., 2002; Rocca et al., 2002). Recently, functional magnetic resonance imaging (fMRI) revealed adaptive changes in the connectivity pattern within the motor system in MS patients with mild motor impairment (Morgen et al. 2004). Similar changes have been observed in cerebellar-neocortical functional connectivity in the healthy brain during motor learning, suggesting that similar mechanisms may contribute to learning and adaptive changes after injury caused by MS (Saini et al., 2004).

Reorganisation of synapses due to focal neuronal injury has been extensively studied in various experimental models. Any injury to axons, i.e. transection, reduction of axonal transport or a focal humoral or inflammatory process has anterograde and retrograde consequences for the neuron. However, reactive changes may also affect regions remote from the affected neuron. Anterograde (Wallerian) degeneration of the peripheral axon segment including all presynaptic elements transsynaptically affects the postsynaptic neurons. 
Anterograde transsynaptic effects may vary from compensatory replacement of synaptic input to various forms of postsynaptic degeneration (Gray 1962; Colonnier and Gray 1962). In contrast, retrograde axotomy reactions adapt the input of the axotomized neuron to the no- or reduced output state (Aldskogius, 1974, Grant and Walberg, 1974). These reactions may lead to the complete compensation of the lost postsynaptic partners via transsynaptic and/or transneuronal synaptic reorganisation within the neuronal network (Cowan, 1970; Prof. Wolff - personal communication). Recent studies in an animal model of MS suggested a reorganisation of synapses that compensated for the affected functional circuit (Kerschensteiner et al., 2004).

Chronic MS, however, leads to cumulative permanent disability in most cases. The chronic stage is often accompanied by cortical and spinal cord atrophy and substantial damage to axons, whose preservation correlates with the clinical outcome of the patients (Bjartmar, 2000, De Stefano 1998). Motor cortex was shown to be frequently affected in SPMS (Sailer et al., 2003). Cerebellar ataxia is a prominent clinical symptom of the chronic diasease (Adams and Victor's Neurology, $7^{\text {th }}$ edition). The pons and cerebellum are known predilection sites for plaque formation (Carswell, 1838). The pontine nuclei and the cerebellar dentate nucleus are relay stations of the motor network providing the backfire loop of motor control. Therefore, we have chosen the dentate nucleus and the pontine nuclei to examine the local and remote neuronal response on focal demyelination in MS.

\subsection{Grey matter lesions}

The presence of MS lesions involving the grey matter has been shown in both pathologic (Brownell and Hughes 1962; Lumsden, 1970; Dawson, 1916; Dinkler, 1904; Sander, 1898; Rossolimo, 1897; Taylor, 1892; Schwab and McGeer 2002; Dawson, 1916) and imaging studies (Catalaa et al. 1999; Newcombe et al. 1991; Chen et al. 2004). However, primarily due to biased tissue sampling and insensitive staining techniques, the extent of cortical involvement has been largely underestimated. Recently, the studies of Kidd, Peterson, and Bo revealed an important involvement of the cerebral cortex in MS patients using immunohistochemistry for myelin proteins (Bo et al. 2003b; Peterson et al. 2001; Kidd et al. 1999). Cortical demyelination was suggested to be a widespread phenomenon, involving all cerebral lobes roughly equally (Bo et al. 2003b). Different types of lesions were proposed according to lesional topography (Bo et al. 2003b; Kidd et al. 1999; Peterson et al. 2001). Extensive subpial demyelination involving many adjacent gyri was identified by Bo et al. (Bo et al. 2003b). Cortical lesions were found to be less inflammatory than white matter lesions 
(Bo et al. 2003a). Peterson et al. identified axonal and dendritic transections as well as dying neurons as identified by DNA fragmentation in cortical MS lesions (Peterson et al. 2001).

\subsection{Aim of the study}

To date, only few histopathological studies are available on grey matter lesions in MS. The aim of this work was to study in detail demyelination, inflammation, remyelination and the pathology of neurons including dendrites and synapses in grey matter MS plaques. We asked whether inflammatory demyelination affects and if so, to which extent, the cortex of MS patients at early and late time points in the disease. We compared inflammatory and degenerative components of grey versus white matter plaques. Furthermore, we asked whether the localisation of demyelinated lesions in grey versus white matter influenced their propensity to remyelinate. Finally, we defined the local and remote effects of demyelination on neurons and their synaptic contacts in frontal cortex and in the cerebellar and pontine grey matter nuclei. 


\section{MATERIALS AND METHODS}

All studies were carried out on human brain tissue material. Formalin-fixed and paraffin embedded tissue blocks from 183 MS patients and healthy control subjects were available for this research purpose at the Institute of Neuropathology, University of Goettingen, (Germany). Out of the 183 patients tissue from 33 patients with definite clinical diagnosis of MS was obtained at autopsy. Tissue from different parts of the brain was sampled on the basis of macroscopically visible white matter lesions. Brain tissue from the other $150 \mathrm{MS}$ cases was taken at biopsy. The histological diagnosis of MS was in every case suggested by independent neuropathologists. Brain tissue suitably fixed (by in situ vascular perfusion- see below) for electron microscopical analysis was available from one MS patient and one healthy control person. All studies were approved by the ethics committee of the University of Goettingen, Germany.

\subsection{Materials and methods to study cortical de- and remyelination}

\subsubsection{Brain tissue}

Brain autopsy samples of $33 \mathrm{MS}$ patients and 10 healthy controls were evaluated. $33 \mathrm{MS}$ patients with long-standing MS were studied to assess the frequency and extent of cortical deand remyelination. A subset, i.e. 17 patients, was selected for the detailed morphological study of remyelination (i.e. oligodendrocyte pathology) on the basis of the availability of frontal lobe lesions (for clinical data see Table 1). The age of the 33 MS patients at the time of death ranged from 28 to 81 years (mean \pm SD: $59.15 \pm 11.54$; median: 60 ys). The mean disease duration prior to autopsy was 17 years (mean $\pm \mathrm{SD}$ : $17.17 \pm 9.28$, median: $15 \mathrm{ys}$ ). Two patients harboured MS lesions as an incidental finding at autopsy. No information on the disease duration was available for four patients; in one patient, it was uncertain. One patient was diagnosed with relapsing remitting MS, 11 patients had primary progressive MS, 14 patients secondary progressive MS, and in 7 patients with chronic MS, the disease course was uncertain (Table 1). The age of the selected subset of 17 MS patients at time of death was between 49 and 71 years (mean \pm SD: $60.35 \pm 6.29$; median: $60 \mathrm{ys}$; female to male ratio: 7:10). Mean disease duration prior to autopsy was 18.79 years (SD: \pm 8.89 ; median: 16 ys; range: 8-39 ys). Six patients had a primary progressive and seven patients secondary progressive disease course. In four chronic cases, the disease course could not be deduced from the clinical files. Each of the 17 MS cases had up to three frontal lobe blocks. The 10 
controls were age matched and between 40 and 73 years old at the time of death (mean \pm SD: $59.3 \pm 9.73$ ys; female to male ratio: $3: 7$ ).

\subsubsection{Neuropathological techniques and immunohistochemistry}

3-5 $\mu \mathrm{m}$ paraffin sections were stained with haematoxylin-eosin (HE), luxol fast blue (LFB)/periodic-acid Schiff (LFB/PAS) and Bielschowsky's silver impregnation for the assessment of inflammation, demyelination, and axonal density, respectively. Oligodendrocyte pathology was assessed by immunostaining with antibodies against myelin basic protein (MBP) and 2', 3'-cyclic nucleotide 3'-phosphodiesterase (CNP). An antiactivated caspase-3 antibody was applied to examine caspase-mediated cell death of oligodendrocytes (for antibodies used see Table 2).

For immunohistochemistry, sections were deparaffinized, pretreated with microwaving $(3 \times 5$ minutes at $800 \mathrm{~W})$ in citric acid buffer $(10 \mathrm{mM}, \mathrm{pH}$ 6.0) and unspecific reactions blocked with 10\% FCS/PBS (Stadelmann at al., 2002). Primary antibodies were applied at the dilution indicated (in Table 2) and incubated over night at $4{ }^{\circ} \mathrm{C}$. After application of the biotynilated secondary antibody, avidin peroxydase (Dako, Glostrup, Denmark) was added and developed with, 3, 3'-diaminobenzidine hydrochloride (DAB, Sigma, St. Luis, Mo., USA). Alternatively, an alkaline phosphatase/anti-alkaline-phosphatase-based technique (APAAP, Dako) with Fast Red (Sigma) was used to visualise bound primary antibody. Sections obtained from controls and MS patients were handled identically and simultaneously. Negative controls were performed by omitting the primary antibody and applying nonimmune sera or isotype control antibodies.

\subsubsection{In situ hybridization}

In situ hybridization for PLP mRNA was performed as described in detail earlier (Lumsden 1970; Dawson 1916; Dinkler 1904). Briefly, hybridization was performed using digoxigeninlabeled riboprobes detected by AP-conjugated anti-digoxigenin Fab-fragments. NBT/BCIP was used as chromogen. For immunohistochemistry after in situ hybridization, sections were incubated with anti-PLP antibody and processed as described above. Sections were counterstained with haematoxylin.

\subsubsection{Electron microscopy}

Formalin fixed, paraffin embedded archival brain tissue was processed for electron microscopy. Areas identified on corresponding MBP-immunostained sections were cut out of 
the paraffin blocks and post-fixed in glutaraldehyde followed by osmification and embedding in araldite. Quantitative analysis was performed on ultrathin sections of six MS patients and two controls. Fiber thickness was measured at the shortest diameter and the g-ratio calculated (g-ratio $=$ diameter of axon/diameter of axon plus two times myelin sheath [axon/fibre ratio]). G-ratios of at least 100 myelinated axons per patient were obtained. The Kruskal-Wallis analysis of variance followed by Dunn's multiple comparison tests was applied to compare gratios between control cortex, remyelinated cortex, and normal appearing cortex.

\subsubsection{Morphometric image analysis}

To determine the extent of cortical demyelination, the cortical areas of a total of 91 MBPstained brain sections from the 29 MS patients with cortical lesions were scanned with a Color View digital camera (Soft Imaging System, Münster, Germany) mounted on an Olympus BX51 microcope (Olympus, Tokyo, Japan). The total cortical area and the area of cortical demyelination were measured using Analysis ${ }^{\circledR}$ software (Soft Imaging System GmbH, Münster, Germany). The nonparametric Mann-Whitney U-test was applied to compare the extent of demyelination in the frontal, temporal, parietal and occipital lobes.

\subsubsection{Quantitative morphometry of immuno-labelled cells}

Immunopositive oligodendrocytes were counted using an ocular morphometric grid at a magnification of 400x (area of the grid: $62500 \mu \mathrm{m}^{2}$ ). The grid was placed 10 times in the lesional centre and 10 times at the lesional border. In control sections and sections without apparent cortical demyelination ('normal appearing cortex'), immunopositive oligodendrocytes were counted in 10 visual fields in cortical layers II-III and V-VI. KruskalWallis and Mann-Whitney U-tests were used to compare the density of immunolabelled oligodendrocytes between the different groups.

\subsubsection{Extent of remyelination}

The extent of remyelination of white matter and cortical MS lesions was assessed applying the following arbitrary score: (0) no remyelination, (1) little remyelination at the lesional border, (2) substantial remyelination, either confluent or patches of remyelination, and (3) nearly complete or complete remyelination (shadow plaque). The Mann-Whitney-U test was applied to compare scores of white matter and cortical remyelination. 


\subsection{Materials and methods to study inflammation, dendrites and synapses in cortical lesions}

\subsubsection{Brain tissue}

Brain autopsy samples from 17 MS patients and from 10 control subjects (for details see 2.1.1. and Table 1.) were included to study inflammation, density of dendrites and synapses in the frontal cortex of patients with long-standing MS. Brain biopsy samples from $4 \mathrm{MS}$ patients were selected to study inflammation in detail in early MS. The age of 4 MS patients at the time of biopsy ranged from 28 to 52 years (mean \pm SD: $37.7 \pm 10.8$ ys). The mean disease duration prior to biopsy was 6.7 weeks. All patients were female. 1 tissue block per patient was analysed. All 4 tissue blocks harboured lesions both, in cortex and the white matter.

\subsubsection{Neuropathological techniques and immunohistochemistry}

3-5 $\mu \mathrm{m}$ paraffin sections were prepared. All sections were stained with haematoxylin-eosin (HE), luxol fast blue (LFB)/periodic-acid Schiff (LFB/PAS) and Bielschowsky's silver impregnation for formal investigation of inflammation, demyelination, and the axonal density. Demyelinated areas were identified on LFB/PAS and MBP-immunostained sections.

Autopsy sections were additionally immunostained with antibodies against CD3, CD8 and CD20 for CD3+ T-lymphocytes, CD8+ T-lymphocytes and B-cells to assess the extent and composition of inflammatory cells in the cortical and white matter lesions. Antibodies against KiM1P (CD68 equivalent), MHCII were used to determine the density of microglia/macrophages and glial fibrillary acidic protein (GFAP) to determine the density of activated astrocytes. At least one tissue section with cortical lesions per case was immunostained for neurofilament (SMI31) to confirm axonal preservation in areas of cortical demyelination. Samples were immunolabelled against microtubulus associated protein II (MAPII) and synaptophysin to determine the density of dendrites and synapses in the cortical plaques.

Biopsy sections were treated with antibodies against inflammatory cells; CD3, CD8 and CD20 for T-lymphocytes, CD8+ T-lymphocytes and B-cells, plasmacells; KiM1P, MRP14, MHCII for all, early active and antigen presenting microglia/macrophages; glial fibrillary acidic protein (GFAP) for activated astrocytes. Immunoglobulin and complement deposition was investigated by antibodies against IgG and C9neo. Acute axonal and neuronal injury was 
determined by antibodies against amyloid precursor protein (APP) and neurofilament H (SMI 35) (for antibodies used see Table 2; for the immunostaining procedures see 2.1.2).

\subsubsection{Quantitative morphometry of immuno-labelled structures}

In autopsy samples, density of KiM1P-positive microglia/macrophages and GFAP-positive astrocytes was determined using an ocular morphometric grid at a magnification of 400x (area of the grid: $62500 \mu \mathrm{m}^{2}$ ). To count KiM1P-positive cells, the grid was placed 10 times in the centre of cortical plaques and 10 times in the periplaque cortical area. To count GFAPpositive cells, the grid was placed 10 times in the cortical plaques. In control sections and sections without apparent cortical demyelination ('normal appearing cortex'), KiM1P and GFAP immunreactive cells were counted in 10 visual fields in cortical layers II-III and V-VI. Following the Kolmogorov-Smirnov test for normal distribution of data, ANOVA and T-tests were applied to compare the cell densities of cortical plaques with normal appearing cortex and with controls. Density of MAPII-positive dendrites was determined using an ocular morphometric grid with 25 intersections at a magnification of $1000 x$. Each dendrite that crossed one of the intersections was taken into the calculation. In this way, dendrites were counted in 3 visual fields in 3 cortical layers (cortical layer I-II, cortical layer III-IV, cortical layer V-VI), respectively. Following the Kolmogorov-Smirnov test for normal distribution of data, ANOVA and T-test and was applied to determine the difference in the dendritic density between cortical plaques, normal appearing cortex and control cortex.

In biopsy samples, density of inflammatory cells was determined in parallel, in cortical and white matter lesions in the same sections. Immunopositive CD3+ and CD8+ lymphocytes were counted using the ocular morphometric grid at a magnification of 1000x (area of the grid: $10.000 \mu \mathrm{m}^{2}$ ). The grid was placed 3 times at the vessel wall and 3 times in a grid distance from the vessel wall in the perivascular parenchyma. KiM1P, MRP14-positive cells and APPpositive axons were counted at a magnification 400x (area of the grid: $62500 \mu \mathrm{m}^{2}$ ). The grid was placed 5 times in the demyelinated parenchyma. To determine the anatomical difference in the axonal density between the white matter and the cortex, 5 control sections were stained using Bielschowsky' silver impregnation method. The axons were counted using the 25 intersection ocular grid, which were placed 10 times in lower cortical layers and 10 times in the subcortical white matter at a magnification of 1000x (area of the grid: $10000 \mu \mathrm{m}^{2}$ ). Each axon that crossed one of the intersections was taken into the calculation. Following the normality test, T-test or Mann-Whitney-U test was applied to compare the density of the various immunoreactive structures in lesions in the cortex and white matter. 


\subsubsection{Image analysis, densitometry}

To quantify synapses in the frontal cortex in MS, images were cuptured on synaptophysinstained sections under 200x using Color View digital camera (Soft Imaging System, Münster, Germany) mounted on an Olympus BX51 microcope (Olympus, Tokyo, Japan). The pictures were taken in 3 fields in 3 cortical layers (cortical layer I-II, cortical layer III-IV, cortical layer V-VI). Same light intensity and exposure time were applied to all photographs. All images were converted to the grey scale and analysed with ImageJ 1.31v. A fixed threshold value was kept. Following the normality test, ANOVA and T-test and was applied to determine the statistical difference in light intensity values between the control, cortical plaques and the normal appearing cortex.

\subsection{Materials and methods to study synaptic contacts in the cerebellar dentate nucleus and in the pontine nuclei}

\subsubsection{Brain tissue prepared for histology}

Tissue blocks containing the cerebellar dentate nucleus and the pons were sampled for histology from 24 MS patients and 10 controls. The age of the 24 MS patients at the time of death ranged from 39 to 82 years (mean \pm SD: $59.7 \pm 9$ years). Most of the patients had chronically suffered from MS (duration mean \pm SD: $15.4 \pm 8.7$ years). One case was studied in acute stage of MS. No information on the disease duration was available for five other patients (for clinical data see Table 3.). The age of controls ranged from 36 to 85 (mean \pm SD: $62.7 \pm 15.1$ years $)$.

For the dentate nucleus, $18 \mathrm{MS}$ patients were selected to compare the distribution pattern of synapses with that of controls and estimate their numerical densities by light microscopy. Nine of these MS patients had demyelinated plaques in the dentate nucleus, whereas the others did not show any focal demyelination either at gross autopsy or in serial sections from the respective cerebellum. Information obtained from the clinical files contained no evidence for cerebellar symptoms manifested during the disease course.

For the pontine nuclei, synapses were studied in nine patients. All of these had demyelinated plaques in the brainstem at the level of the pons. Three MS patients had lesions in both, the dentate nucleus as well as the pons. 


\subsubsection{Brain tissue prepared for electron microscopy}

To identify structural changes of synapses in the dentate nucleus and in the pontine nuclei, brain tissue was fixed for electron microscopical analysis from one MS patient and one control. The tissue of the MS patient was kindly provided by John Prineas (University of Sydney, Australia), the tissue of the control subject was kindly provided by Miklos Palkovits (Semmelweis University Budapest; Hungary).

The patient was a 39 year old woman with a 14 years history of MS. Initially the disease ran a relapsing and remitting course, but for the last three years of her life the disease was progressive with no periods of remission. During this phase of her illness she exhibited motor and sensory deficits and at the time of her death she had been confined to bed for two years. Immunmodulatory therapy was not received by the patient at any stage of her illness. Brain tissue was fixed in situ by vascular perfusion with $3 \%$ glutaraldehyde in $0.1 \mathrm{M}$ cacodylate buffer within 20 minutes of death (Prineas, 1975). The tissue was post-fixed in Dalton's solution, embedded in Spurr's epoxy resin and sampled for electron microscopy using $1 \mu \mathrm{m}$ thick sections stained with toluidine blue.

As control served a 55 years old man, who did not show any neurological disease throughout his life. Tissue was fixed by vascular perfusion with Zamboni's solution (4\% paraformaldehyde, picric acid, $0.1 \mathrm{M}$ phosphate buffer, $\mathrm{pH}$ 7.4) within 1 hour after death. The cerebellum with the dentate nucleus was post-fixed with $0.1 \%$ glutaraldehyde, whereas the pons was post-fixed with $0.5 \%$ glutaraldehyde. Tissues samples were embedded in araldite; $1 \mu \mathrm{m}$ sections were prepared and stained with toluidine blue.

\subsubsection{Histological techniques}

Three micron thick paraffin sections were stained with haematoxylin-eosin (HE), luxol fast blue (LFB) /periodic-acid Schiff (LFB/PAS) and antibodies against the myelin basic protein (MBP), synaptophysin (SYN) and against glutamic acid decarboxylase 65/67 (GAD). Inflammatory activity was determined in LFB and MBP stained sections. All lesions were inactive regarding the demyelinating activity, according to the criteria of Brück et al. (Ann Neurol, 1994). The synaptic density and distribution of all and GABAergic synapses were assessed by immunostaining against SYN and GAD, respectively (for antibodies used see Table 2; for the immunostaining procedures see 2.1.2). 


\subsubsection{Electron microscopy}

Electron microscopy was performed on thin sections obtained from tissue samples of one patient with chronic MS and one control brain (see above). Samples were taken from the dentate nucleus and paramedian parts of pontine nuclei. Sections of the MS patient were selected to contain both demyelinated and myelinated regions. All images were captured at the transmission electron microscope (EM 10C, Zeiss) using MegaView III digital camera and the software Analysis ${ }^{\circledR}$ (Soft Imaging System, Münster, Germany).

\subsubsection{Statistical analysis}

The numerical density of axo-somatic synaptic boutons was estimated by counting SYNpositive structures localised at the soma membrane of 5 adjacent neurons in the dentate nucleus of $18 \mathrm{MS}$ patients and 10 controls. The extent of demyelination and pariplaque regions - available on the sections - did not allow for quantification of a larger area. Only neurons which were situated near the centre of the grey matter band were counted, in order to avoid a bias caused by quantifying SYN-positive structures on distinct neuronal subpopulations (e.g. neurons at the periphery of the grey matter band and "displaced neurons" in the surrounding white matter possessed on average fewer axo-somatic synapses in the control brains). SYN-positive structures were quantified under light microscope (Olympus BX41) with oil immersion and a final magnification of 1000x. Following the KolmogorovSmirnov test for normal distribution of data, T-test was applied to compare the number of "synapses" on the neuronal soma membrane a) in the demyelinated areas of the dentate nucleus of 9 MS patients with the number of axo-somatic "synapses" of controls b) in areas beyond the plaque borders (periplaque areas) of the same 9 MS patients with the controls c) from the dentate nucleus of the other 9 MS patients, in which demyelination could not be detected with the controls.

Statistica 6.0 (StatSoft, Inc., Tulsa, OK, USA) software was used for all statistical calculations. 


\begin{tabular}{|c|c|c|c|c|c|c|}
\hline Case & Age/Sex & $\begin{array}{l}\text { Disease } \\
\text { course }\end{array}$ & $\begin{array}{l}\text { Disease } \\
\text { duration } \\
\text { (years) }\end{array}$ & $\begin{array}{l}\text { Total } \\
\text { cortical } \\
\text { area }\left(\mathrm{mm}^{2}\right)\end{array}$ & $\begin{array}{l}\text { Cortical } \\
\text { lesional } \\
\text { area } \\
\left(\mathrm{mm}^{2}\right) \\
\end{array}$ & $\begin{array}{l}\text { Cortical } \\
\text { lesional } \\
\text { area } \\
(\%) \\
\end{array}$ \\
\hline 1 & $74 / \mathrm{F}$ & $?$ & incidental & 387,8 & 11,38 & 2,93 \\
\hline $2 *$ & $71 / \mathrm{F}$ & $?$ & 20 & 319,62 & 109,89 & 34,38 \\
\hline $3 *$ & 49/M & $?$ & $?$ & 115,91 & 15,69 & 13,59 \\
\hline $4 *$ & $66 / \mathrm{M}$ & $?$ & $?$ & 683,03 & 28,98 & 4,24 \\
\hline 5 & $38 / \mathrm{M}$ & $?$ & $?$ & 152,73 & 3,06 & 2,0 \\
\hline 6 & $63 / \mathrm{M}$ & $?$ & incidental & 395,46 & 117,1 & 29,61 \\
\hline $7 *$ & $66 / F$ & $?$ & 30 & 148,81 & 11,86 & 7,97 \\
\hline 8 & $74 / \mathrm{M}$ & $\mathrm{PP}$ & 10 & 110,68 & 29,61 & 26,75 \\
\hline $9 *$ & $57 / \mathrm{M}$ & $\mathrm{PP}$ & 15 & 2335,42 & 171,51 & 7,38 \\
\hline 10 & $45 / \mathrm{F}$ & $\mathrm{PP}$ & 14 & 374,81 & 60,42 & 16,12 \\
\hline 11 & $70 / \mathrm{F}$ & $\mathrm{PP}$ & 7 & 713,05 & 40,51 & 5,68 \\
\hline 12 & $57 / \mathrm{M}$ & $\mathrm{PP}$ & 11 & 208,37 & 85,58 & 41,07 \\
\hline $13 *$ & $61 / \mathrm{F}$ & PP & 19 & 979,05 & 87,17 & 8,9 \\
\hline 14 & $51 / \mathrm{M}$ & PP & 8 & 390,87 & 31,3 & 8,01 \\
\hline $15^{*}$ & $60 / \mathrm{F}$ & PP & 14 & 459,67 & 130,62 & 28,42 \\
\hline $16^{*}$ & $59 / \mathrm{F}$ & PP(?) & 9 & 247,71 & 25,6 & 10,34 \\
\hline $17 *$ & $60 / \mathrm{M}$ & $\mathrm{PP}(?)$ & 10 & 664,51 & 148,2 & 22,3 \\
\hline $18^{*}$ & $52 / \mathrm{F}$ & $\mathrm{PP}(?)$ & 8 & 454,31 & 0 & 0 \\
\hline 19 & $35 / \mathrm{F}$ & RR & 23 & 567,3 & 0 & 0 \\
\hline 20 & $28 / \mathrm{F}$ & SP & 4 & 301,51 & 14,12 & 4,68 \\
\hline 21 & $69 / \mathrm{M}$ & SP & 7 & 911,37 & 0 & 0 \\
\hline $22 *$ & $54 / \mathrm{M}$ & SP & 11 & 359,64 & 1,74 & 0,48 \\
\hline $23 *$ & $70 / \mathrm{M}$ & SP & $22-32$ & 601,4 & 199,39 & 33,15 \\
\hline $24 *$ & $52 / \mathrm{M}$ & SP & 16 & 310,1 & 16,71 & 5,39 \\
\hline $25^{*}$ & $63 / \mathrm{M}$ & SP & 19 & 715,14 & 308,53 & 43,14 \\
\hline 26 & $57 / \mathrm{M}$ & SP & 12 & 129,35 & 31,0 & 23,97 \\
\hline 27 & $53 / \mathrm{F}(?)$ & SP & $25(?)$ & 91,65 & 7,94 & 8,66 \\
\hline 28 & $81 / \mathrm{F}$ & SP & 36 & 234,72 & 0 & 0 \\
\hline $29 *$ & $61 / \mathrm{M}$ & $\mathrm{SP}(?)$ & $21-36$ & 668,45 & 222,82 & 33,31 \\
\hline $30^{*}$ & $66 / \mathrm{M}$ & $\mathrm{SP}(?)$ & $34-44$ & 303,48 & 13,89 & 4,58 \\
\hline 31 & $71 / \mathrm{M}$ & SP(?) & $?$ & 204,57 & 18,39 & 8,99 \\
\hline $32 *$ & $59 / \mathrm{F}$ & $\mathrm{SP}(?)$ & 16 & 279,74 & 56,18 & 20,08 \\
\hline 33 & $60 / \mathrm{F}$ & $\mathrm{SP}(?)$ & 25 & 291,73 & 163,14 & 55,92 \\
\hline
\end{tabular}

Table 1 Clinical data and extent of cortical demyelination of the 33 MS patients studied. 17 MS patients $(*)$ were selected to study lesional topography, inflammation, dendritic and synaptic pathology in chronic cortical lesions and for the detailed morphological study of remyelination in the frontal lobe; n/a: not available; ?: questionable.

Abbreviations: PP: primary progressive MS; SP: secondary progessive MS; F: female; M: male 


\begin{tabular}{|c|c|c|c|}
\hline Antigen & $\begin{array}{l}\text { Antibody } \\
\text { type/clone }\end{array}$ & Dilution & Source \\
\hline MBP & $\begin{array}{l}\text { mAb } \\
\text { (Cat. No. } 1118 \\
099 \text { ) }\end{array}$ & $1: 500$ & $\begin{array}{l}\text { Boehringer Mannheim GmbH, } \\
\text { Mannheim, Germany }\end{array}$ \\
\hline PLP & plpc1 & $1: 500$ & Serotec, Oxford, England, UK \\
\hline CNPase & SMI91 & $1: 200$ & $\begin{array}{l}\text { Sternberger Monoclonals, Inc., } \\
\text { Lutherville, MD, USA }\end{array}$ \\
\hline activated Caspase- 3 & rabbit $\mathrm{pAb}$ & $1: 500$ & $\begin{array}{l}\text { IDUN Pharmaceuticals, La Jolla, } \\
\text { CA, USA }\end{array}$ \\
\hline $\begin{array}{l}\text { Phosphorilated } \\
\text { neurofilament }\end{array}$ & SMI31 & $1: 10000$ & Sternberger Monoclonals, Inc. \\
\hline MBP & rabbit $\mathrm{pAb}$ & 1:2000 & Dako, Glostrup, Denmark \\
\hline Synaptophysin & $\begin{array}{l}\mathrm{mAb} \\
\mathrm{SY} 38\end{array}$ & $1: 10-1: 50$ & Dako, Glostrup, Denmark \\
\hline GAD & rabbit $\mathrm{pAb}$ & $1: 2000$ & Sigma, St. Luis, MO, USA \\
\hline MAP II & $\mathrm{mAb}$ & $1: 200$ & NeoMarkers, Labvision, CA, USA \\
\hline
\end{tabular}

Table 2a Antibodies used for immunohistochemistry

Abbreviations: mAb: monoclonal antibody; pAb: polyclonal antibody 


\begin{tabular}{|c|c|c|c|}
\hline Antigen & $\begin{array}{l}\text { Antibody } \\
\text { type/clone }\end{array}$ & Dilution & Source \\
\hline CD 3 & rat $\mathrm{pAb}$ & $1: 200$ & $\begin{array}{l}\text { Serotec, Oxford, England, UK } \\
\text { (MCA 1477) }\end{array}$ \\
\hline $\mathrm{CD} 8$ & $\begin{array}{l}\mathrm{mAb} \\
\mathrm{C} 8 / 1448\end{array}$ & $1: 50$ & $\begin{array}{l}\text { Dako, Glostrup, Denmark } \\
\text { (M 7103) }\end{array}$ \\
\hline CD68 /KiM1P & $\mathrm{mAb}$ & $1: 1500$ & $\begin{array}{l}\text { Gift of Heinz-Joachim Radzun, } \\
\text { Goettingen, Germany }\end{array}$ \\
\hline CD 20 & $\mathrm{mAb}$ & $1: 50$ & Dako, Glostrup, Denmark \\
\hline $\begin{array}{l}\text { MHC II/ } \\
\text { HLA-DP,DQ,DR }\end{array}$ & $\mathrm{mAb}$ & $1: 100$ & $\begin{array}{l}\text { Dako, Glostrup, Denmark } \\
\text { (M 0775) }\end{array}$ \\
\hline GFAP & $\mathrm{mAb}(6 \mathrm{~F} 2)$ & $1: 50$ & $\begin{array}{l}\text { Dako, Glostrup, Denmark } \\
\text { (M 0761) }\end{array}$ \\
\hline MRP 14 & mAb (S100A9) & 1:1000 & $\begin{array}{l}\text { BMA, Augst, Switzerland } \\
\text { (T-1027) }\end{array}$ \\
\hline CD 163 & mAb (10D6) & $1: 100$ & $\begin{array}{l}\text { Novo Castra, Dossenheim, } \\
\text { Germany } \\
\text { (NCL-CD 163) }\end{array}$ \\
\hline C9 neo & $\mathrm{mAb}$ & $1: 50$ & $\begin{array}{l}\text { Gift of Miriam Vigar, Wales, } \\
\text { Great Britain }\end{array}$ \\
\hline $\mathrm{IgG}$ & $\mathrm{mAb}(\mathrm{A} 57 \mathrm{H})$ & $1: 25$ & Dako, Glostrup, Denmark \\
\hline APP & $\mathrm{mAb}(\mathrm{A} 4)$ & $1: 3000$ & $\begin{array}{l}\text { Chemicon International Inc. } \\
\text { (MAB 348) }\end{array}$ \\
\hline Neurofilament $\mathrm{H}$ & mAb (SMI35) & $1: 10000$ & $\begin{array}{l}\text { Sternberger Monoclonals, Inc., } \\
\text { Lutherville, MD, USA }\end{array}$ \\
\hline
\end{tabular}

Table 2b Antibodies used for immunohistochemistry

Abbreviations: mAb: monoclonal antibody; pAb: polyclonal antibody 
Materials and Methods

\begin{tabular}{|l|l|l|l|l|l|l|}
\hline \hline Case & Age/Sex & $\begin{array}{l}\text { Disease } \\
\text { course }\end{array}$ & $\begin{array}{l}\text { Disease } \\
\text { duration } \\
\text { (years })\end{array}$ & $\begin{array}{l}\text { Region } \\
\text { studied }\end{array}$ & $\begin{array}{l}\text { Presence of } \\
\text { MS lesion }\end{array}$ & $\begin{array}{l}\text { Inflammato } \\
\text { ry activity } \\
\text { of the } \\
\text { lesions }\end{array}$ \\
\hline \hline 1 & $57 / \mathrm{M}$ & SP & 12 & Dentate & yes & inactive \\
\hline $2^{*}$ & $39 / \mathrm{F}$ & n/a & n/a & Dentate/Pons & yes & inactive \\
\hline 3 & $63 / \mathrm{M}$ & SP & 19 & Dentate & yes & inactive \\
\hline 4 & $52 / \mathrm{F}$ & PP? & 8 & Dentate & yes & inactive \\
\hline $5^{*}$ & $71 / \mathrm{M}$ & SP? & $14 ?$ & Dentate/Pons & yes & inactive \\
\hline 6 & $59 / \mathrm{F}$ & SP? & 16 & Dentate & yes & inactive \\
\hline $7^{*}$ & $54 / \mathrm{M}$ & SP & 11 & Dentate/Pons & yes & inactive \\
\hline 8 & n/a & n/a & n/a & Dentate & yes & inactive \\
\hline 9 & $57 / \mathrm{F}$ & SP? & 9 & Dentate & yes & inactive \\
\hline 10 & $69 / \mathrm{M}$ & SP & 7 & Dentate & no & no lesion \\
\hline 11 & $49 / \mathrm{F}$ & acute & $<1$ & Dentate & no & no lesion \\
\hline 12 & $57 / \mathrm{M}$ & PP & 23 & Dentate & no & no lesion \\
\hline 13 & $60 / \mathrm{M}$ & PP & 26 & Dentate & no & no lesion \\
\hline 14 & $51 / \mathrm{M}$ & PP & 8 & Dentate & no & no lesion \\
\hline 15 & $59 / \mathrm{F}$ & Devic & 5 & Dentate & no & no lesion \\
\hline 16 & $66 / \mathrm{F}$ & PP & 30 & Dentate & no & no lesion \\
\hline 17 & n/a & n/a & n/a & Dentate & no & no lesion \\
\hline 18 & $82 / \mathrm{M}$ & n/a & n/a & Dentate & no & no lesion \\
\hline 19 & n/a/M & PP & 11 & Pons & yes & inactive \\
\hline 20 & $57 / \mathrm{M}$ & SP & 12 & Pons & yes & inactive \\
\hline 21 & $57 / \mathrm{M}$ & SP? & 29 & Pons & yes & inactive \\
\hline 22 & $61 / \mathrm{F}$ & PP & 31 & Pons & yes & inactive \\
\hline 23 & $70 / \mathrm{F}$ & PP & 7 & Pons & yes & inactive \\
\hline 24 & $63 / \mathrm{M}$ & n/a & n/a & Pons & yes & inactive \\
\hline
\end{tabular}

Table 3 Clinical data of 24 MS patients selected to study the synaptic contacts in the dentate nucleus and in the pons. 3 MS patients $(*)$ had demyelination in both regions.

Abbreviations: n/a: not available; ?: questionable 


\section{RESULTS}

\subsection{PATHOLOGICAL HALLMARKS OF MULTIPLE SCLEROSIS IN THE GREY MATTER: DEMYELINATION, INFLAMMATION, GLIOSIS AND NEURONAL INJURY}

\subsubsection{Demyelination in cortex of patients with chronic MS}

\subsubsection{Demyelinated lesions on average cover $14 \%$ of cortical grey matter}

Demyelinated lesions located in the cortical grey matter were detected and evaluated by immunostaining with antibodies against MBP (Fig. 1A). In 180 tissue blocks of 33 chronic MS cases more than 200 cortical lesions were identified. 29/33 patients examined harboured cortical demyelination. On average, $14 \%$ of the total cortical grey matter areas examined were demyelinated (see Table 1). The extent of cortical demyelination was slightly larger in the frontal and temporal lobes (frontal lobe: $17 \%$ of cortex demyelinated; temporal lobe: 19\%) compared to the parietal and occipital lobes (parietal lobe: $12 \%$; occipital lobe: $8 \%$ ). $26 \%$ of the insular cortex was found to be demyelinated. However, these differences did not reach statistical significance.

\subsubsection{Cortical demyelination is mostly located subpially}

Frontal lobe sections of 13 MS cases were selected to study the spatial distribution of lesions in the cortex in MS brains (see Table 1). The topography of cortical lesions was examined according to the classification used by Peterson et al. (Peterson et al., 2001). Lesions located at the leucocortical junction and extending into both the white and grey matter were designated type 1 lesions. Type 2 lesions were usually round shaped and resided entirely in the cortex. Type 3 lesions designated cortical demyelination extending from the subpial surface to the external pyramidal layer (cortical layer III) or even to the multiform layer (cortical layer IV) often extending over many gyri (Fig. 1A). Consistent with the finding of Peterson et al, type 3 lesions were by far the most common in the frontal lobe sections examined. 46/72 lesions (64\%) were located immediately beneath the pial surface. The subpial lesions showed often concave shape with the basis on the cortical surface. In a subset of cases (3/13) general subpial demyelination was observed (Bo et al. 2003). These lesions extended vertically until cortical layer III or IV without a definite lesional border at the margins of the sections, thus involving ribbon-like large areas of the cortical surface. 19/72 
lesions (26\%) were type 2, and the remaining type 1 lesions accounted for $10 \%(7 / 72)$ of all cortical lesions identified.

\subsubsection{Inflammation in cortex of patients with chronic MS}

Inflammation is reduced in cortical lesions compared to white matter lesions

The degree of inflammation in cortical lesions was studied on frontal lobe sections from 17 chronic MS patients (see Table 1). 13/17 patients harboured cortical demyelination (see topography of cortical lesions above), while in the other 4 patients cortical lesions were not detected ('normal appearing cortex'). Lymphocytes were visualised by immunohistochemistry for CD3, CD8 and CD20 (pan marker of T- cells, marker of cytotoxic CD8+ T-cells and Bcells), while macrophages and microglial cells were detected using antibodies against the CD68 equivalent KiM1P (pan marker for macrophage/microglia cells) and MHCII (marker for antigen presenting cells).

All white matter lesions were chronic MS plaques. In these lesions, few perivascular CD3positive T-lymphocytes, CD 20-positive plasma cells and KiM1P-positive macrophages were present (chronic inactive lesions) or hypercellular KiM1P/MHCII-immunreactive lesional edge bordered the hypocellular centre of the otherwise inactive white matter plaques (chronic active lesions) (Chang et al., 2002; Canella and Raine, 1995; Bö et al., 1994; Sanders et al., 1993) (Fig 1B).

In cortex of all control cases, T-cells and B-cells were essentially absent; KiM1P-positive cells were evenly distributed and showed morphology of resting microglial cells. In the majority of cortical lesions in 11/13 (85\%) MS patients the number of CD3-positive Tcells and CD20- positive B-cells was not increased compared to the control cases, the periplaque regions of the same sections and the 'normal appearing cortex' of MS brains. Tcells and B-cells on the meninges above the superficial lesions (type 3 lesions) were not more than in control cases. In these intracortical plaques microglia appeared evenly distributed; demarcation of the cortical plaque by microglia was not observed. The density of KiM1Ppositive microglia cells was moreover reduced in the demyelinated cortex compared to the periplaque cortex; the 'normal appearing cortex' and the controls (controls: 61.7 \pm 8.9 ; within the lesions (p): $26.3 \pm 5.7$; outside of the lesions/periplaque (pp): $69.8 \pm 20.1$; normal appearing cortex (NAC): $68.6 \pm 22.2$ [mean $\pm \mathrm{SD}$ ], control vs. plaque $\mathrm{p}<0,001$; t-test). This result is consistent with what has been observed in the chronic inactive white matter plaques (Brück W, Stadelmann C, unpublished observation). The differences in densities of KiM1P- 
positive cells between control cortex, periplaque cortex and 'normal appearing cortex' were not statistically significant (Fig. 2).

In the other 2/13 (15\%) MS patients, KiM1P-positive macrophage/microglia cells with a subset of them immunreactive to MHCII marked a clear boundary between demyelinated and periplaque area (chronic active lesions) (Fig. 1C). These demyelinated lesions were located at the leucocortical junction (type 1), extending into both the white and grey matter. Thus, a direct comparison could be made with respect to the density of inflammatory cells in the cortical versus white matter part of the same lesion. The number of demarcating macrophages/microglia cells instantly decreased and remained constantly reduced in the cortical part compared to the white matter part of the lesions (Fig.1D). Moderate perivascular cuffs accompanied the microglia demarcation (Fig.1E-F). The number of perivascular CD3positive lymphocytes gradually decreased from the white matter towards to the cortex; i.e. most T-cells were found in the white matter, fewer $\mathrm{T}$ cells were present around the vessels at the white/grey matter junction, whereas the least T-cells were found in the cortical part of the lesions that extended through white and grey matter areas (Fig.1E-F). Apart from the perivascular positions, T-cells in the cortical parenchyma were not detected. In the meninges, CD3-immunreactive T-lymphocytes and CD20- positive plasma cells formed cellular aggregates above the chronic active leucocortical plaques (Fig.1G-H). These results suggest that inflammation in cortical lesions is reduced compared to white matter lesions in patients with long-standing MS.

Figure 1 Demyelination is extensive but inflammation is sparse in cortical lesions of patients with chronic MS. (A) 3 types of cortical lesions can be recognised by low power microscopy: leucocortical lesions (type 1), small intracortical lesions (type 2) and the most common subpial, superficial lesions (type 3). (B) A hypercellular edge and hypocellular lesional centre characterise chronic active lesions in the white matter. The cellular infiltrate largely consists of macrophages/microglia that demarcates the plaque borders (arrows). (C) Demarcation of microglia is also present in the cortex. In case of leucocortical lesions (D) the density of microglia cells in cortex is substantially reduced (arrow on top, right inset) compared with the white matter part of the lesion (arrow at the bottom, left inset). This also holds true for the density of perivascular lymphocytes. (E) The number of CD3positive perivascular T-cells is apparently higher in the white matter part than $(\mathrm{F})$ in the cortical part of chronic lesions. (G) T-lymphocytes (arrows) and (H) plasma cells (arrows) infiltrate the meninges above the chronic active cortical plaques. (A) immunohistochemistry for MBP; (B-D) immunohistochemistry for KiM1P; (E-G) immunohistochemistry for $\mathrm{CD} 3 ;(\mathrm{H})$ immunohistochemistry for CD20.

Scale bars: $A, C=2000 \mu \mathrm{m} ; \mathrm{B}=200 \mu \mathrm{m} ; \mathrm{D}=1000 \mu \mathrm{m} ; \mathrm{D}$ inset $=200 \mu \mathrm{m} ; \mathrm{E}-\mathrm{H}=100 \mu \mathrm{m}$ 


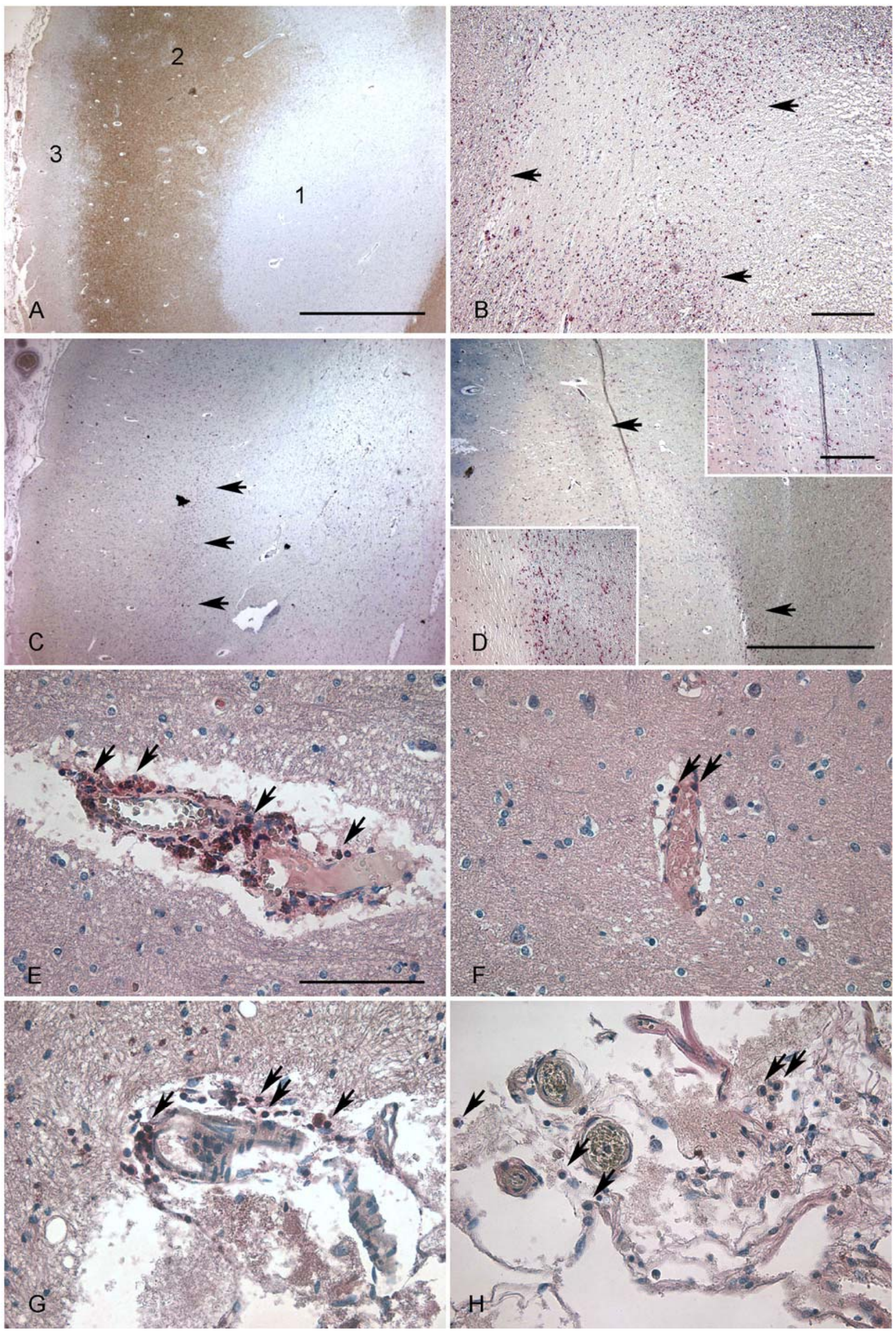

Figure 1 


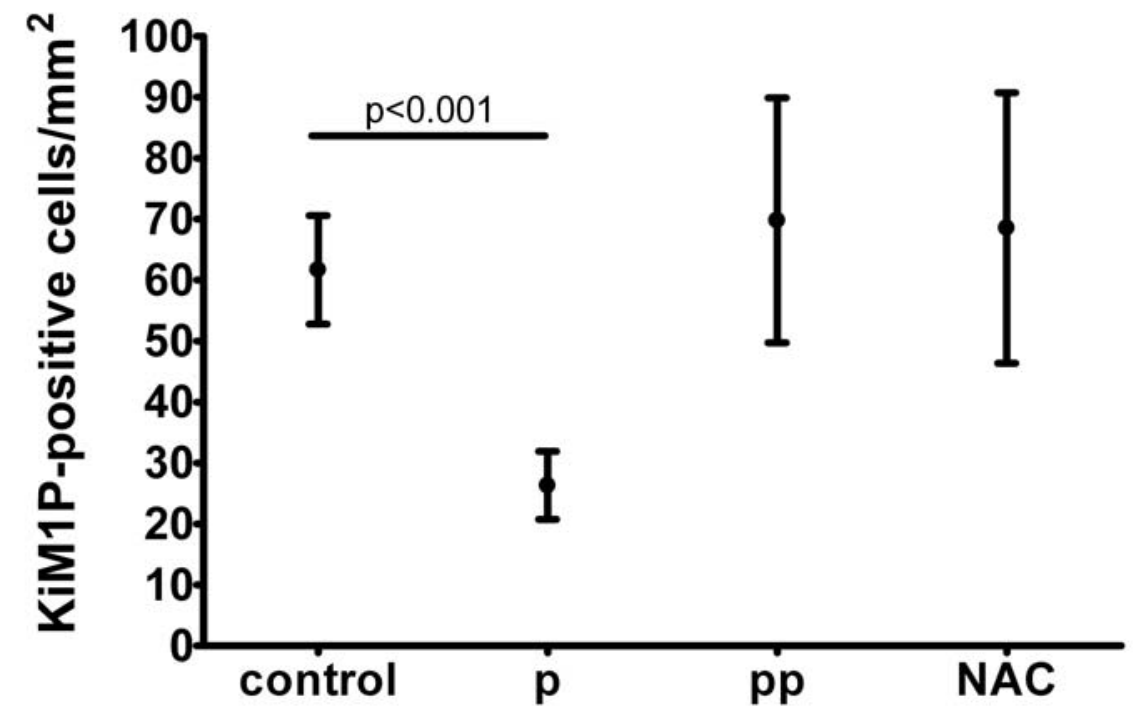

Figure 2 Microglia cells are reduced in the demyelinated cortex (control vs. plaque $p<0.001$; t-test). The differences in the densities of KiM1P-immunreactive cells between control cortex, periplaque cortical grey matter and "normal appearing cortex" are not statistically significant.

Abbreviations: p: plaque; pp: periplaque; NAC: normal appearing cortex

\subsubsection{Reactive astrogliosis in chronic cortical plaques}

Diffuse, mild gliosis characterises the cortex with multiple sclerosis

One of the main characteristics of chronic white matter plaques is the glial scar formed by fibrillary processes of reactive astrocytes. This dense scar that is typical for white matter plaques was however, not seen in the cortex of patients with chronic MS. Instead, mild and diffuse astrogliosis prevailed in all cortical plaques. The density of GFAP-expressing astrocytes was quantified in the frontal cortex of the 17 chronic MS brains. The number of GFAP-positive cells was higher in MS cortex compared to controls (controls: $8 \pm 6.5$; in the cortical plaques: $56.6 \pm 29.1$; in normal appearing cortex (NAC): $51.7 \pm 19.8$ [mean $\pm \mathrm{SD}$; control vs. plaque: $\mathrm{p}<0.01$; control vs. NAC: $\mathrm{p}<0.05$, t-test). This mild gliosis was consistently found in all MS patients, i.e. in demyelinated cortical areas but in 'normal appearing cortex' as well (Fig. 3). This finding suggests that large proportions of 'normal appearing cortex' of MS brains have been affected by pathologic stimuli. 


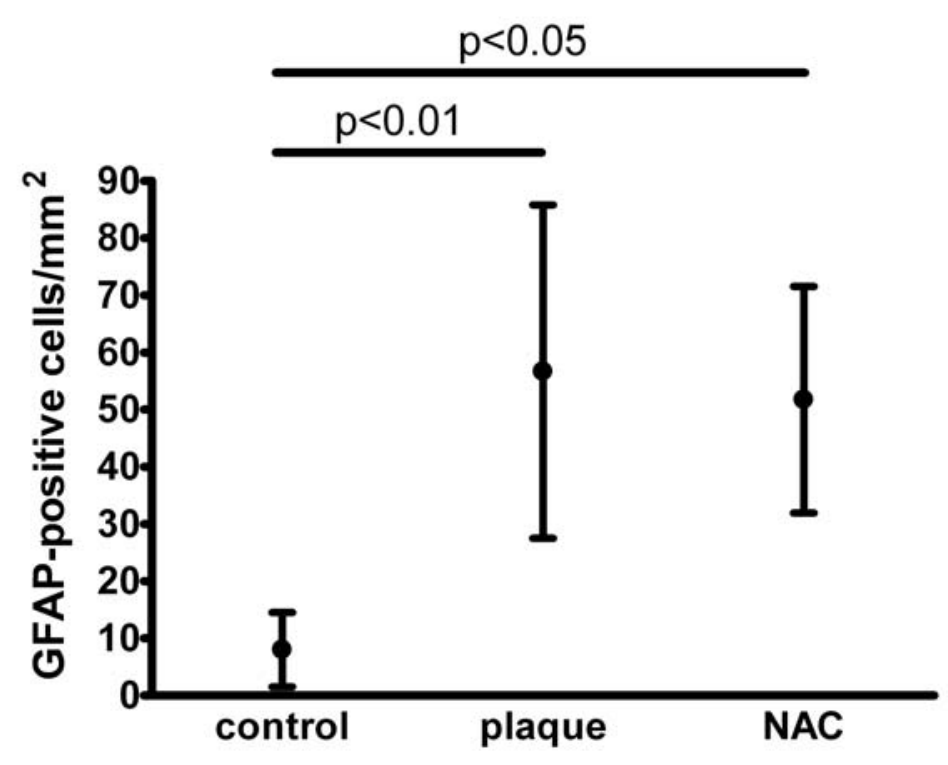

Figure 3 Mild, diffuse astrogliosis characterises the cortex of all patients with chronic MS. The density of GFAP-positive cells is higher in cortical lesions compared with cortex from control subjects (control vs. plaque: $\mathrm{p}<0.01$; t-test). This mild gliosis is also seen in non-demyelinated cortex ('normal appearing cortex') from MS patients (control vs. NAC: $\mathrm{p}<0.05$; t-test).

NAC: normal appearing cortex

\subsubsection{Inflammation in cortex of patients with early MS}

To investigate whether the cortex is affected by inflammatory demyelination in early MS, brain biopsy tissue from 150 MS cases was inspected. Samples from 35 patients had cortical tissue. 8 out of the $35(23 \%)$ patients showed - asides from white matter lesions - cortical plaques. The composition and density of inflammatory cells and extent of the acute neuroaxonal injury was investigated and compared in active inflammatory grey versus white matter lesions. Thus, cortical and white matter lesions were studied in parallel in the brain sections of every MS patient concerned. Inflammatory cells were identified and quantified by CD3, CD8 immunhistochemistry for all and CD8+ T-lymphocytes; Kim1P, MRP 14, MHCII for all, early active and MHC II-positive macrophages. Acute axonal damage was assessed by immunhistochemistry for APP. Neuronal injury was determined by immunhistochemistry to SMI 35 and morphological criteria (Nissl, 1892). 
Results

\subsubsection{Topography of cortical plaques in early MS}

In acute MS two patterns of cortical lesions were identified. The majority, 6 out of 8 cases (75\%) showed lesions situated at the transitional zone between the white matter and the cortex and were designated as 'cortico-subcortical lesions' (type 1 lesions). The other 2 patients (25\%) represented distinct, multiple, 'small perivascular lesions' (type 2 lesions). Corticosubcortical lesions appeared as single but extensive demyelination involving both the white and the grey matter parenchyma (Fig. 4A). Small perivascular lesions appeared as scattered, small demyelinated areas in the cortex as well as in the white matter counterpart (Fig. 7A-B). The most frequent cortical lesion of late MS, which affects subpial, superficial cortical layers (type 3 lesions) was not encountered in the biopsy samples.

\subsubsection{Early cortico-subcortical lesions are highly inflammatory and destructive}

Cortico-subcortical lesions appeared as hypercellular, highly inflamed, destructive lesions (Fig. 4A). Mononuclear cells aligned in concentric rows filled the perivascular space in both the cortex and white matter (Fig. 4B-D). The density of perivascular CD 3-immunreactive Tlymphocytes was similar in the cortical and in the white matter part of the lesions (Fig. 5A) (cell counts from a representative case: white matter (cells $/ \mathrm{mm}^{2}$ ): $4500 \pm 1666$; cortex: $4711 \pm$ $1426[$ mean $\pm \mathrm{SD}])$. It holds true for the density of infiltrating T-lymphocytes in the parenchyma (white matter $\left(\right.$ cells $/ \mathrm{mm}^{2}$ ): $366.7 \pm 206.2$; cortex: $544.4 \pm 250.6$ [mean $\pm \mathrm{SD}$ ]) (Fig. 5A). The density of CD8+ cytotoxic T-cells shared this distribution in the perivascular space (white matter (cells $/ \mathrm{mm}^{2}$ ): $2189 \pm 730.5$; cortex: $1644 \pm 381.2[$ mean $\pm \mathrm{SD}]$ ) and in the parenchyma (white matter (cells $/ \mathrm{mm}^{2}$ ): $133.3 \pm 132.3$; cortex: $200 \pm 173.2$ [mean $\pm \mathrm{SD}$ ]) (Fig. 5B). The proportion of the CD8+ T-cell, subpopulation of all T-cells in the perivascular space was slightly reduced in the cortex; however this reduction was not statistically significant (ratio of perivascular $\mathrm{CD} 8+$ and $\mathrm{CD} 3+$ lymphocytes in the white matter: $\sim 0.5$, in the cortex: $\sim 0.4)$.

Apart from T-lymphocytes, foamy macrophages and large, pleiomorphic astrocytes populated the white matter parenchyma of the lesions. The cytoplasm of these macrophages contained myelin debris visualised by the lipophylic dye luxol fast blue (LFB). Few such activated, foamy macrophages were also present at the transition of white matter and cortex, however they were entirely absent from the intracortical grey matter. Instead, extensive and diffuse activation of microglia characterised the lesion in the cortical counterpart. The density of KiM1P-immunreactive microglia was slightly reduced in the cortex compared with KiM1Pimmunreactive macrophages/microglia cells in the white matter (KiM1P-positive cells, white 
matter (cells/mm²): $761.6 \pm 89.51$; cortex: $672.0 \pm 109.1$ [mean \pm SD]) (Fig. 4E-F; Fig. 5C). This reduction was more pronounced when the density of MHCII positive cells was determined and compared (Fig. 6A-B). Both, macrophages and astrocytes were found expressing the MHC II antigen in the white matter, whereas in the cortex, MHC II was predominantly expressed by microglial cells. Furthermore, the proportion of activated MRP14-expressing macrophage/microglia was significantly reduced in the cortex compared with the white matter (MRP14-positive cells, white matter $\left(\right.$ cells $\left./ \mathrm{mm}^{2}\right): 352.0 \pm 124.5$; cortex: $163.2 \pm 39.84$ [mean $\pm \mathrm{SD}$ ]; MRP14/KiM1P ratio: white matter: $\sim 0.4$; cortex: $\sim 0.25$ ) (Fig. 4G-H, Fig. 5C).

Acute axonal injury was characterised by immunhistochemistry for amyloid precursor protein (APP), a protein that is transported by fast axonal transport and accumulates at sites of axonal injury. Conspicuously less APP-positive structures were found in the cortical than in white matter part of the lesions (APP-positive structures $/ \mathrm{mm}^{2}$ white matter: $1174.4 \pm 160.2$; cortex: $451.2 \pm 94.25[$ mean $\pm \mathrm{SD}]$ normalised to controls: white matter: 1174.4; cortex: 603.2; white matter vs. cortex $\mathrm{p}<0.0001$, t-test) (Fig. 5D, Fig. 6C-D). However, neuronal cell bodies showed the morphology of apparent neuronal injury, characterised by swollen somata, central chromatolysis, peripherally displaced nucleus, pale cytoplasm, loss of nucleolus and finally immunreactivity to SMI 35 (Fig. 6E-F). Processes of ramified microglia embraced the perycarion of these neurons (Fig. 4F, Fig. 6E).

The blood brain barrier appeared compromised in the white matter as shown by massive leakage for the immunoglobulin IgG (Fig. 6G). In contrast, it appeared largely intact in the cortex despite the severe inflammation by which white matter and cortex were equally affected (Fig. 6H). 
Figure 4 Cortico-subcortical lesions are hypercellular inflammatory lesions of early MS. (A) A demyelinated lesion is situated in both, the grey (above the dashed line) and the white matter (below the dashed line). Due to the dense inflammatory cell infiltrates the cytoarchitecture is substantially distorted, which makes it difficult to discern the cortex from the white matter. (B) Inflammatory cells densely infiltrate the vessel walls, the perivascular space and the parenchyma in the cortex. (C) The perivascular inflammatory cells are mainly composed of T-lymphocytes in the white matter part (D) and in the cortical part of the lesion. Perivascular cell density (cells/surface of vessel wall) appears nearly identical in the white and the grey matter parts of the lesion. (E) In the white matter KiM1P-positive cells are predominantly foamy macrophages, while (F) in the cortex they are exclusively microglia cells. Note that microglia processes embrace the cell bodies of numerous neurons indicating substantial neuronal damage. (G) A subset of these macrophages expresses the MRP 14 antigen in the white matter and $(\mathrm{H})$ microglia cells in the grey matter. (A-B) histological staining for LFB; (C-D) immunohistochemistry for CD3; (E-F) immunohistochemistry for KiM1P; (G-H) immunohistochemistry for MRP14 protein.

Scale bars: $\mathrm{A}=200 \mu \mathrm{m} ; \mathrm{B}-\mathrm{H}=100 \mu \mathrm{m}$ 

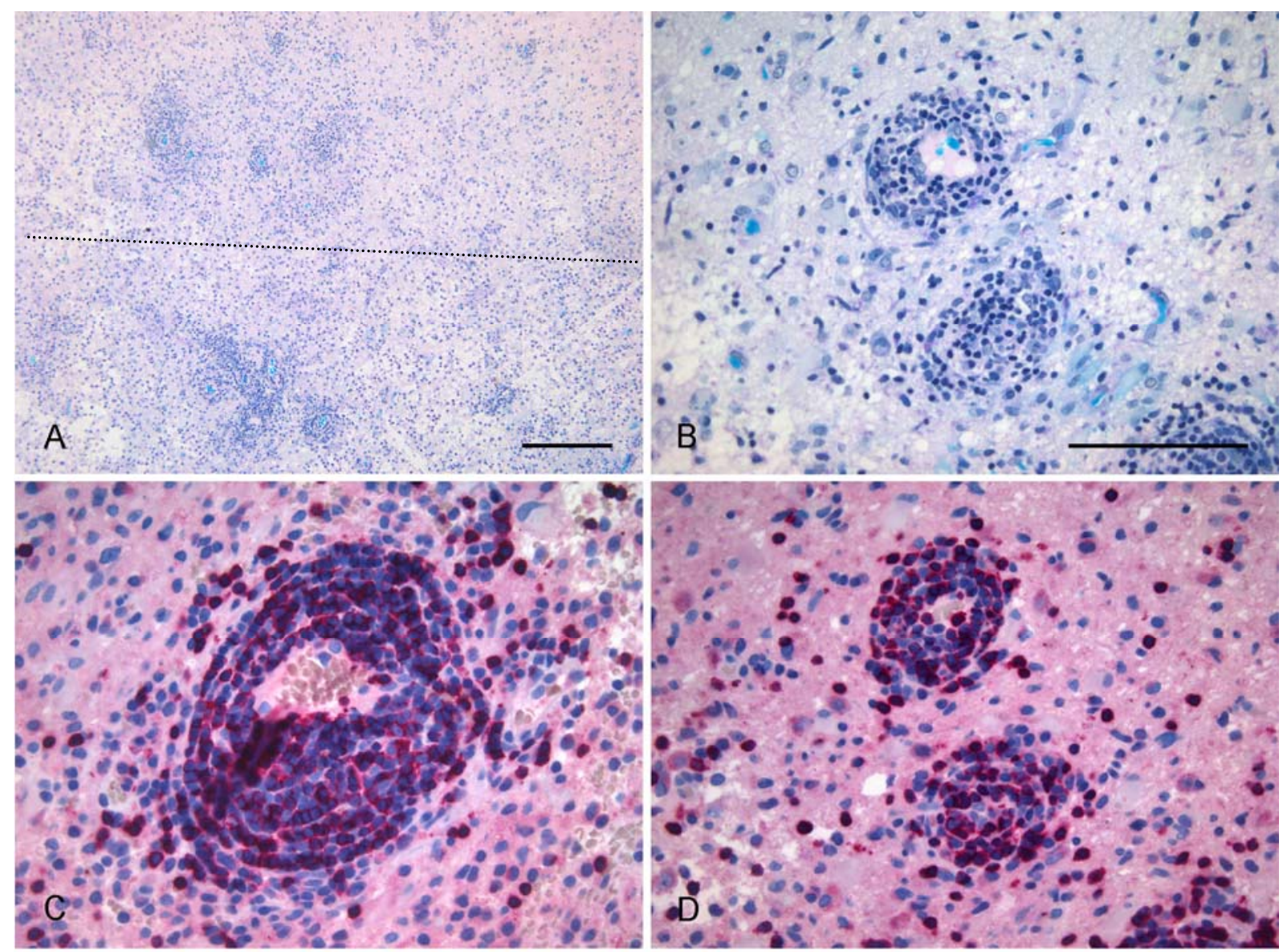

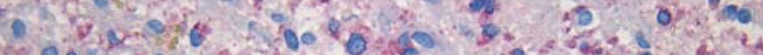

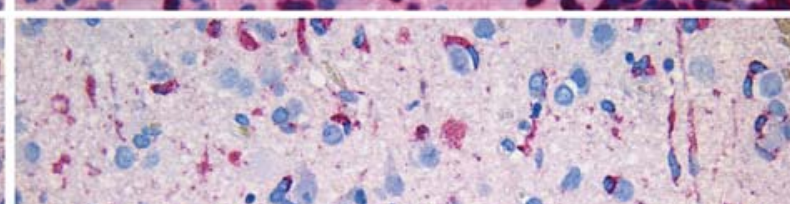

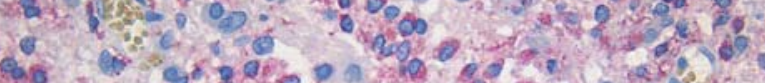

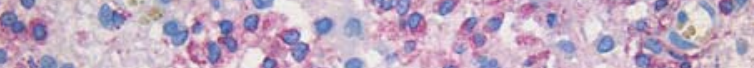

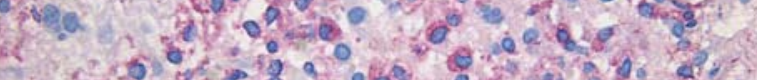

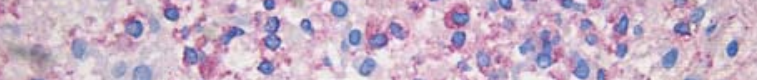

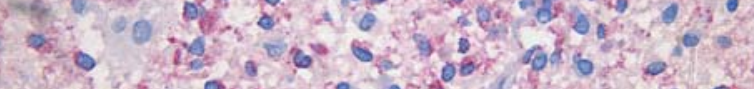

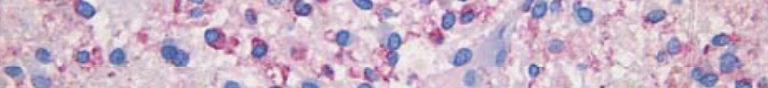

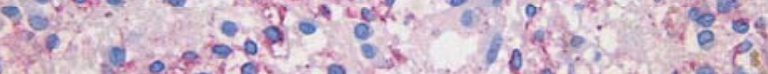

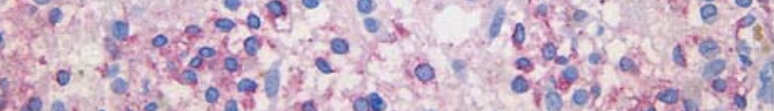

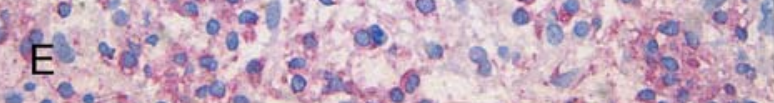

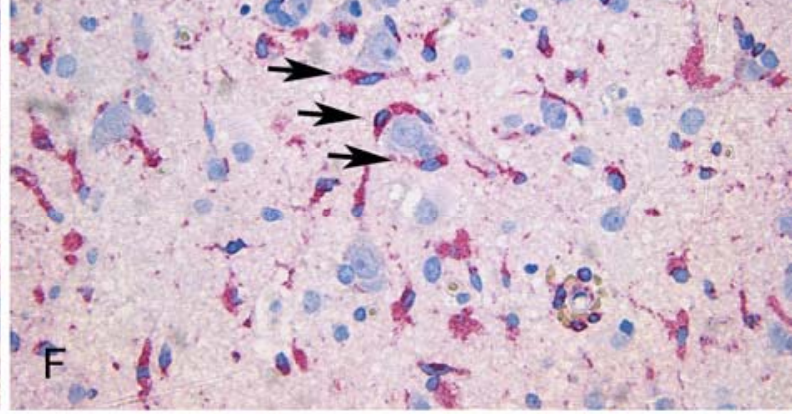

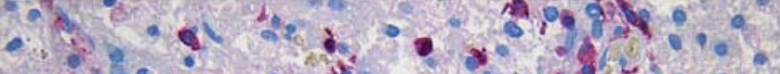

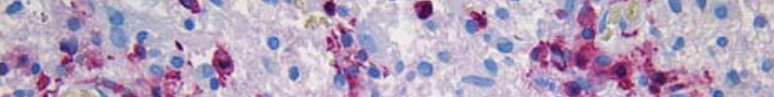

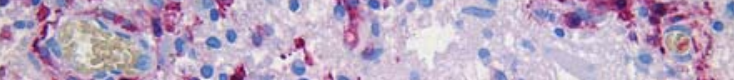

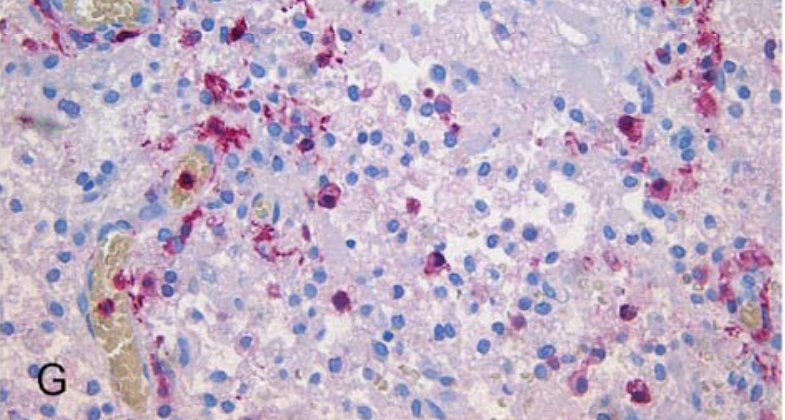

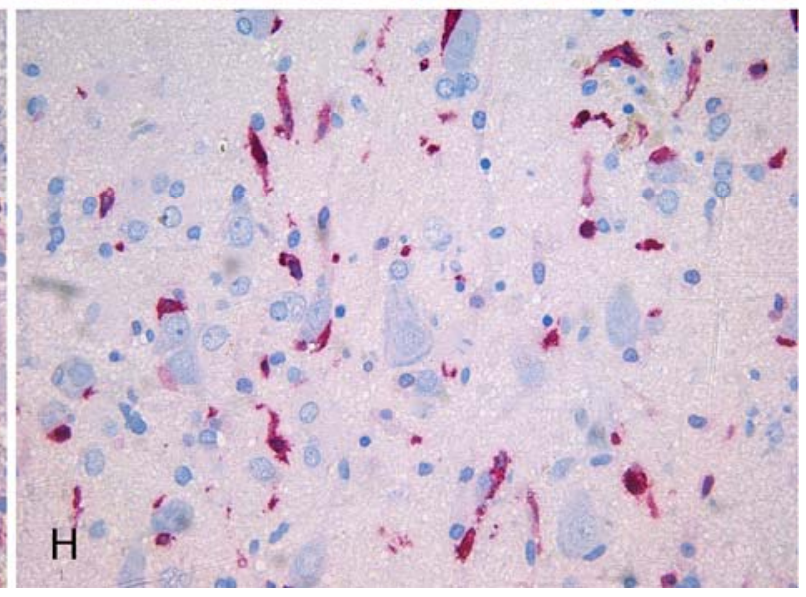

Figure 4 
A

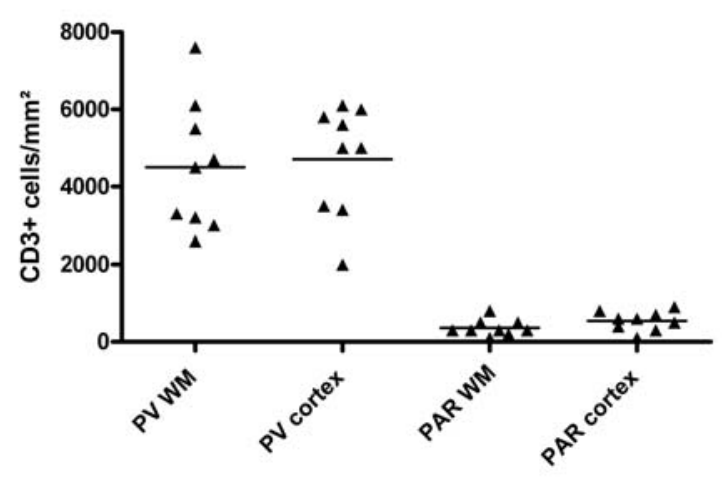

C

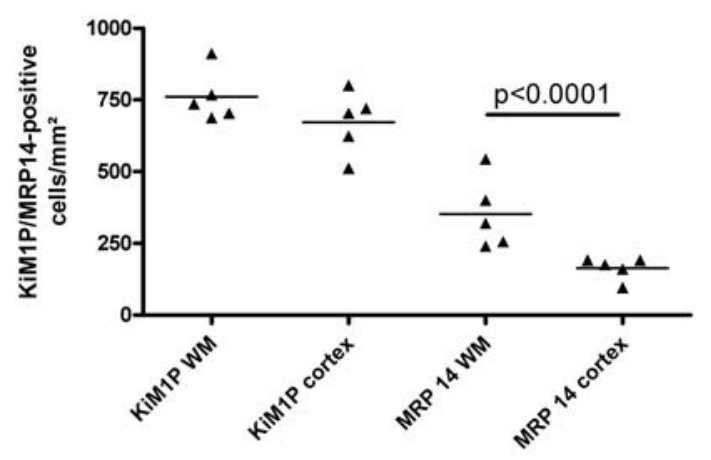

B

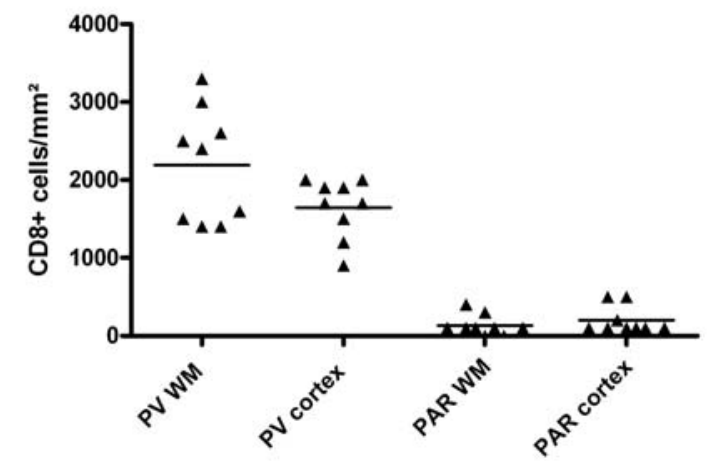

D

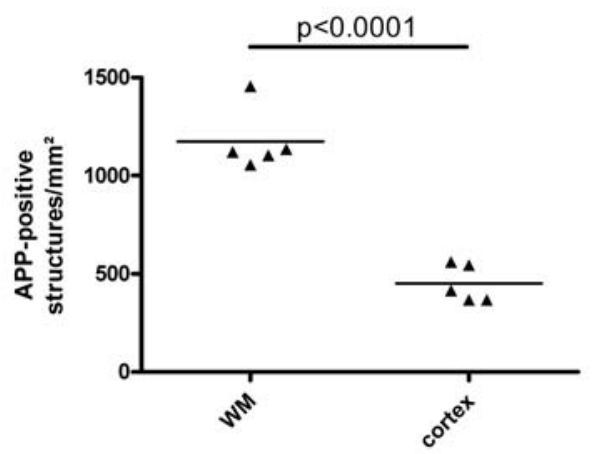

Figure 5 The cell density of T-lymphocytes is similar; however macrophages/microglia cells are reduced in the cortical compared with the white matter part in early cortico-subcortical lesions. (A) Densities of CD3+ and (B) CD8+ T-lymphocytes are similar in the perivascular position and in the parenchyma in the cortical and in the white matter part of the lesion. (C) There is a slight reduction in density of KiM1P-positive cells and a conspicuous reduction in density of MRP14-immunreactive cells in the cortex, compared to densities of these cells in the white matter. In addition, (D) the extent of acute axonal injury is significantly smaller in the cortex compared with the white matter in the same lesion. All graphs depict cell counts taken from a single representative early cortico-subcortical MS lesion.

Abbreviations: PV: perivascular position; PAR: parenchyma; WM: white matter 
Figure 6 Less MHC II-posistive cells, less acute axonal injury and an intact BBB but pronounced acute neuronal injury characterise the cortex in the early cortico-subcortical lesions. (A) Both macrophages with round morphology (more intensively stained cells) and astroglial cells with broad processes (less intensively stained cells) are involved in MHCII antigen expression. (B) In the cortex the density of antigen-presenting cells is greatly reduced compared with white matter part. It is predominantly the microglia cells that are immunreactive for MHC II. (C) Acute axonal injury in the white matter. Accumulation of APP in axons with impaired anterograde axonal transport (arrows). (D) The extent of acute axonal damage (arrows) is much lower in cortex. (E) Apparent injury to neurons indicated by disintegration of the nucleus and central chromatolysis (arrows). Note that microglia cells, wich contain LFB-positive myelin debris embrace the neuronal soma. (F) Neuronal injury is also detected by immunostaining for SMI 35. Arrows point at the immunreactive, injured cells. (G) While in the white matter BBB breakdown is apparent as indicated by the massive leakage of immunoglobulin into the tissue, $(\mathrm{H})$ the $\mathrm{BBB}$ in cortex remains intact. Note, that there is no serum leakage around inflamed vessels in the cortex (arrow). (A-B) immunohistochemistry for MHC II; (C-D) immunohistochemistry for APP; (E) histological staining for LFB; (F) immunohistochemistry for SMI 35 and (G-H) immunhistochemistry for IgG.

Scale bars: A-B, G-H $=200 \mu \mathrm{m} ; \mathrm{C}-\mathrm{D}, \mathrm{F}=100 \mu \mathrm{m} ; \mathrm{E}=20 \mu \mathrm{m}$ 

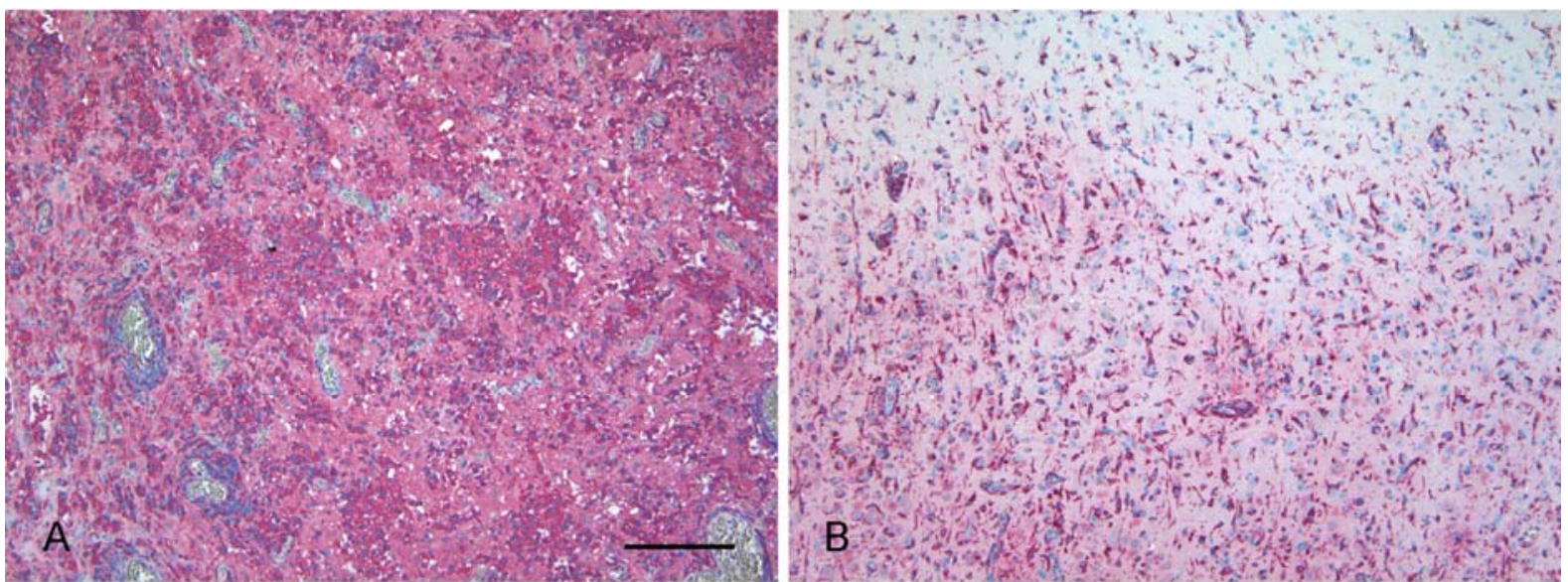

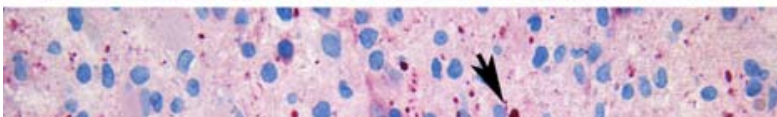

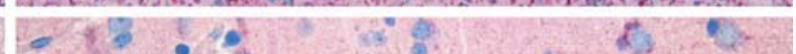

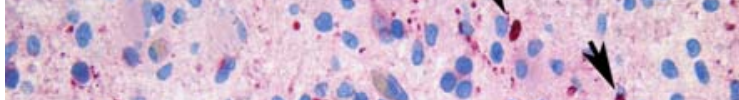

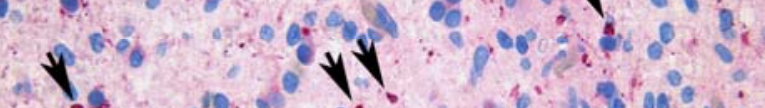

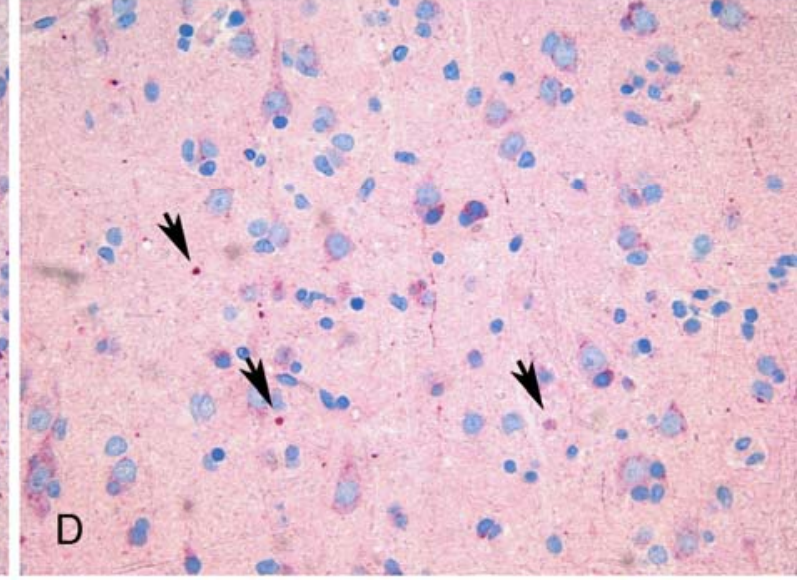

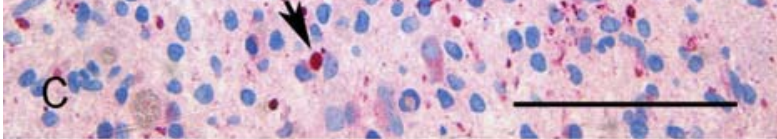
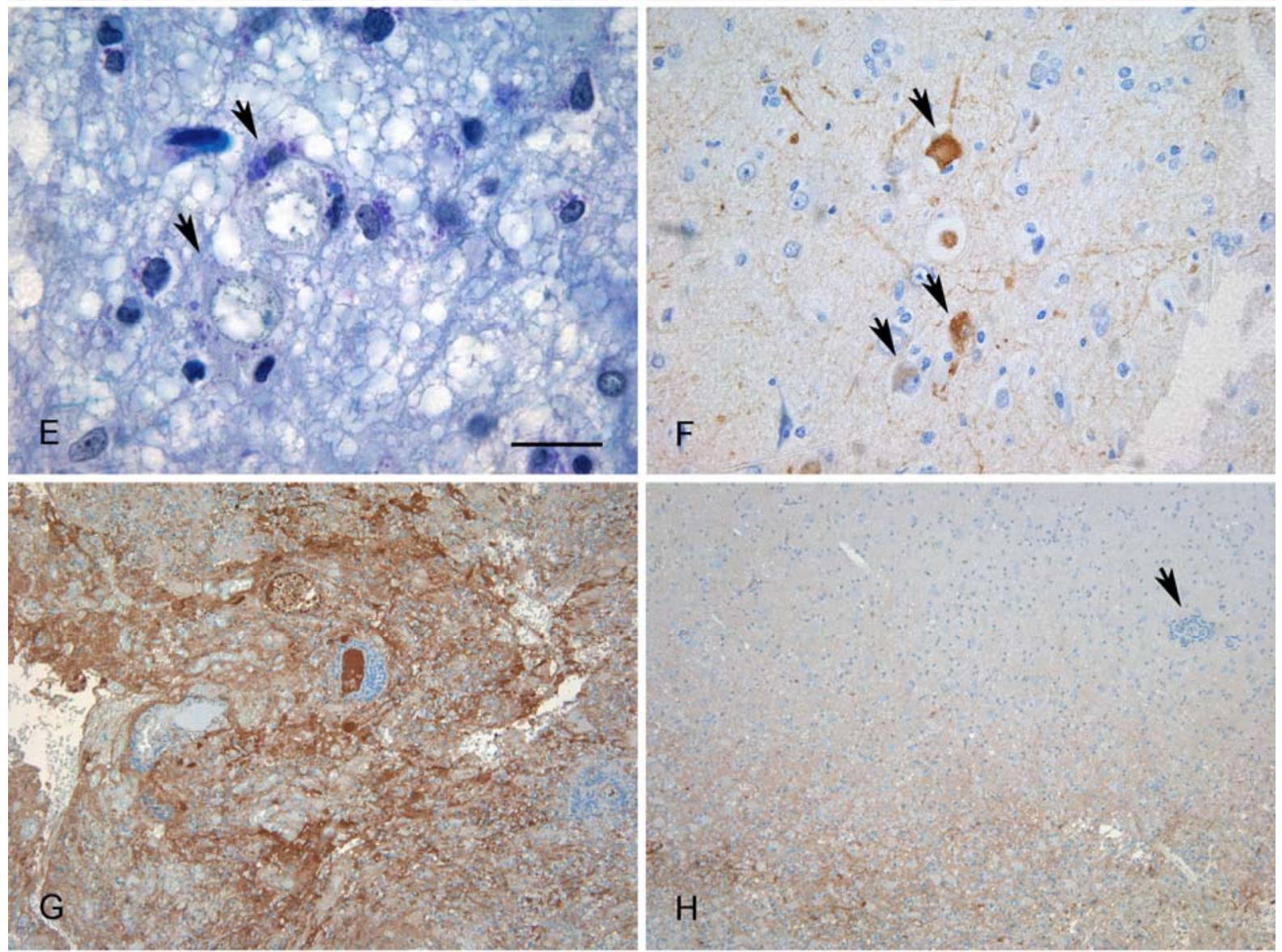

Figure 6 


\subsubsection{Small perivascular cortical lesions are less destructive}

Small perivascular cortical lesions exhibited less destructive, predominantly demyelinating features (Fig. 7A-B). Although lesions typically arose around blood vessels, these demyelinated areas were not associated with significant perivascular lymphocyte infiltration. Only single CD3+ T-cells were situated at the rim of the cortical and white matter lesions (Fig. 7C-F).

Foamy macrophages in the white matter and ramified microglia in the cortex appeared to be the predominant inflammatory cells of the lesions (Fig. 8A-B). In the white matter only macrophages but not astrocytes expressed the MHC II antigen, whereas in the cortex they were exclusively the microglia cells. Density of macrophage/microglia cells was lower in cortical than white matter lesions (Fig. 8A-B). Moreover, the proportion of MRP14-positive cells was substantially smaller in the cortex than the white matter (Single representative case: KiM1P-positive cells, white matter (cells $\left./ \mathrm{mm}^{2}\right): 620.8 \pm 92.19$; cortex: $192.0 \pm 22.63$ [mean $\pm \mathrm{SD}$ ]; MRP14-positive cells, white matter (cells $/ \mathrm{mm}^{2}$ ): $307.2 \pm 102.1$; cortex: $70.40 \pm$ 29.07 [mean \pm SD] MRP14/KiM1P ratio: white matter: $\sim 0.48$; cortex: $\sim 0.36$ ) (Fig. 8C-D). Bcells, plasma cells and complement deposition were not detected on the vessel walls or on myelin in any of the lesions.

Acute axonal injury was less prominent in the cortex than in the white matter (Fig. 8E-F). The difference in the normalised values to axonal density in controls was statistically significant (APP-positive structures $/ \mathrm{mm}^{2}$, white matter: $220.8 \pm 63.40$; cortex: $121.6 \pm 50.09$ [mean $\pm \mathrm{SD}$ ]; normalised to controls: white matter: 220.8; cortex: 162.6; cortex vs. white matter $\mathrm{p}<0.025)$. Above all, neurons were negative to SMI 35 and appeared morphologically intact. While the BBB was apparently compromised in the white matter, BBB leakage was not observed in any of the small perivascular grey matter plaques.

Taken together, the two patterns of early MS lesions identified in our material share similar characteristics, i.e. (i) identical T-cell infiltration but (ii) reduced macrophage/microglia activation and (iii) less acute axonal damage in cortical than white matter lesions; (iv) absence of haematogenous macrophages in the cortex and (v) largely intact cortical blood brain barrier. The difference between the two types of cortical lesions lies upon the extent of inflammatory cell infiltration, which is also reflected in neuronal and axonal injury in the more inflamed cortico-subcortical lesions (Table 4). 

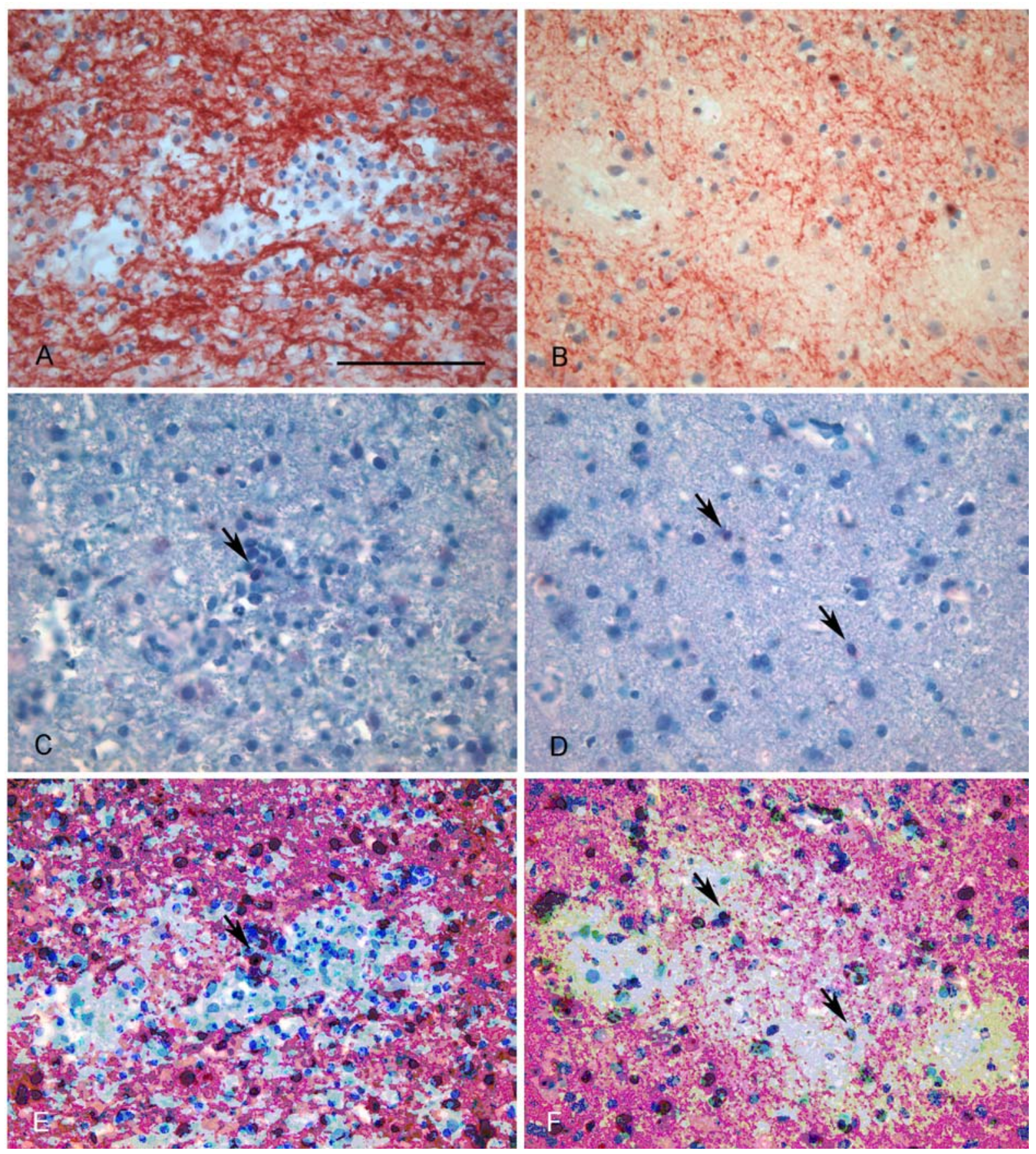

Figure 7 Small perivascular cortical demyelinated lesion in early MS. Lesions are distinct demyelinated areas, usually arising around small vessels in both $(\mathrm{A}, \mathrm{C}, \mathrm{E})$ the white and $(\mathrm{B}, \mathrm{D}, \mathrm{F})$ the grey matter. The demyelinations in the (A) white matter and (B) in the cortex are of similar appearance (white and grey matter lesions in the same section). Lymphocytic infiltration is entirely absent within both (C) white and (D) grey matter lesions. Instead, 1-2 T-lymphocytes (arrows) are situated at the border of the lesions of the (E) white and the (F) grey matter. (A-B) immunohistochemistry for MBP; (C-D) immunohistochemistry for CD3; (E-F) MBP and $\mathrm{CD} 3$ overlay images.

Scale bars: A-F $=100 \mu \mathrm{m}$ 

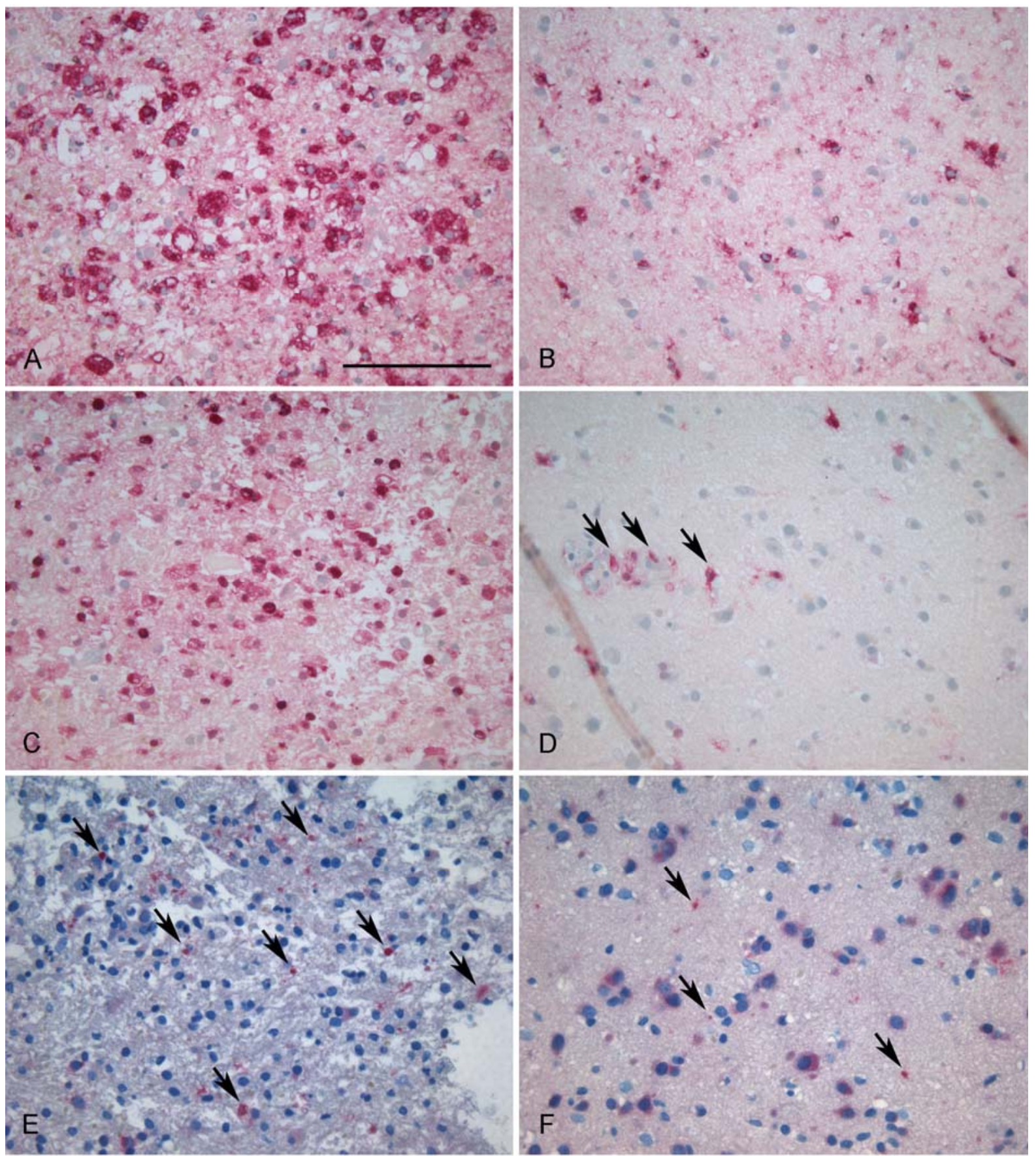

Figure 8 Relatively mild inflammation and little neuroaxonal damage characterise small perivascular lesions in the cortex. (A) Foamy macrophages populate the white matter lesions (C) with a subset expressing the early activation antigen MRP14. (B) In the cortical lesions, the macrophage/microglia cell density is lower than in the white matter lesions (D) with only few MRP14+ microglia cells that are mainly situated in the perivascular space (arrows). (E-F) The degree of acute axonal damage (arrows) is (F) lower in the cortex than (E) in lesions in the white matter. (A-B) immunohistochemistry for KiM1P; (C-D) immunohistochemistry for MRP14; (E-F) immunhistochemistry for APP.

Scale bars: A-F $=100 \mu \mathrm{m}$ 
Results

\begin{tabular}{|c|c|c|c|c|c|c|c|c|c|}
\hline \multirow[b]{2}{*}{ Case } & \multirow{2}{*}{$\begin{array}{l}\text { Disease } \\
\text { duration }\end{array}$} & \multirow[b]{2}{*}{ Localisation } & \multirow{2}{*}{$\begin{array}{l}\text { T-cells } \\
\text { CD3+ } \\
\text { CD8+ }\end{array}$} & \multicolumn{2}{|c|}{$\begin{array}{l}\text { Macrophage and } \\
\text { microglia }\end{array}$} & \multirow[b]{2}{*}{ Astroglia } & \multirow{2}{*}{$\begin{array}{c}\mathrm{IgG} \\
\text { leakage }\end{array}$} & \multirow{2}{*}{$\begin{array}{l}\text { Compl/ } \\
\text { B-cells }\end{array}$} & \multirow{2}{*}{$\begin{array}{l}\text { Neuronal } \\
\text { damage }\end{array}$} \\
\hline & & & & $\begin{array}{c}\text { Morpho- } \\
\text { logy }\end{array}$ & $\begin{array}{l}\text { MRP14 } \\
+\end{array}$ & & & & \\
\hline \multirow{2}{*}{1} & \multirow{2}{*}{1 week } & \multirow{2}{*}{$\begin{array}{c}\text { Small } \\
\text { perivascular } \\
\text { lesions in } \\
\text { WM\&C }\end{array}$} & $\begin{array}{l}\text { WM:1-2 } \\
\text { cells in par }\end{array}$ & $\begin{array}{l}\text { WM: } \\
\text { MФ }\end{array}$ & $\begin{array}{c}\text { WM: } \\
0\end{array}$ & $\begin{array}{l}\text { WM: } \\
\text { diffuse }\end{array}$ & WM: + & \multirow{2}{*}{-} & \multirow{2}{*}{ - } \\
\hline & & & $\begin{array}{l}\mathrm{C}: 1-2 \text { cells } \\
\text { in par }\end{array}$ & $\begin{array}{c}\text { C: } \\
\text { Mglia }\end{array}$ & $\begin{array}{l}\mathrm{C}: \\
0\end{array}$ & $\begin{array}{c}\text { C: } \\
\text { diffuse }\end{array}$ & C: - & & \\
\hline \multirow{2}{*}{2} & \multirow{2}{*}{$\begin{array}{c}3 \\
\text { months }\end{array}$} & \multirow{2}{*}{$\begin{array}{c}\text { Small } \\
\text { perivascular } \\
\text { lesions in } \\
\text { WM\&C }\end{array}$} & $\begin{array}{l}\text { WM:1-2 } \\
\text { cells in pv }\end{array}$ & $\begin{array}{l}\text { WM: } \\
\text { MФ }\end{array}$ & $\begin{array}{l}\text { WM: } \\
\text { few }\end{array}$ & $\begin{array}{l}\text { WM: in } \\
\text { plaque }\end{array}$ & WM: + & \multirow{2}{*}{-} & \multirow{2}{*}{-} \\
\hline & & & $\begin{array}{c}\text { C: } 1-2 \text { cells } \\
\text { in } p v\end{array}$ & $\begin{array}{c}\text { C: } \\
\text { Mglia }\end{array}$ & $\begin{array}{l}\text { C: } 1-2 \\
\text { cells }\end{array}$ & $\begin{array}{c}\text { C: } \\
\text { diffuse }\end{array}$ & C: - & & \\
\hline \multirow{2}{*}{3} & \multirow[t]{2}{*}{2 weeks } & \multirow{2}{*}{$\begin{array}{l}\text { Cortico- } \\
\text { subcortical }\end{array}$} & $\begin{array}{c}\text { WM: } \\
\text { Massive } \\
\text { infiltrate in } \\
\text { pv \& par }\end{array}$ & $\begin{array}{l}\text { WM: } \\
\text { MФ }\end{array}$ & $\begin{array}{l}\text { WM: } \\
\text { many in } \\
\text { par }\end{array}$ & $\begin{array}{l}\text { WM: } \\
\text { diffuse }\end{array}$ & WM: + & \multirow[t]{2}{*}{-} & \multirow[t]{2}{*}{+} \\
\hline & & & $\begin{array}{l}\text { C: Massive } \\
\text { infiltrate in } \\
\text { pv \& par }\end{array}$ & $\begin{array}{c}\text { C: } \\
\text { Mglia }\end{array}$ & $\begin{array}{l}\text { C: few } \\
\text { in pv }\end{array}$ & $\begin{array}{c}\text { C: } \\
\text { diffuse }\end{array}$ & C: - & & \\
\hline \multirow[t]{2}{*}{4} & \multirow[t]{2}{*}{$\begin{array}{c}3 \\
\text { months }\end{array}$} & \multirow{2}{*}{$\begin{array}{l}\text { Cortico- } \\
\text { subcortical }\end{array}$} & $\begin{array}{c}\text { WM: } \\
\text { Massive } \\
\text { infiltrate in } \\
\text { pv \& par }\end{array}$ & $\begin{array}{l}\text { WM: } \\
\text { MФ }\end{array}$ & $\begin{array}{l}\text { WM: } \\
\text { many in } \\
\text { par }\end{array}$ & \multirow[t]{2}{*}{ No section } & WM: + & \multirow[t]{2}{*}{-} & \multirow[t]{2}{*}{+} \\
\hline & & & $\begin{array}{c}\text { C: Massive } \\
\text { infiltrate in } \\
\text { pv \& par }\end{array}$ & $\begin{array}{c}\text { C: } \\
\text { Mglia }\end{array}$ & C: no & & C: - & & \\
\hline
\end{tabular}

Table 4 Characteristics of the two types of cortical lesions in early MS illustrated in two representative cases each with cortico/subcortical and small perivascular lesions.

Abbreviations: WM: white matter; C: cortex; pv: perivascular position; par: parenchyma; Mglia: microglia; $\mathrm{M} \Phi$ : macrophage; Compl: complement 


\subsubsection{Neuronal injury}

\section{Neurons appear atrophied but largely preserved in chronic cortical lesions}

To define the long term consequences of inflammatory demyelination with regard to neuronal injury, the density of dendrites and synapses was determined in chronic cortical MS lesions. Autopsy brain samples from 17 MS patients (see Table 1) were immunostained for SMI 31, MAPII and synaptophysin. SMI 31 recognizes phosphorilated neurofilaments and is used as a marker of intact axons. MAPII is used to delineate the neuronal soma and the microtubulus containing dendritic tree. Synaptophysin labels synaptic vesicles, the signal clusters refer to presynaptic boutons.

No difference in neuronal cell density was observed between MS cases and controls. However, a slight atrophy of most cortical neurons was noted when the diameter of the soma in the nuclear plane was measured (Fig. 9A-B). Axons appeared largely preserved in all chronic cortical plaques. However, there was a consistent reduction of dendrites per surface area in all cortical layers in all demyelinated MS plaques studied. Moreover, a similar reduction in dendritic density was found in the 'normal appearing cortex' of MS brains (MAPII structures/25 [Nr. of dendrites that intersect once any point of the 25 points ocular grid], control: $5.87 \pm 0.25$ in the cortical plaques: $4.56 \pm 0.36$; in normal appearing cortex (NAC): $4.58 \pm 0.06$ [Mean $\pm \mathrm{SD}$ ]; control vs. plaque $\mathrm{p}<0.0001$; control vs. NAC $\mathrm{p}<0.0001$ ) (Fig. 10). In contrast, the density of the synapses did not differ from controls and was similar in all cortical plaques and all MS cortices examined (light intensity through synaptophysin stained sections, control: $26886 \pm 7067$; in the cortical plaques: $28448 \pm 7339.8$; in normal appearing MS cortex: $30985 \pm 13328$ [Mean \pm SD], control vs. plaque and control vs. normal appearing cortex: not significant). These results imply that neurons and synaptic boutons are largely preserved in the cortex of patients with chronic MS. However, the consistent reduction of dendritic density in all MS brains suggest, that the demyelinated and 'normal appearing cortex' may be similarly affected. 

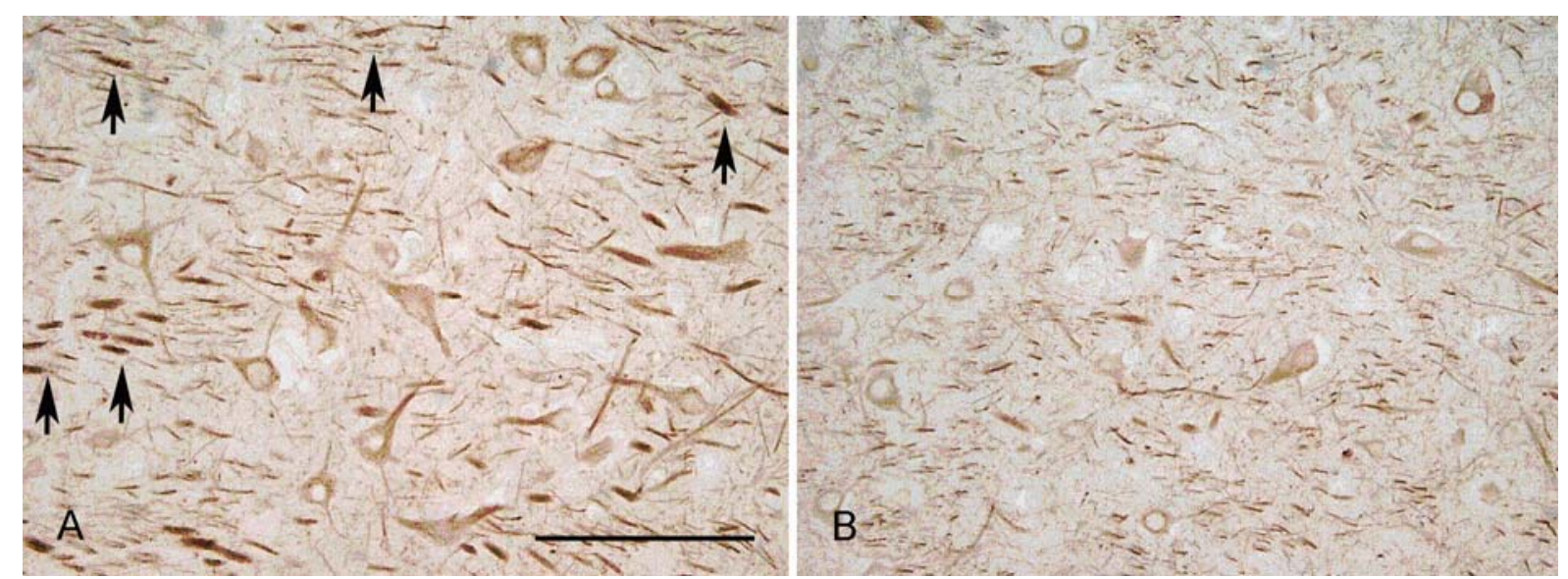

Figure 9 Neurons are well preserved in chronic cortical MS lesions. (A) MAPII staining outlines the cell body and the microtubules containing dendrites in control cortex. (B) In chronic cortical plaques neurons are slightly atrophied. Dendrites are thinner, apical dendrites (arrows on the control image) are essentially lost (cortical layer III). (A-B) immunohistochemistry for MAPII.

Scale bar: A-B: $200 \mu \mathrm{m}$

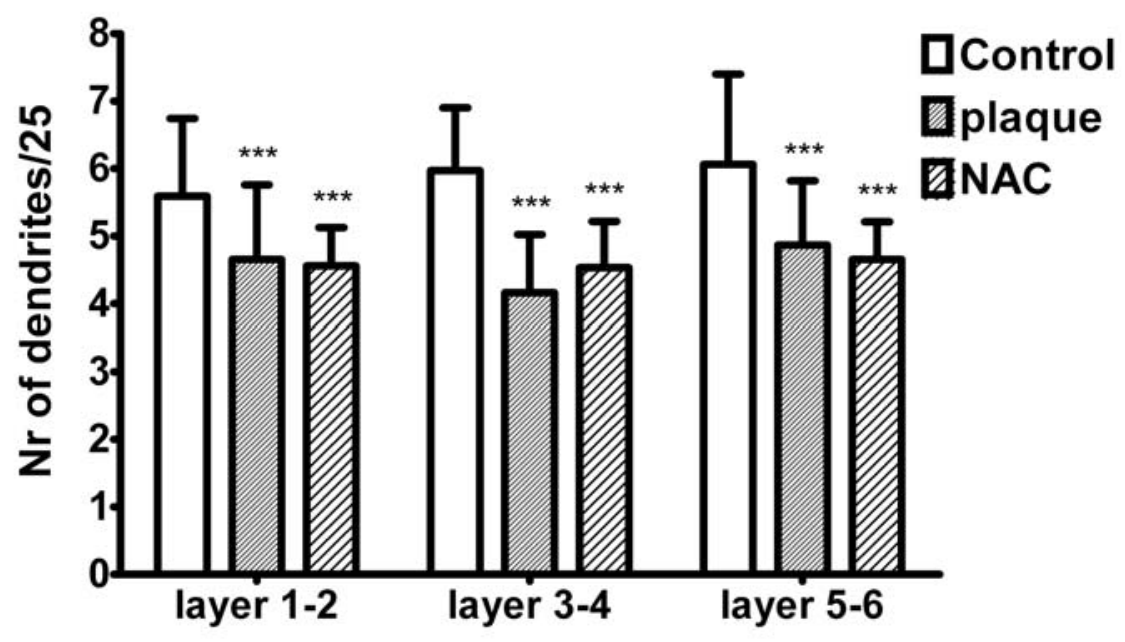

Figure 10 Reduction of dendrites per surface area in all cortical layers. This reduction was similar in the cortical plaques and in the normal appearing MS cortex (control vs. plaque $p<0.0001$; control vs. NAC $\mathrm{p}<0.0001$; t-test).

Abbreviations: NAC: normal appearing cortex 


\subsection{COMPENSATORY MECHANISMS IN THE GREY MATTER IN MULTIPLE SCLEROSIS: REMYELINATION AND ADAPTIVE REMODELLING OF SYNAPTIC CONTACTS}

\subsubsection{Remyelination of cortical lesions in patients with chronic MS}

\subsubsection{Remyelination is extensive in cortical MS lesions}

Frontal lobe sections of 17 MS (see Table 1) cases were used to study the remyelination and presence of oligodendrocytes in the cortex. 13/17 MS patients had cortical demyelination, the remaining 4 had no cortical lesions in the frontal lobe; however, they harboured cortical lesions in other brain regions. Control brains did not show any cortical lesions (Fig. 11A). Some demyelinated cortical lesions had sharply defined lesional borders (Fig. 11B), others rather showed a rim or patches of loosely arranged myelin in MBP immunohistochemistry (Fig. 11C). Myelinated cortical areas with seemingly thinner, irregular, punctuate, and less orderly arranged myelin were judged remyelinated by light microscopical appearance (Fig. 11C). This light microscopical appearance may in part result from thinner myelin sheaths with shorter internodes (Gledhill et al. 1973; Bruck et al. 2003). Furthermore, in MS patients, cortical areas with a myelin appearance closely resembling control cortex but with slightly thinner and less dense myelin sheaths were observed ('normal appearing cortex') (Fig. 11D).

The 17 MS patients were divided into three groups according to the presence or absence of remyelinated cortical fibres as assessed by light microscopy. The first group (demyelinated cases, $\mathrm{DM} ; \mathrm{n}=6$ ) consisted of patients with demyelinated lesions without apparent remyelination (Fig. 11B). Patients with a rim of thinly myelinated fibres at the lesional border or patches of irregular myelin suggestive of incomplete remyelination were classified into the second group (patients with remyelination; RM, n=7) (Fig. 11C). The third group contained patients without apparent cortical lesions ('normal appearing cortex' (NAC), n=4) (Fig. 11D).

\subsubsection{Electron microscopy reveals thin myelin sheaths in remyelinated cortical lesions}

Electron microscopic examination is the gold standard for the detection of remyelination. Therefore, we performed ultrastructural investigations on two cases each in the above defined groups (2 DM, 2 RM, 2 NAC and 2 controls). The quotient axon/fibre diameter known as gratio is relatively constant in the PNS and CNS within a certain species and considered to be around 0.7 for myelinated CNS fibres in humans (Schmitt and Bear, 1937; Friede and Beuche, 1985a; Coetzee et al. 1996; Hildebrand et al. 1993). Demyelinated axons have a g-ratio of 1.0, and remyelinated fibres yield g-ratios higher than normal. Most likely because of axon 
shrinkage due to the fixation, embedding, and re-embedding procedures in our formalin-fixed material, the g-ratios in our study were lower in all tissue sections examined (Friede and Beuche, 1985b).

In control cortex, myelin was abundant, intact, and the thickness of the myelin sheaths increased with the axon calibre (g-ratio control: mean $\pm \mathrm{SD}$ : $0.65 \pm 0.09$; Fig. 12A, D; Fig.13). Cases from the demyelinated (DM) group had only single axons with myelin sheaths (g-ratio not calculated). Cases with remyelination (RM) showed thin myelin sheaths around axons of various calibres (g-ratio RM: mean \pm SD: $0.76 \pm 0.07$; Fig. 12B, E; Fig. 13) indicating remyelination on the electron microscopical level. G-ratios between control cortex and RM MS lesions were significantly different $(\mathrm{p}<0.001)$. Unexpectedly, myelin sheaths in the NAC appeared rather thin (Fig. 12C, F) and g-ratios obtained from the NAC group were significantly higher than those of controls and almost as high as those of RM cases (g-ratio NAC: $0.72 \pm 0.09$; RM: $0.76 \pm 0.07$ [mean $\pm \mathrm{SD}$ ]; control vs. RM p $<0.001$; control vs. NAC $\mathrm{p}<0.001$; Kruskal-Wallis; Fig. 13). This suggests that large proportions of NAC are in fact remyelinated.

Figure 11 (A) Cortex of control brain with intact myelin. (B) Demyelinated cortical MS lesion. A sharp border separates well preserved myelin from the lesion, where myelin is entirely absent. (C) Cortical lesion with patches of irregular, dotted myelin that incompletely cover the lesional area. (D) Normal appearing MS cortex. The myelin forms a dense mesh and is undistinguishable from non-MS cortex. (E) Myelin basic protein (MBP)expressing oligodendrocytes at the border of a cortical lesion suggestive of remyelination (arrows). (F) 2', 3'cyclic nucleotide 3'-phosphodiesterase (CNP)-expressing cells in the same lesion. (G-H) Proteolipid protein (PLP) mRNA expressing myelin-forming cells in NAC and around a remyelinated cortical lesion in the same patient. (G) In the normal appearing cortex, few PLP mRNA positive cells are detected (arrow). (H) Numerous PLP mRNA positive cells line the remyelinated border of a cortical MS lesion (arrow). (A-E) immunohistochemistry for MBP; (F) immunohistochemistry for CNP; (G-H) in situ hybridization for PLP mRNA with immunohistochemistry for PLP protein.

Scale bars: A-F $=200 \mu \mathrm{m} ; \mathrm{A}-\mathrm{F}$ inset $=20 \mu \mathrm{m} ; \mathrm{G}-\mathrm{H}=200 \mu \mathrm{m}$; G-H inset $=100 \mu \mathrm{m}$. 
Results
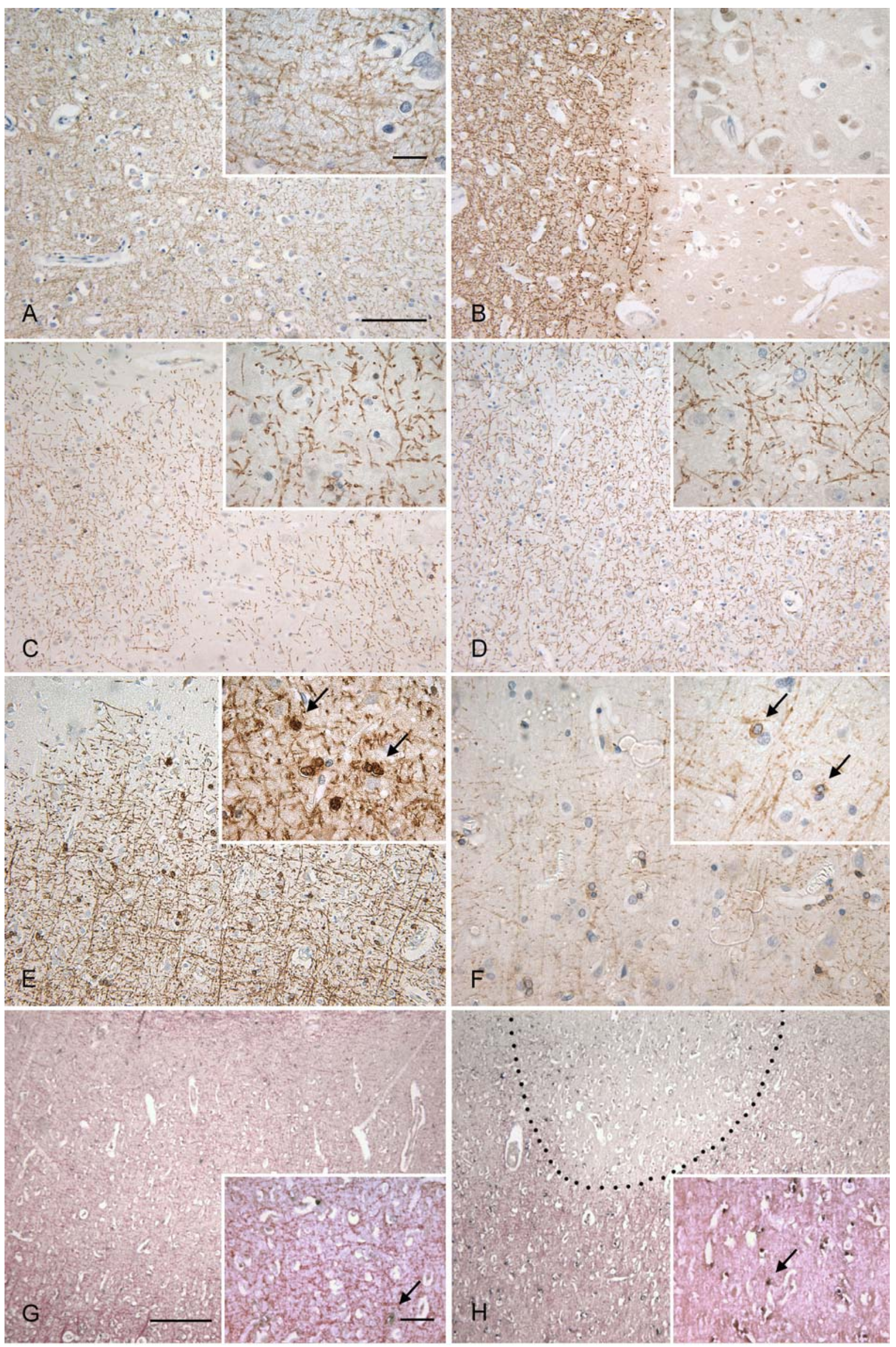

Figure 11 


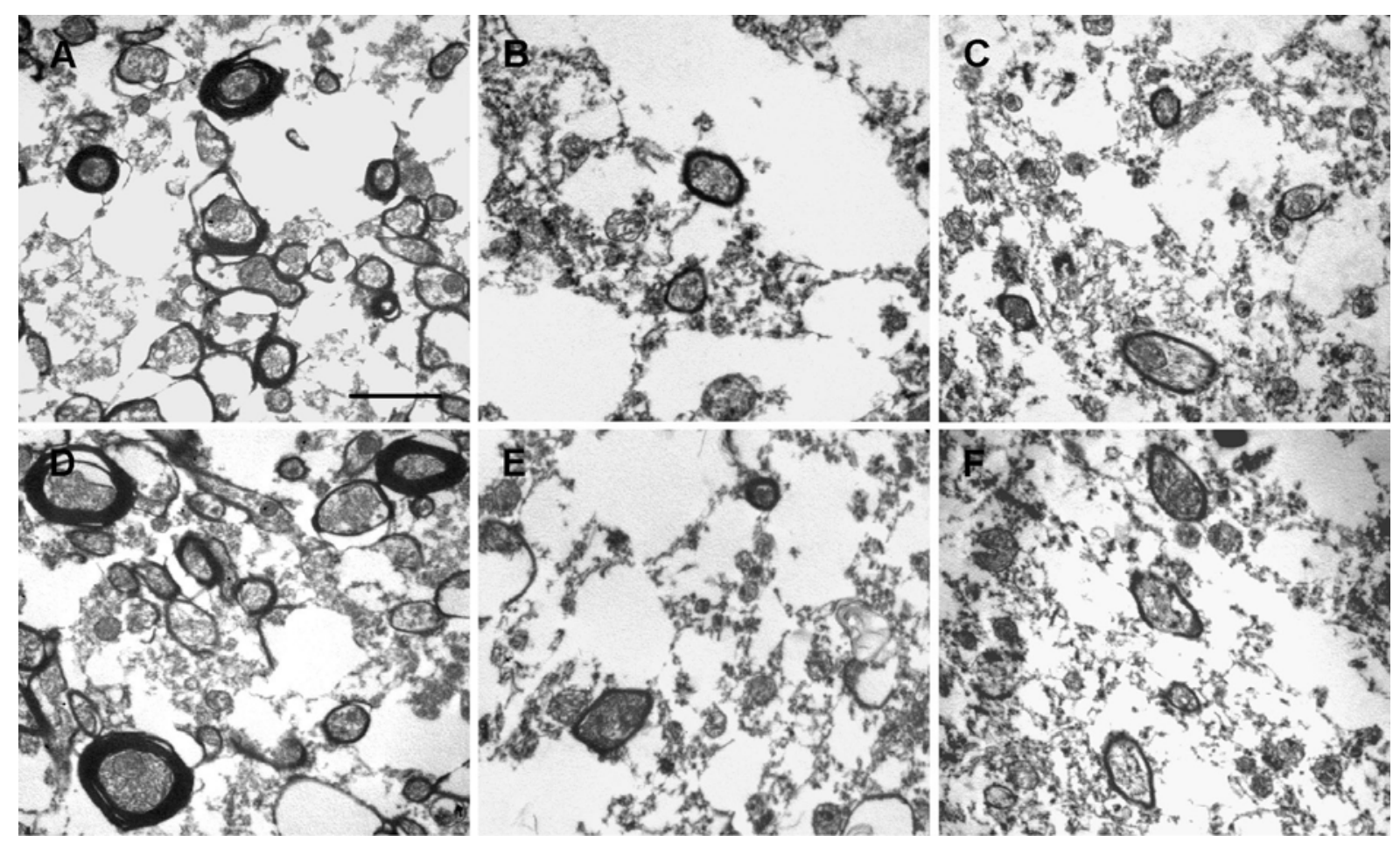

Figure 12 Electron micrographs of (A, D) control cortex, (B, E) cortical lesion with remyelination and (C, F) normal appearing MS cortex. (A, D) In control cortex myelin sheaths of regular thickness enwrap the axons. (B, E) Thinner myelin sheaths indicative of remyelination are detected. (C, F) Myelin sheaths of cortical fibres in 'normal appearing cortex' have a thickness similar to that observed in remyelinated lesions.

Scale bars: A-F $=2 \mu \mathrm{m}$

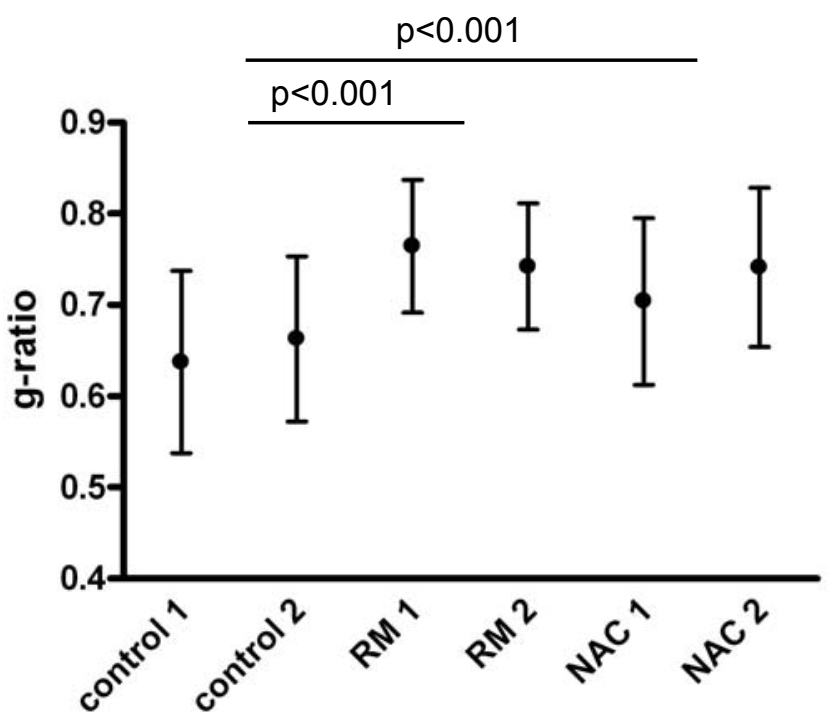

Figure 13 Axon to fibre (= g-) ratios in partially remyelinated cortical lesions (RM) and normal appearing cortex (NAC) of 2 representative MS cases each compared with 2 controls. Remyelinated fibres had uniformly thin myelin sheaths, thereby yielding higher g-ratios (RM vs. control: $\mathrm{p}<0.001$; NAC vs. control: $\mathrm{p}<0.001$ ).

Abbreviations: RM: remyelination; NAC: normal appearing cortex 


\subsubsection{Oligodendrocytes are abundant in remyelinated cortical lesions}

Myelin protein expression in oligodendrocytes was examined by immunohistochemistry for MBP and CNP and in situ hybridization for PLP mRNA (Fig. 11E-H). In healthy control cortex, the density of MBP positive oligodendrocytes was $22.8 \pm 15$ cells $/ \mathrm{mm}^{2}$ and of CNPpositive oligodendrocytes $38.52 \pm 11.5$ cells $/ \mathrm{mm}^{2}$ [mean $\pm \mathrm{SD}$ ] (Fig. 14). Cortical lesions with remyelination at the border were characterized by a low oligodendrocyte density in the demyelinated plaque center $(\mathrm{RM} / \mathrm{dc})$ and a high number of oligodendrocytes at the remyelinated lesion border (RM/b) (Fig. 11E-F, Fig. 14A-B) (MBP: RM/dc: $15.4 \pm 12.9$; RM/b: $62.2 \pm 37.5$ cells $/ \mathrm{mm}^{2}$; CNP: RM/dc: $26.4 \pm 12.7 \mathrm{RM} / \mathrm{b}: 79.6 \pm 29.3$ cells $\left./ \mathrm{mm}^{2}\right)$. The density of MBP and CNP expressing oligodendrocytes in remyelinated cortical areas was significantly higher compared with control and normal appearing cortices (MBP: control vs. $\mathrm{RM} / \mathrm{b}: \mathrm{p}=0.0097$; NAC vs. RM/b: $\mathrm{p}=0.0424$; CNP: control vs. RM/b: $\mathrm{p}=0.0002$; NAC vs. $\mathrm{RM} / \mathrm{b}: \mathrm{p}=0.0061)$. In situ hybridization for PLP mRNA confirmed higher numbers of oligodendrocytes at the border of remyelinating lesions (Fig. 11H) compared with NAC (Fig. $11 G)$. No significant differences in oligodendrocyte cell counts in the demyelinated centers (dc) of cortical lesions in RM and DM cases were found. In demyelinated cortical lesions, cell densities of MBP- and CNP-positive oligodendrocytes were significantly reduced compared with control cortex (MBP: control: $22.8 \pm 15$ cells $/ \mathrm{mm}^{2}$ [mean $\pm \mathrm{SD}$; DM/dc: $5.2 \pm 6.4$ cells $/ \mathrm{mm}^{2} ; \mathrm{p}=0.0047$; CNP: control: $38.5 \pm 11.5$; DM/dc: $4.4 \pm 3.1$ cells $\left./ \mathrm{mm}^{2} ; \mathrm{p}=0.0002\right)$. In contrast to remyelinating lesions, MBP positive oligodendrocytes were not present in higher numbers at the lesional border $(\mathrm{DM} / \mathrm{b})$. However, a considerable population of CNP positive oligodendrocytes were aligning around the sharply demarcated cortical plaques (MBP: control: $22.8 \pm 15$ cells $/ \mathrm{mm}^{2}$ [mean $\pm \mathrm{SD}$ ]; DM/b: $12.8 \pm 15.5$ cells $/ \mathrm{mm}^{2}$; CNP: control: 38.5 \pm 11.5 cells $/ \mathrm{mm}^{2} ; \mathrm{DM} / \mathrm{b}: 62.9 \pm 21.9 ; \mathrm{CNP}$ control vs. $\left.\mathrm{DM} / \mathrm{b} \mathrm{p}=0.0312\right)$. Some of these CNPpositive oligodendrocytes had a dark, condensed nucleus suggestive of apoptosis. However, the occurrence of caspase-mediated apoptotic cell death could no be confirmed by immunhistochemistry for activated caspase-3. No significant differences in cell densities were found between NAC and control cases (MBP: control: $22.8 \pm 15$ cells $/ \mathrm{mm}^{2}$ [mean $\pm \mathrm{SD}$ ]; NAC: $20.8 \pm 14.8$ cells $/ \mathrm{mm}^{2}$; CNP: control: $38.5 \pm 11.5$ cells $/ \mathrm{mm}^{2}[$ mean $\pm \mathrm{SD}]$; NAC: $29 \pm$ 19.5 cells $\left./ \mathrm{mm}^{2}\right)$. 


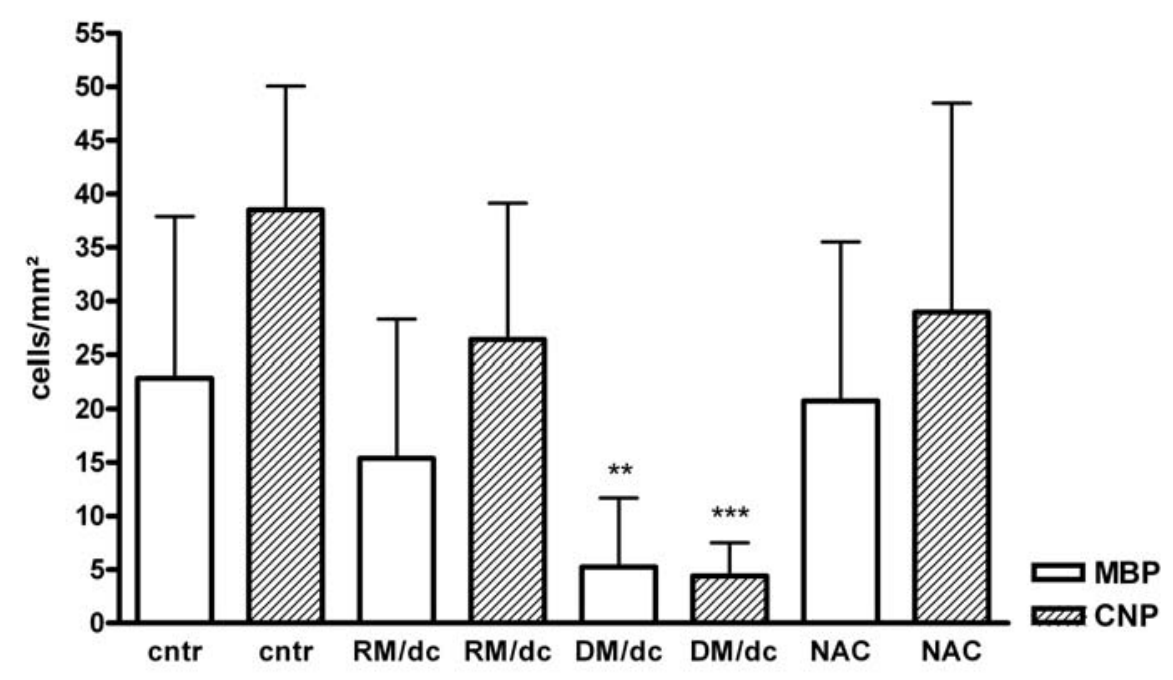

B

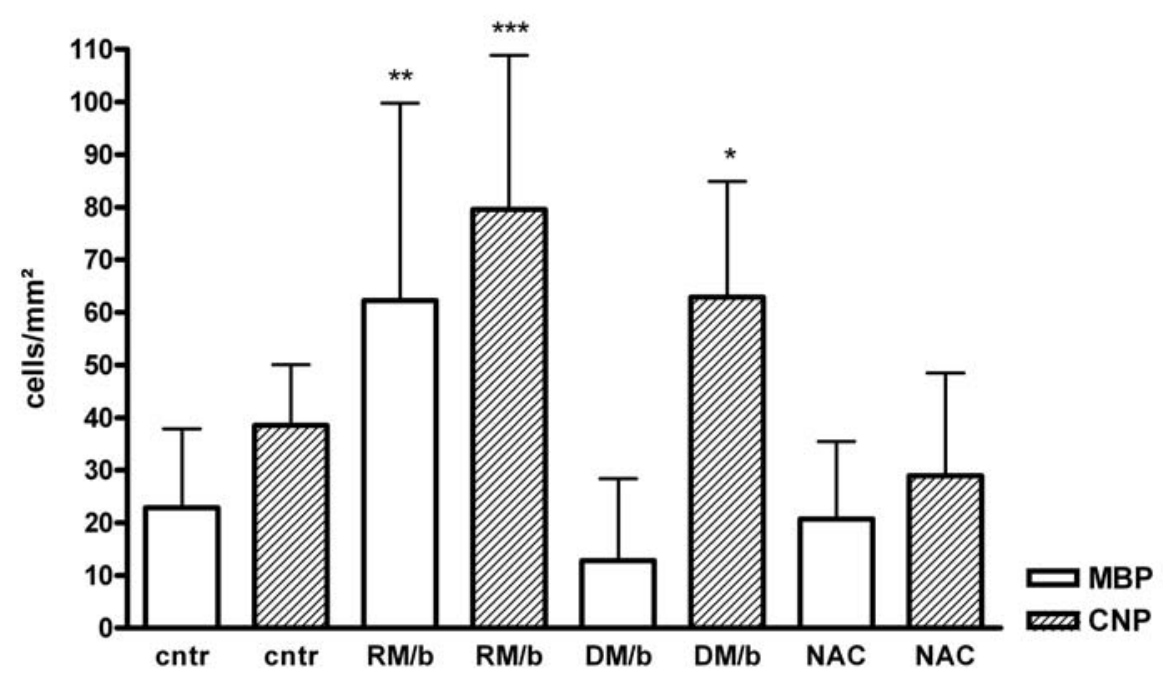

Figure 14 MBP- and CNP-positive cells (A) in the lesional centre and (B) at the lesional border. (A) Within demyelinated cortical lesions MBP- and CNP-positive cells were essentially absent (DM), whereas the oligodendroglial cell density within RM lesions and in the NAC was similar to controls. (B) The borders of demyelinated lesions mostly had a sharp edge with almost no MBP-positive cells, however, some cases had a large population of CNP-positive cells lining the lesional border (DM vs. control: $p<0.05$ ). Significant numbers of MBP- and CNP-positive cells accompanied cortical remyelination (control vs. lesional border: MBP: $\mathrm{p}<0.01$, CNP: $\mathrm{p}<0.001)$. No difference in oligodendroglial cell density was observed between controls and normal appearing MS cortex.

Abbreviations: cntr: control; RM dc: demyelinated lesional centre of cortical lesions with remyelination; DM dc: demyelinated lesional centre of cortical lesions without remyelination; RM b: lesional border of cortical lesions with remyelination; DM b: lesional border of cortical lesions without remyelination; NAC: normal appearing cortex 
3.2.1.4. Remyelination of cortical lesions is more extensive than remyelination of white matter lesions

The degree of remyelination of lesions in the cortical grey matter and the white matter was compared using the same arbitrary score for both grey and white matter lesions: (0) no remyelination: demyelinated cortical or white matter lesions with sharp lesional borders (Fig. 15A, B); (1) remyelination at the border of the lesions (Fig. 15C, D); (2) substantial, but "patchy" remyelination throughout the lesion (Fig. 15E, F); (3) almost complete and complete remyelination ("shadow plaque") (Fig. 15G, H). In total, 246 white matter and 217 cortical lesions were examined in 33 MS patients. A significantly higher degree of remyelination was observed in cortical as opposed to white matter lesions suggesting a higher propensity for remyelination in the grey matter (Fig. 16A; Table 5 (WM: $1.32 \pm 1.07$ [mean \pm SD]; cortex: $1.89 \pm 0.97 ; \mathrm{p}<0.0001)$. On a case per case basis, cortical remyelination was judged more extensive than white matter remyelination in 27/29 MS cases (Fig. 16B; Table 5). Given our electron microscopical results, some of the 50 blocks with NAC may in fact be completely remyelinated which further strengthens the results above.

Table 5 Extent of remyelination in cortical and white matter lesions

\begin{tabular}{|l|c|c||l|c|c|}
\hline \hline \multicolumn{3}{|c||}{ White matter } & \multicolumn{3}{c|}{ Cortex } \\
Score & lesions & $(100 \%=246)$ & Score & lesions & $(100 \%=217)$ \\
\hline \hline 0 & 68 & 27.6 & 0 & 23 & 10.6 \\
\hline 1 & 76 & 30.9 & 1 & 47 & 21.7 \\
\hline 2 & 57 & 23.2 & 2 & 79 & 36.4 \\
\hline 3 & 45 & 18.3 & 3 & 68 & 31.3 \\
\hline
\end{tabular}

Figure 15 Evaluation of remyelination in the white matter and in the cortical grey matter. (A,C,E,G) White matter lesions with (A) no remyelination, (C) a thin rim of remyelination at the lesional border; (E) substantial remyelination; (G) nearly complete remyelination. (B,D,F,H) Cortical grey matter with (B) complete demyelination; (D) thin remyelination at the edge of the cortical plaque; (F) substantial remyelination; (H) nearly complete remyelination. Scale bars: A-H $=500 \mu \mathrm{m} ; \mathrm{A}-\mathrm{H}$ inset $=100 \mu \mathrm{m}$ 


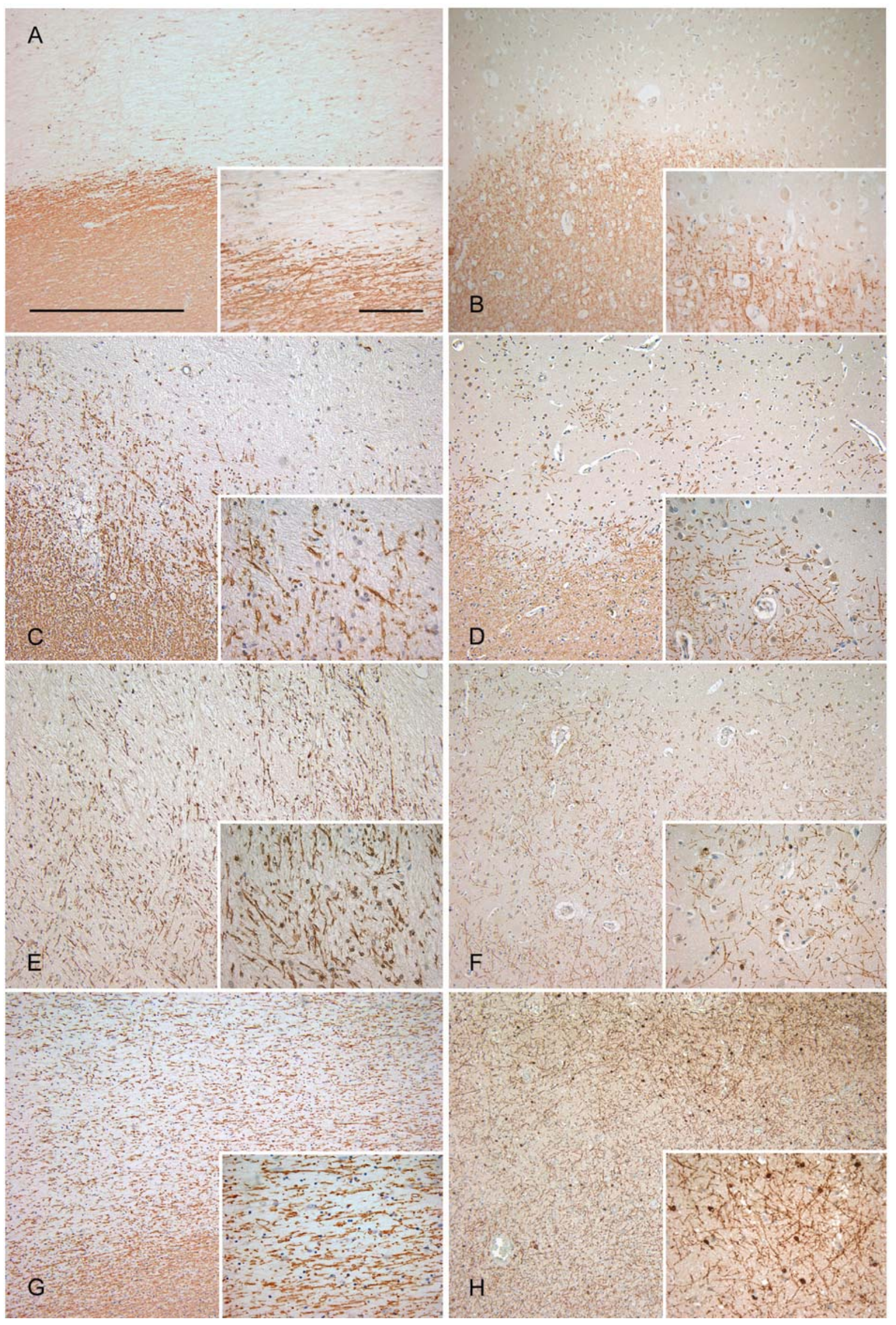

Figure 15 


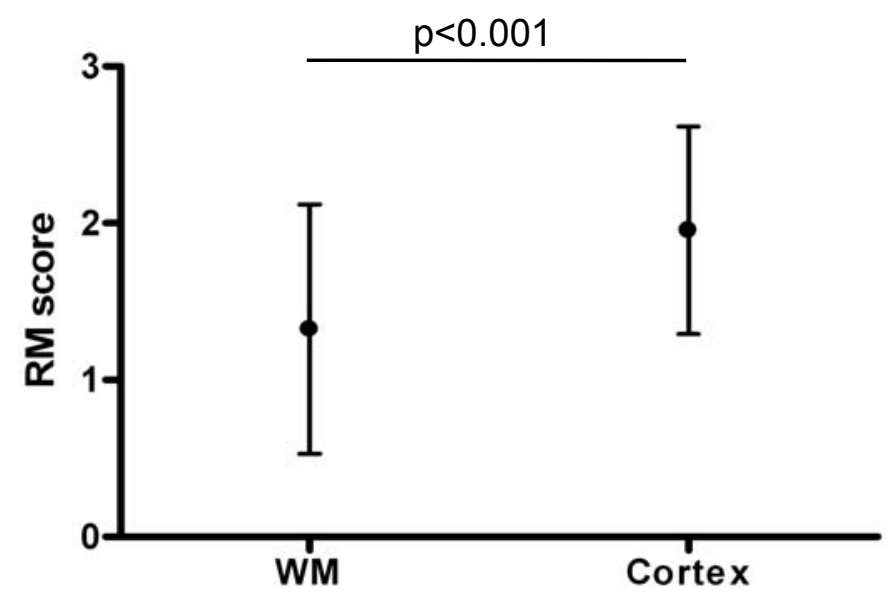

B

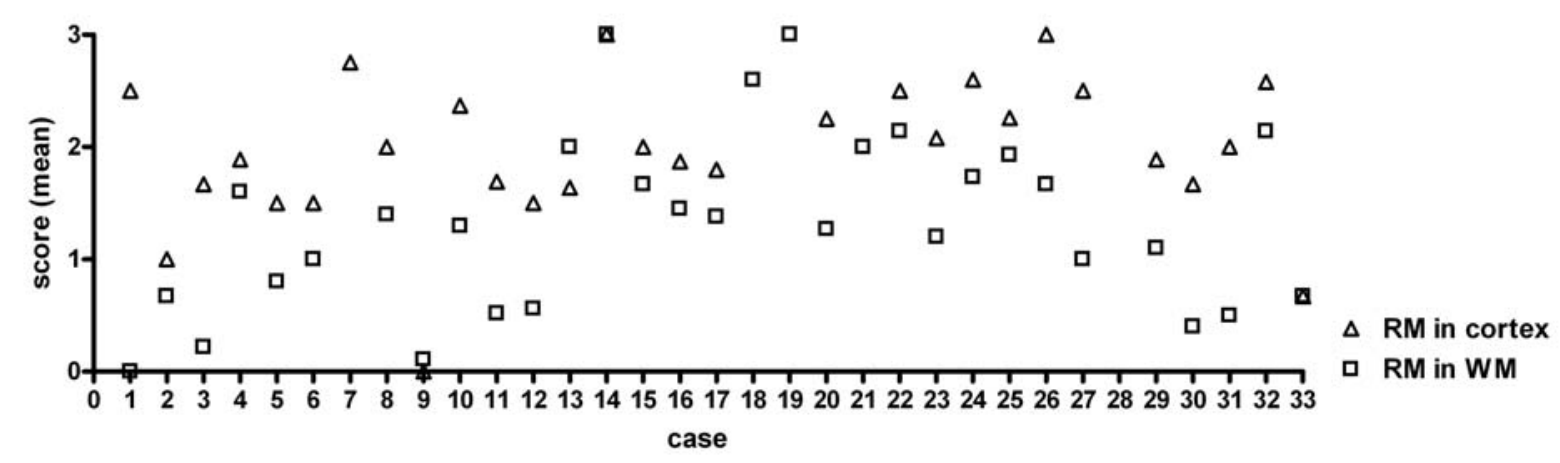

Figure 16 (A) Degree of remyelination in the cortical grey and in the white matter using a semiquantitative score: (0) no remyelination, (1) little remyelination at the lesional border, (2) substantial remyelination, either confluent or patches of remyelination, and (3) nearly complete remyelination. 246 white and 217 grey matter lesions were examined. Remyelination was more extensive in cortical as compared with white matter lesions $(\mathrm{p}<0.0001)$. (B) Degree of remyelination in the cortex and in the white matter of the 33 MS patients examined. Y values refer to the average scores of remyelination assigned to all white matter and cortical lesions of an individual patient. Remyelination of cortical lesions was consistently more extensive in all patients examined (RM scores in WM vs. cortex per case, $\mathrm{p}<0.0001$; paired t-test). Patient 7 had no white matter lesion, patients 18 , 19, and 21 had no apparent cortical lesions (NAC) and patient 28 with spinal cord involvement had no lesions in the brain tissue samples available.

Abbreviations: RM: remyelination; WM: white matter; NAC: normal appearing cortex 
Results

\subsubsection{Synaptic remodelling in the cerebellar dentate nucleus and in the pons in patients} with chronic MS

\subsubsection{Regression and remodelling of synapses in the cerebellar dentate nucleus}

\subsection{Elimination of synapses is synapse and neuron specific and occurs irrespective of demyelination}

The dentate nucleus consists of large, spherical neurons embedded in compact neuropil deep in white matter of the cerebellum (Fig. 17A). Except for very few small interneurons, most of these neurons receive a prominent synaptic input from glutamic acid decarboxylase (GAD)positive axons originate from the Purkinje cells of the cerebellar cortex (Fig. 17B1). These GABAergic axon terminals are relatively large and characteristically decorate the somata and stem dendrites of the neurons. Other axon terminals are evenly distributed throughout the neuropil. These are GAD-negative, react with synaptophysin (SYN)-antibodies and are relatively small (Fig. 17B2). According to the literature, the latter represent the glutamatergic (excitatory) afferents which originate from pontine nuclei and provide collateral input to the dentate nucleus, before terminating as mossy/climbing fibers in the cerebellar cortex.

In demyelinated regions of the dentate nucleus, the characteristic arrangement of synapses on the soma and on stem dendrites as described above was found to be lost. In sections stained with antibodies against both antigens synaptophysin and GAD, the number of axo-somatic synapses was severely reduced on many, but not all neurons in demyelinated parts of the dentate nucleus (Fig. 17C, E). At stem-dendrites, the reduction in synaptic numbers was less pronounced but composed of smaller size of boutons (Fig. 17E). In contrast, synapses on the peripheral dendrites appeared well preserved and showed a small size similar to what was seen in controls (Fig. 17C). The density of the neuronal cell bodies seemed unaltered in the demyelinated zones, though the cell size of many neurons appeared smaller than in controls (Fig. 17C). If estimated in 'central cell sections' (i.e., planes including the cell nucleus), diameters were on average smaller, i.e. less than half of what is found in controls (Fig. 17C). Detachment of the axo-somatic synapses affected adjacent cells differently (Fig. 17C inset; Fig. 17E). Thus, synaptic density was different also on neurons, which appeared to be "similarly affected".

Beyond the borders of demyelinated plaques the reduction of axo-somatic synaptic contacts affected subpopulations of the nerve cells (Fig. 17D), which also showed atrophy (Fig. 17D, F). Neurons being almost devoid of axo-somatic synapses occurred in close vicinity to neurons with a substantial number of axo-somatic innervations. No gradual change in density 
of the axo-somatic boutons on sequential neurons was observed. This indicates that neurons are affected individually, but not collectively within a certain region. Therefore, the density of axo-somatic synaptic boutons was quantified in demyelinated areas (plaque zones) beyond the plaque borders in the same sections (periplaque zones) and on neurons from patients whithout demyelination (no plaque) in the dentate nucleus, respectively. There was a significant reduction of synaptophysin-positive "boutons" in the demyelinated dentate nucleus of $9 \mathrm{MS}$ patients (number of synaptophysin-positive boutons on the soma membrane, control: $32.5 \pm$ 2.5; in plaque zones: $4.6 \pm 2.9[$ mean $\pm \mathrm{SD}] ; \mathrm{p}<0.0001$; t-test). The reduction was less consistent but significant in periplaque zones of the same cases (number of synaptophysinpositive boutons on the soma membrane, control: $32.5 \pm 2.5$; periplaque (pp): $14.10 \pm 8.1$; [mean $\pm \mathrm{SD}] ; \mathrm{p}<0.0001 ; \mathrm{t}$-test). Interestingly, axo-somatic innervation was also reduced in the dentate nucleus of the other 9 MS patients in whom no demyelination was detected in the cerebellum (dentate nucleus without demyelination (no p):19.2 $\pm 6.2[$ mean $\pm \mathrm{SD}] ; \mathrm{p}<0.0001$; t-test) (Fig. 18). These findings suggest that the described type of synaptic regression is characteristic for the cerebellar dentate nucleus of patients suffering from MS, irrespectively of whether the postsynaptic neurons are located in demyelinated zones or not.

Figure 17 Conspicuous loss of axo-somatic GAD-positive synapses on subpopulations of atrophied neurons, while GABAergic and non-GABAergic innervation of the dendrites is apparently preserved in the dentate nucleus of MS patients. (A) In the non-MS control, neuronal somata are densely covered by synaptic endings (axo-somatic synapses) as are the stem dendrites (axo-stem dendritic synapses), while on peripheral dendrites (peripheral-dendritic synapses) synapses are less crowded and diffusely distributed. (B1) Synapses are GADpositive predominantly on the soma and near the soma (B2) whereas the synaptophysin-positive boutons are evenly distributed along the whole surface membrane of the dendritic branches. (C) Rarefied synaptic contacts on neurons within the plaque in the dentate nucleus from an MS patient. Note that all neurons appear atrophied, though the degree of their axo-somatic denervation varies considerably (inset). (D) Synaptic contacts outside a demyelinated plaque. Note that the neurons are smaller, axo-somatic synaptic and axo-stemdendritic synaptic contacts are largely lost on a subpopulation of neurons (arrows). (E) Selective loss of axo-somatic and soma-near synaptic contacts on neurons located in a demyelinated plaque (white arrows). Synaptic contacts in the neuropil resemble the density found in periplaque zones and control brains (black arrows; compare it with F and B2). (F) Selective detachement of the axo-somatic synaptic from neurons outside of a plaque. Axo-somatic synapses are entirely lost, whereas synaptic boutons at the stem dentrites and in the surrounding neuropil are better preserved (arrows). (A, B2; C-F) immunohistochemistry for synaptophysin; (B1) immunohistochemistry for GAD.

Scale bars: A, C-D $=100 \mu \mathrm{m}$; B1-2, E-F $=20 \mu \mathrm{m}$; D inset $=20 \mu \mathrm{m}$ 


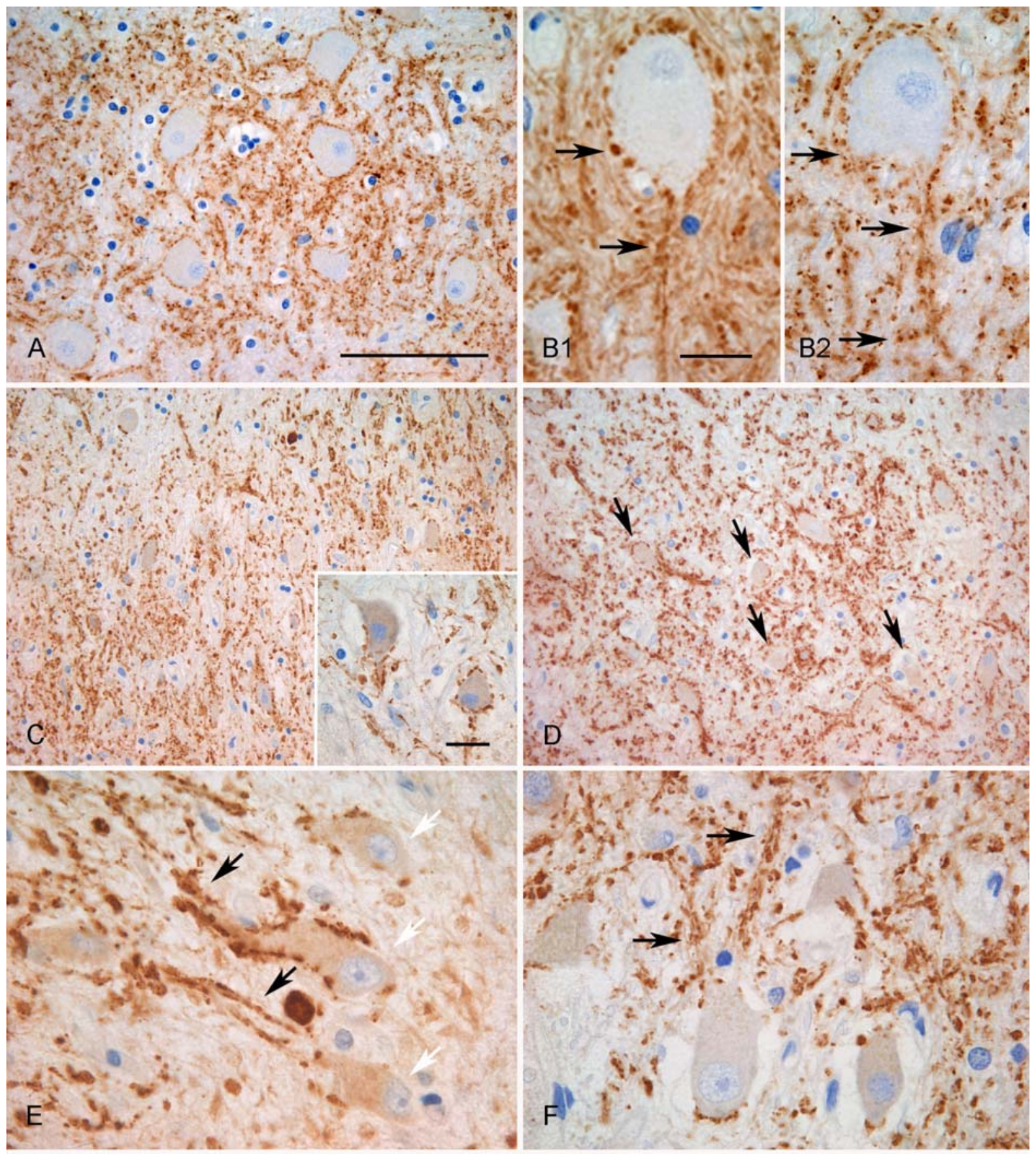

\section{Figure 17}




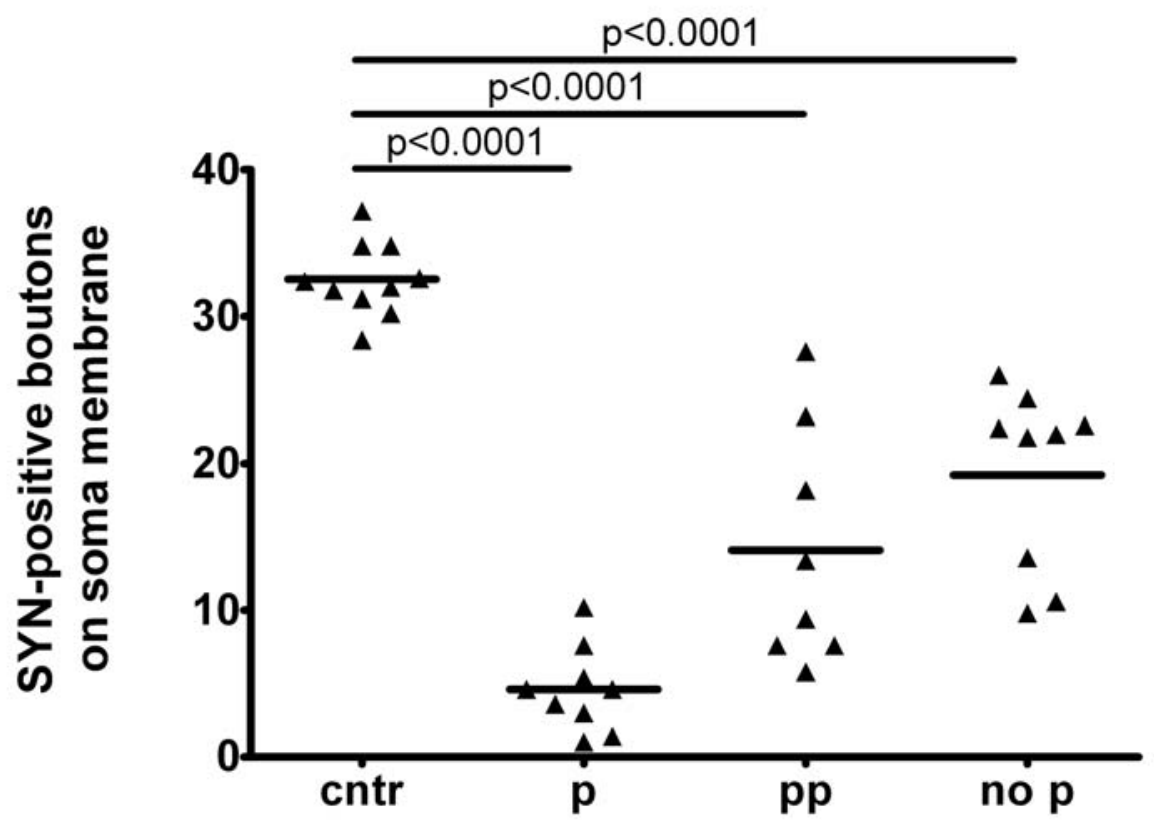

Figure 18 Regression of axosomatic synaptic contacts is region specific in the dentate nucleus in MS. The density of axo-somatic synapses is reduced on the majority of neurons independent of, whether the dentate nucleus is affected by demyelination. The density of SYN-positive "boutons" is clearly reduced in MS cases with demyelinated dentate nucleus within the plaque $(p)(p<0.0001)$ and outside of the plaque $(p p)(p<0.0001)$. The reduction of SYN-positive "boutons" is less pronounced in the dentate nucleus from MS cases where no cerebellar demyelination was detected (no $p)(p<0.0001)$. Each point on the graph indicates the mean value of synaptic clusters of 5 neurons/patient quantified. Horizontal bars in the graph represent the mean.

Abbreviations: cntr: non MS healthy subjects; p: plaque area of dentate nucleus from MS brain; pp: periplaque area of dentate nucleus from MS brain; no p: dentate nucleus from MS brain where no plaque was detected. 


\subsection{Dissociation of axo-somatic and axo-stem dendritic synapses}

Electron microscopy confirmed the absence of synaptic junctions on most cell bodies and on many stem dendrites in the demyelinated zones. The demyelinated region was identified in semithin sections in the dentate nucleus of an MS patient. Direct contacts between pre- and postsynaptic elements were largely missing on the neuronal somata (Fig. 19A). Instead, thin processes and lamellar extensions of fibrous astrocytes covered and insulated somata and large dendritic profiles from the surrounding neuropil (Fig. 19 F-G). Most presynaptic elements but all postsynaptic contact structures on the soma and on the stem dendrites were lost and replaced by the glial structures described above. Short and thin microglial extensions or lamelles of astrocytes engaged the boutons and intruded into the synaptic cleft separating the presynaptic endfeet from the active zone on the soma membrane (Fig. 19B-C). Rarely, synaptic boutons or axonal varicosities persisted, remained in perisomatic or peridendritic position and contained some synaptic vesicles. Nevertheless, active zones were usually absent and replaced by glial structures (Fig. 19E). In rare cases, axonal boutons containing synaptic vesicles and mitochondria (presynaptic-like structures) had remained in contact with the soma membrane of a neuron and were enclosed in the glial covering of the soma. Here, the intercellular clefts were characteristically widened (Fig. 19A-D). However, in the demyelinated zone of the dentate nucleus most synaptic boutons were separated from soma membranes by glial processes. The presence of bundled intermediate filaments (GFAP-type; see Fig. 19C) suggested that many of these processes originated from astrocytes, while some resembled microglial processes (Fig. 19B). These findings suggest the loss of axo-somatic and axo-stem dendritic synapses via dissociation of the contact structures by glial processes in the dentate nucleus of patients with MS.

\subsection{Lysosomal degradation of synapses}

In intact synapses, synaptic vesicles -independent of the transmitter type used- form a population with only small variations in size, while their packing density varies considerably and is highest near the synaptic junction (active zone). Applying the terminology of Gray (1959) to human dentate nucleus, type-I synapses showing the typical asymmetry of paramembraneous postsynaptic densities (PSD) are predominantly situated on peripheral dendritic branches (Fig. 20A-B), while type-II synapses with symmetrical contact structure and thin PSDs were mainly located on stem dendrites and cell bodies (Fig. 20B). In all positions, the majority of synapses showed synaptic vesicles that were accumulated near by 
the active zone (Fig. 20A-C). These findings were identical in the dentate nucleus of our control case and the MS patient.

In the MS patient, however, some synapses exhibited distinct synaptic morphology. In such boutons, synaptic vesicles appeared aggregated, closely abutted and dislocated from the active zone (Fig. 20D-E). More vesicles fused into one selectively at the periphery of the vesicle pool (Fig. 19C; 20D-E). Wealth of secondary lysosomes was seen in such neuronal structures and in processes of microglial and astroglial cells (Fig. 19B, D, G). Autophagosomes (cytolysosomes) were recognised in dendrites (Fig. 20G). These were loaded with degradation products that appeared as aggregates of synaptic vesicles and occasionally as remnants of postsynaptic elements. Residual bodies were observed in myelinated axons which otherwise appeared intact (see intact node of Ranvier in Fig. 20F). Such findings indicate that - in addition to local storage of degradation products in neurons and glial cells - axons with intact intracellular transport systems may remove residues of synaptic regression from demyelinated plaques and periplaque zones (Fig. 20F, H). These finding suggest lysosomal degradation of the presynaptic elements, e.g., phagolysosomes in microglia and astrocytes as well as the transport of residual bodies in intact and in part myelinated axons in the dentate nucleus in MS. The Type I and the type II synaptic contacts with largely normal structure were preserved particularly, which were situated on the peripheral dendrites. 
Figure 19 Presynaptic elements are displaced from the neuronal soma membrane by glial processes in a demyelinated area of the dentate nucleus. (A) Somata with only few axo-somatic synaptic contacts (arrows). A large part of the soma membrane is entirely devoid of axo-somatic synapses. Intercellular spaces neighbour the synaptic boutons (asterisks). (B) Thin microglia processes (arrows) engage synaptic boutons (Sy) on the soma. Intercellular space detaches pre- and postsynaptic surface membranes (asterisks). (C) Wide intercellular space (asterisks) separates the synaptic junction. Large one-membrane coated features (arrows) indicate a process of vesicle reduction. (D) Glial process with lysosomal degradation of synaptic content (Ly) andjacent to an axosomatic synapse (Sy). An astroglial process (arrows) grows into the peri-synaptic intercellular space (asterisk). (E) Lamelles (AL) and filamentous processes (AF) of astrocytes separate synaptic boutons (Sy) from the soma membrane. (F) Stacks of astrocytic lamelles insulate the largely synapse-free soma from the surrounding neuropil. A subsurface cistern (Sc) firms the intercellular connections. Under the glial scar synaptic contact structures persist, such as a synapse without synaptic vesicles (Sy) and a free/vacant postsynaptic density (§) without presynaptic bouton. (G) Astrocytic lamelles (AL) separate the neuropil from the neuronal somata. Note that in contrast to the few axo-somatic synaptic features, synapses in the neuropil (Sy) appear considerably better preserved. In part, synapses of the neuropil undergo lysosomal degradation (arrows). Abbreviations: N: neuron; Sy: synapse; AF: astrocytic filaments; AL : astrocytic lamellae; Sc: subsurface cistern; Ly: lysosome; §: postsynaptic density. Magnifications: A: 9000x; B, D-E, G: 40000x; C: 60000x; F: 15000x

Figure 20 Synaptic contacts on the dendrites are largely preserved and the majority of structures appear normal in the dentate nucleus in MS. In a population of synapses, presynaptic vesicles are reduced by lysosomal degradation and transported as autophagosomes in dendrites and as residual bodies in intact, myelinated axons in the plaque and in the periplaque region. (A) Intact divergent complex synapse with homogeneous vesicles that are located close to the active zone. (B) Normal appearing type I and type II synapse and (C) convergent complex synapse with heterogeneous vesicles (black arrows) and double membrane coated features (white arrows) that might represent spinules from the postsynaptic elements or fnger-like processes of astrocytes. Swollen glial processes surround the synapse and contain pools of glycogen granula. (D) Presynaptic bouton with accumulation (v) and selective fusion of the vesicles (arrows) at the periphery of the vesicle pool in a selected bouton. The bouton appears without any postsynaptic density, thus not forming synaptic contact. Note the glycogen pools in processes of surrounding astrocytes and a morphologically normal synapse (Sy) that is just situated beside. (E) Synaptic contact with presynaptic vesicles (v) that are focally accumulated and dislocated from the active zone (§). Vesicles are heterogenous indicative of fusion (arrows) and subsequent degradation at the periphery of the vesicle pool. (F) Secondary lysosomes (Ly) and a multivesicular body (MVB) transported in intact axons at the Node of Ranvier. (G) Remodelling process in a stem dendrite. Primary lysosomes (MVB) and secondary lysosomes (Ly) with recognisable cellular structure elements such as condensed lamellae of endoplasmic reticulum (inset) appear in a dendrite (D), which is surrounded by intact synapses (Sy). (H) Lysosome transported in myelinated axons in the periplaque region. Abbreviations: Sy: synapse; D: dendrite; v: synaptic vesicle; §: postsynaptic density; Ly: lysosome; MVB: multivesicular body; Ax: axon. Magnifications: A, H: 60000x; B: 50000x; C-F: 40000x; G: 15000x; G inset: 80000 

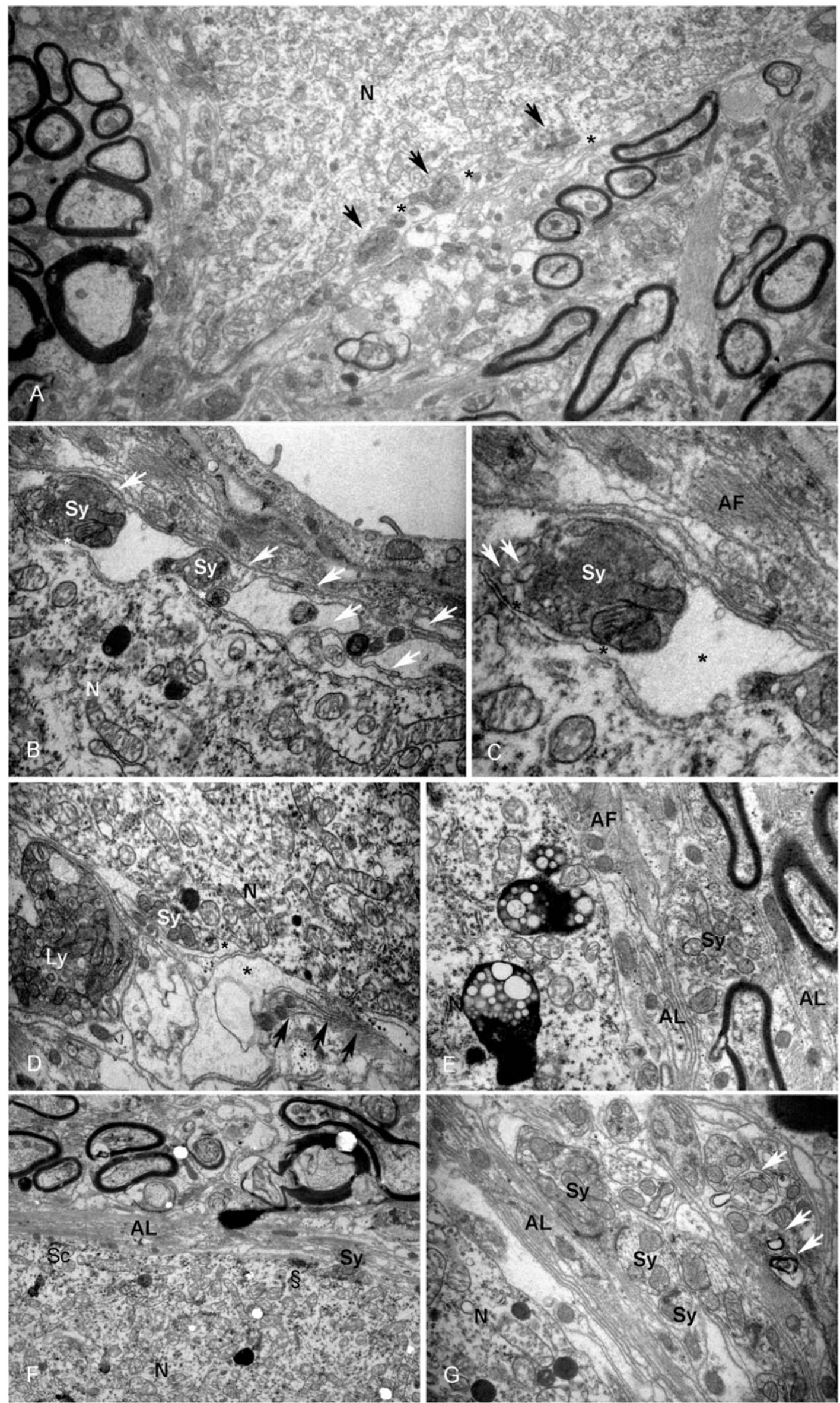

Figure 19 


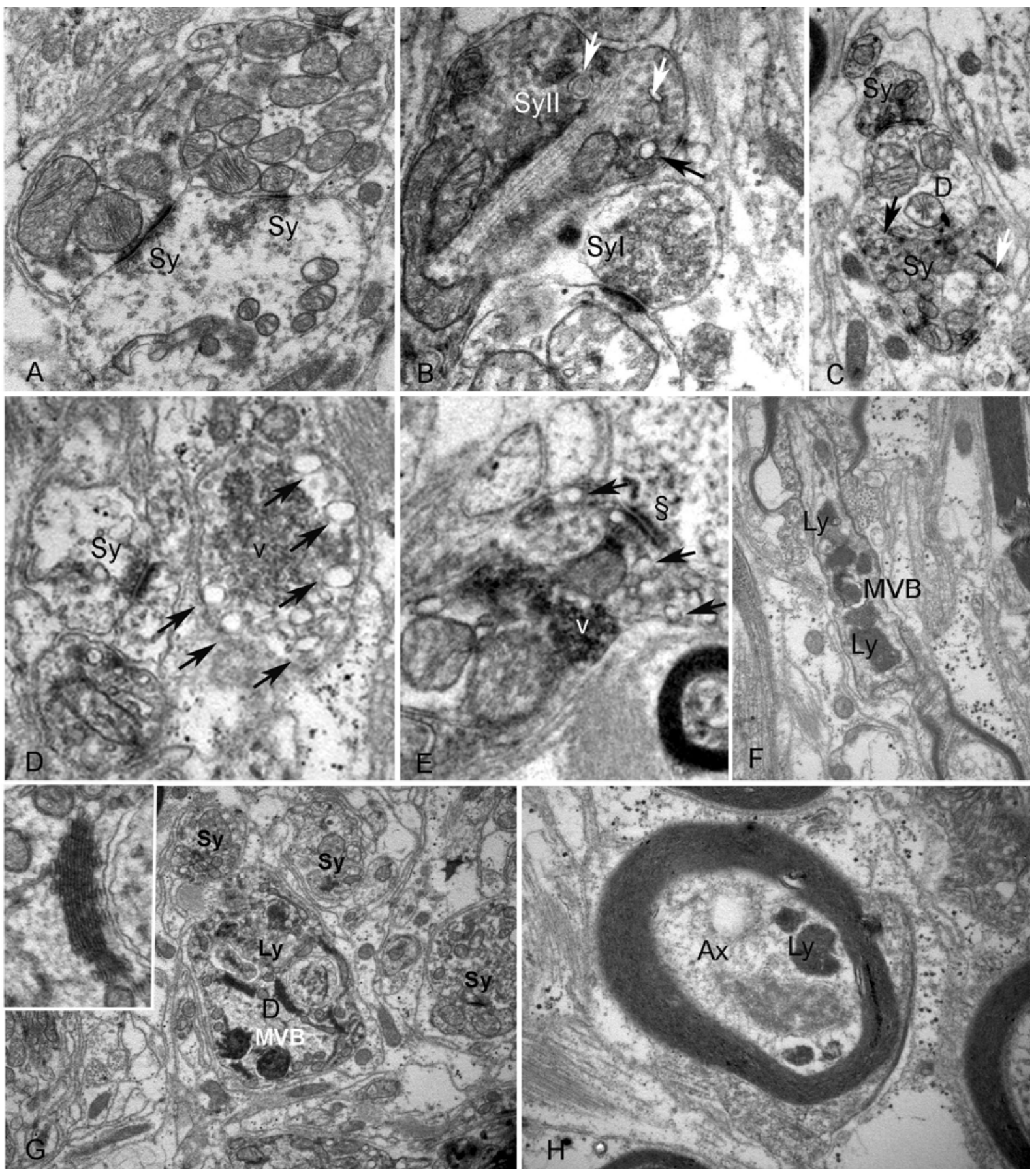

Figure 20 


\subsubsection{Remodelling of synapses in the pontine nuclei}

\subsection{Preserved density of the synapses in the demyelinated pons}

The density and spatial arrangement of synapses were compared between patients with demyelinated plaques and controls in the pons. Synaptic endings were identified by applying antibodies for SYN and GAD. The localisation and extent of demyelination was highly variable among the MS patients studied. Therefore, distribution patterns of synapses in demyelinated regions were compared with the contralateral nuclei in the same sections, if these were not affected by demyelination and with comparable sections of non MS control brains. In controls, the distribution of SYN-positive synapses was more or less diffuse and of moderate density. Axo-somatic and axo-stem synapses did not accumulate on any type of pontine neuron (indicative of axo-somatic synaptic contacts), especially not those made by GAD-positive boutons. The even distribution of synapses did not seem to change within or near demyelinated areas in the pontine nuclei of MS patients.

\subsubsection{Synaptic reorganisation in the demyelinated lesions of the pons}

In contrast to immunohistochemistry, electron microscopy revealed distinct morphological changes of synapses in demyelinated regions of the pontine nuclei. The overall density of synapses appeared smaller than in the pons of control brain. In numerous axonal boutons, synaptic vesicles appeared aggregated and dislocated from the active zone (Fig. 21A-D, G). At the periphery of the vesicle pools, vesicles often had a larger size (Fig. 21C-D). Beside the synaptic vesicles or profiles of smooth endoplasmic reticulum which were bounded by single membranes, there were profiles surrounded by double-membranes indicating coated lysosomes or finger-like protrusions of astroglia, which engulfed the boutons (Fig. 21G-H). These structures indicate that part of the synaptic vesicles might be enclosed in autophago(cytolyso)somes. Since numerous structures were found that had previously been designated in the literature as 'free', 'vacant' or 'vacated postsynaptic densities' (Fig. 21E-H), other synapses might have completely lost their presynaptic boutons. Multivesicular bodies - a form of primary lysosomes - were often seen in axonal processes and dendrites (Fig. 21A, E). Cytolysosomes - secundary lysosomes - and residual bodies containing remnants of presynaptic elements appeared to be transported in morphologically intact axons, which were seen in demyelinated zones but also beyond the borders of the plaques (Fig. 21A, H, K). Processes of filamentous astrocytes embraced the synaptic structures (Fig. 21E-H). Free postsynaptic densities appeared opposed to astrocytic processes (Fig. 21F). Degradation products accumulated in astroglial and microglial cells (Fig. 21H). Subsurface cistern 
associations firmed the intercellular connections between neurons and astroglial cells (Fig. $21 \mathrm{H})$. Thus, despite the failure to detect structural changes by histology in the pons of MS patients, electron microscopy provided evidence that subpopulations of synapses may undergo regression and remodelling in demyelinated regions in the pons. Synaptic regression is suggested by (i) accumulation of primary lysosomes in presynaptic elements and in preterminal axons and dendrites; (ii) focal aggregation of vesicles and their incorporation in cytolysosomes; (iii) lysosomal degradation of presynaptic structures (from subpopulations of synaptic vesicles to whole boutons) and finally by (iv) the appearance of vacant postsynaptic densities. Additionally, removal of regressive synapses occurs as intraaxonal transport of residual bodies in intact, myelinated axons. Accumulation of residual bodies in glial processes suggests a contribution of astroglial (and rarely also microglial) cells to the remodelling of synaptic contacts.

Figure 21 Regression and remodelling of synapses in the demyelinated pons. (A-B) Large amount of synaptic vesicles are accumulated ( $\mathrm{v}$ ) in the boutons. These focal accumulations are often accompanied by (A) multivesicular bodies (MVB) at the nerve endings and (B) are often seen without postsynaptic densities. (C-D) Other presynaptic endings exhibit heterogeneous vesicles that are focally accumulated (v) and selectively fused (arrows) at the periphery of the vesicle pool. The entire vesicle aggregate is dislocated from the active zone (§). (E-F) Postsynaptic contact structures are seen of which presynaptic partners are missing from all of the synaptic positions. (E) The free/vacant postsynaptic densitites (§) of a complex synapse is accompanied by processes of filamentous astrocytes (AF), which are situated in perisynaptic positions. (F) Filamentous astroglial process (AF) neighbours and covers a vacant postsynaptic density (§) of a dendrite. Note that the endoplasmic reticulum (ER) in the dendrite is anchored to the plasma membrane, which is an unusual position for this intracellular compartment. (G) At least 3 synaptic structures are seen in close vicinity. On the left top synaptic vesicles are focally accumulated (v) and dislocated from the active zone (§). On the bottom there is a selective fusion (white arrow) and lysosomal degradation (black arrow) of the synaptic vesicles. No postsynaptic contact structure, which could belong to that presynaptic ending is seen. Processes of the astrocytes in the perisynaptic positions show pools of glycogen grains. On the right a vacant postsynaptic density (§) is situated on a dendrite. H) A dissolved synaptic junction appears as a vacant postsynaptic density, the vesicles appear eliminated into phagosomes (arrow), which an astrocyte transports away from the active zone. J) An innervated dendrite is surrounded by glycogen grains containing astrocytic processes. Synaptic boutons show dense aggragation of vesicles. Middle part of the dendrite (outlined) undergoes formation of an autophagosome. K) Secondary lysosomes (Ly) are transported in an axon (Ax?) or a dendrite.

Abbreviations: Ax: axon; Ly: lysosome; v: synaptic vesicle; §: postsynaptic density; MVB: multivesicular body Sy: synapse; m: mitochondria; D: dendrite; AF: astrocytic filaments; ER: endoplasmic reticulum; Sc: subsurface cistern

Magnifications: A-D: 40000x; E: 60000x; F, G; K: 40000x; H-J:15000x 

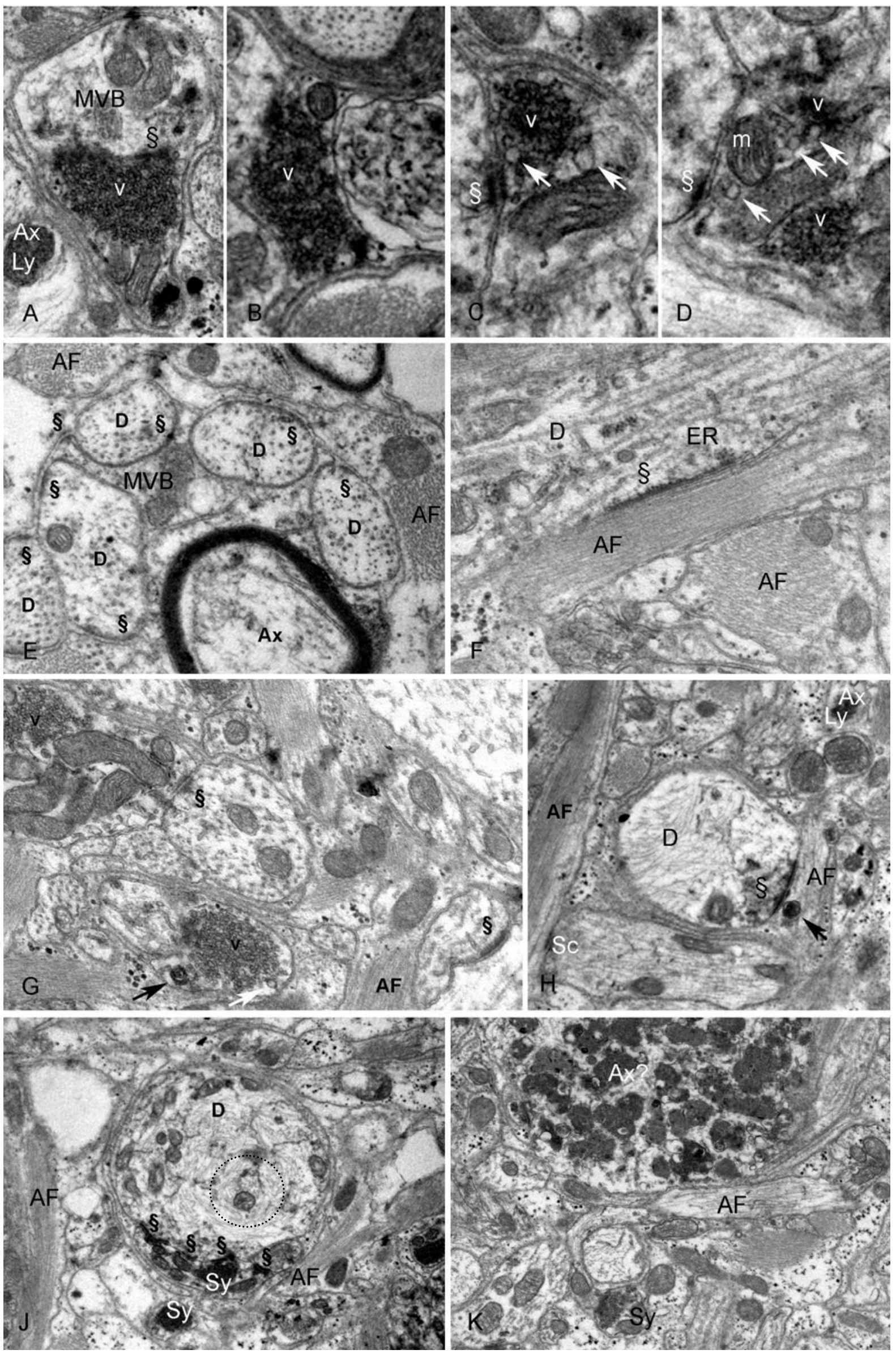

\section{Figure 21}




\section{DISCUSSION}

The aim of our study was to delineate the fundamental histopathological characteristics of multiple sclerosis in the grey matter. Our work identified extensive cortical demyelination associated with marginal inflammation in the vast majority of patients with chronic MS. However, we found evidence for T-cell/macrophage-mediated active inflammatory demyelination in the cortex of patients with early MS. In these early cortical lesions, the density of infiltrating T-lymphocytes was similar, but the extent of acute axonal damage was substantially reduced compared with white matter lesions of the same patient. Furthermore, detailed microscopical analysis revealed remyelination in cortical lesions. Remyelination was observed more frequently and was found to be more extensive in cortical than white matter lesions. Neurons appeared, though atrophied, well preserved in number in all grey matter areas examined. Light microscopic and subsequent ultrastructural analysis provided evidence for disease specific synaptic changes in the dentate nucleus and remodelling of synaptic contacts in the pontine nuclei even in late stages of MS.

\subsection{Extensive demyelination and little inflammation in cortical lesions in chronic MS}

\subsubsection{Humoral immunity may be responsible for subpial lesions}

Seven different types of cortical MS plaques have been identified according to their topography (Kidd et al., 1999). We used a modified system, where we distinguished subpial, intracortical and leucocortical demyelination in 33 chronic MS brains (Peterson et al., 2001). Cortical demyelination was extensive with the vast majority of lesions being situated directly beneath the pia mater. However, this type of cortical lesion was absent from biopsy tissues with early MS. The features of subpial lesions, i.e. ribbon-like demyelination, suggest a pathogenetic role for diffusible factors (e.g. immunglobulins or inflammatory mediators) derived from the meninges or the cerebrospinal fluid (CSF).

In the CSF several discrete oligoclonal IgG bands can be visualized in about two third of MS patients (Adams and Victor's Neurology, $7^{\text {th }}$ edition). Clonal accumulation of B-cells and plasma cells in the CSF (Monson et al., 2005; Ritchie et al., 2004; Owens et al., 2003) and ectopic B-cell follicle-like structures with germinal centres have been confirmed in the meninges of patients with secondary progressive MS (Serafini et al., 2004). Centroblasts that are usually restricted to the lymph nodes were shown in the CSF of MS patients (Corcione et al., 2004). The CNS shows propensity to act as a B-cell fostering environment in numerous neurological disorders (Uccelli et al., 2005). Molecules regulating B-cell homing and survival 
are produced in the CNS. As an example, B-cell activating factor of the TNF family (BAFF) was shown to play a substantial role in B-cell maturation, survival and production of immunoglobulin (reviewed in Kalled, 2005). Studies on BAFF transgenic mice indicated that overexpression of BAFF is associated with the development of autoimmune pathology (Mackay and Tandye, 2004). We showed diffuse reactive astrogliosis in cortex of chronic MS patients. Recent work identified astrocytes as a source of BAFF and suggests that local production of BAFF in the CNS promotes B-cell maintenance in MS (Krumbholz et al., 2005).

B-cells and immunoglobulins mediate inflammatory demyelination in a proportion of white matter lesions in early MS (Lucchinetti, 2000, Lucchinetti, 1996). The number of T-cells and macrophages infiltrating the lesions is gradually decreasing over time, whereas B-cells and plasma cells become prominent in white matter lesions in late MS (Rodriguez and Lennon, 1990). Thus, the immune patterns may not remain constant during the disease course (Lassmann et al., 2001), but merge into a B-cell mediated final common pathway. Since subpial lesions are not present in early but frequent in late MS, subpial demyelination may be a late event occurring during disease evolution by accumulation of plasma cells and immunglobulins in the CSF and in the meninges.

\subsubsection{Minor inflammation may support repair mechanisms in cortical lesions}

We showed reduced inflammation and mild, diffuse astrogliosis in large number of chronic intracortical MS plaques. Inflammation and/or gliosis may be deleterious and/or beneficial. Pathological analysis of active MS lesions documented ongoing remyelination in the presence of inflammatory demyelination (Ozawa, 1994). Thus, the inflammatory response may contribute to both injury and repair (Brück et al., 2003b). On the one hand, cytokines and growth promoting factors released by reactive astrocytes and microglia as part of the acute inflammation were shown to promote endogenous remyelination (Compston, 2004). In an animal model of chronic demyelination, induction of acute inflammation resulted in myelination of chronically demyelinated axons by myelination competent precursor cells (Foot and Blakemore, 2005). On the other hand, inflammatory cells were also shown to create an environment in which surviving oligodendrocyte precursors fail to differentiate and remyelinate. Transforming growth factor beta1 (TGF- 31 ), a cytokine produced by immune as well as other cell types can stimulate astrocytes to express a surface protein, Jagged 1. This protein binds to Notch receptors and in turn inhibits the maturation of the oligodendrocytes (John et al., 2002). We showed astrogliosis in demyelinated, remyelianted and in the normal 
appearing cortex in MS. However, the dense glial scar that is typical for matter plaques was not observed in the cortex. The reason for the diffuse astrocytic reaction in MS cortex may be explained by axonal (Wallerian) degeneration secondary to subcortical MS plaques, transneuronal degeneration from certain demyelinated brain regions; persistence of astrocytes in the remyelinated lesions (Lassmann, 1983), general astrocytosis due to soluble inflammatory factors, such as tumor necrosis factor- $\alpha$ (TNF- $\alpha$ ) (Fontana et al., 1980; Selmaj et al., 1990). In accordance with the good propensity for remyelination that we observed in cortical lesions, our results suggest that little inflammation with less tissue destruction and mild astrogliosis may be beneficial, providing a favourable milieu for tissue repair in the cortex of MS brains.

\subsection{Inflammatory demyelination in cortical lesions in early MS}

Cortical lesions are hardly detected by imaging methods in vivo, and inflammation is marginal in chronic cortical MS plaques. This raised the question, whether the cortex is at all affected by inflammatory demyelination in early MS. We investigated brain biopsy samples containing cortical tissue and found cortical demyelination in 8 (23\%) out of 35 MS patients. The average disease duration from first symptom to biopsy was about 6 weeks. Hence, the cortical lesions were probably among the initial lesions in the disease of these patients. Despite the inflammatory intracortical lesions, only one patient showed purely cortical symptoms, i.e. symptomatic epilepsy and aphasia.

\subsubsection{Adaptive immune response and pathological heterogeneity in cortical lesions}

We could distinguish two types of early cortical lesions; cortico-subcortical (leucocortical) and small intracortical lesions. Only one lesion type was found in an individual patient. Cortico-subcortical lesions were identified as T-cell and macrophage-mediated demyelination (immune pattern 1). Small perivascular lesions were reminiscent of complement-mediated white matter lesions (immune pattern 2). Despite no complement deposition on the vessel walls and on the myelin, equally no B-cells or plasma cells were detected in these lesions; the concentric perivascular pattern of demyelination may suggest a pathogenetic role for soluble factors. Thus, heterogeneity of immunmechanisms (Lucchinetti, 2000, Lucchinetti, 1996) may lead to different types of cortical lesions in early MS.

We could show cellular adaptive immunity, namely a pronounced T-cell response in the cortex of patients with early MS. The density and the composition of the T-cell infiltrates did 
not vary between the early cortical and white matter lesions in a given patient. This suggests that the cortex is subjected to a similar destructive inflammatory process as the white matter. However, the extent of acute axonal damage was significantly lower in cortical compared with white matter lesions in all patients examined. Furthermore, the majority of early cortical lesions were "destructive" cortico/subcortical lesions. Acute injury to neurons was identified by chromatolysis/tigrolysis, swollen cytoplasm and displaced nucleus (Nissl, 1892). In chronic cortical plaques however, the neuronal density and tissue cytoarchitecture appeared largely preserved. Thus, the cortical microenvironment may suppress the inflammatory process and/or may be more resistant against the parenchymal damage caused by inflammation.

\subsubsection{Macrophages may convey axonal damage in the lesions}

We showed cells with microglia morphology in the cortex, whereas large number of foamy macrophages in the white matter in biopsy cases with early MS. Furthermore, the relative density of MRP 14-expressing macrophages/microglia was markedly reduced in cortical compared with white matter lesions. Since T-cell density and composition was nearly identical in cortical and white matter tissue, a substantial role for MRP 14-immunreactive macrophages in acute axonal damage must be assumed. The MRP 14 antigen is a calcium binding protein of the S-100 family (Goebeler et al., 1993; Roth et al. 1993). The expression of MRP 14 is restrained to the maturation stage of neutrophil granulocytes and monocytes. Monocytes express MRP 14 early in their activation and tissue invasion until their terminal differentiation to macrophages (Hessian et al., 1993). Numerous studies suggest a detrimental role for infiltrating macrophages in neurodegeneration. Macrophages produce proinflammatory cytokines like tumor necrosis factor alpha (TNF- $\alpha$ ), IL-1 and IL-6, which were found neurotoxic in vitro (Chao et al., 1995). Macrophages were shown to express inducible nitric oxid synthase (iNOS) and cyclo-oxygenase (COX-2) in MS lesions (Rose et al. 2004; Hill et al., 2004). Glutamate was shown to be secreted in large quantities by macrophages (Piani et al., 1993), thus leading to excitotoxic tissue damage. Macrophages were found immunreactive for glutaminase and co-localised with dystrophic axons in MS brain (Werner et al., 2001). Macrophages express matrix metalloproteinase-12 (MMP-12) that was shown to be selectively expressed during active demyelination in MS plaques (Vos et al., 2003). This proteinase was found to directly cause axonal transection and to facilitate leukocyte migration through the blood brain barrier (Newman et al., 2001). Therefore, absence of foamy 
macrophages and minor population of early activated, MRP14-expressing cells may contribute to the little acute axonal injury in the MS cortex.

\subsubsection{Grey matter BBB prevent monocyte extravasation in cortical lesions}

We found no immune-histological evidence for blood brain barrier disruption in all cortical MS lesions studied. By contrast, we showed leakage for immunoglobulin in all white matter plaques. BBB breakdown is a known characteristic of the white matter MS lesions. Abnormalities of blood vessel tight junction were shown in active and chronic white matter lesions as well as in the normal appearing white matter (Kirk et al., 2003; Plumb et al., 2002). This suggests either structural and/or functional differences in BBB between the cortex and the white matter, which becomes apparent in early MS.

According to our results, grey matter vessels may also provide a selective barrier to invasion of monocytes. What makes grey matter BBB impermeable for immunoglobulins and rather selectively for monocytes, when at the same time the BBB in the white matter gets compromised? No differences in structural characteristics of CNS vessels in grey versus white matter have been reported so far. However, even when the endothelial BBB becomes "leaky", leukocyte recruitment into the CNS remains controlled (Greter et al., 2005; Engelhardt et al., 1998; Zeine and Owens, 1992). Adhesion molecules, chemokines and chemokine receptors determine patterns of cell type and tissue-specific homing of lymphocytes. For a given leukocyte, extravasation is mediated by: a rolling determinant (selectin-selectin binding carbohydrate moiety), a leukointegrin-activator (chemokine-chemokine receptor), a mediator of arrest (leukointegrin-CAM pair) and chemokine-chemokine receptor interaction that drives diapedesis (Foxman, 1997; Campbell 2000). Any of these determinants may be differentially expressed in the grey matter, thus selectively preventing the transendothelial trafficking of monocytes. Mice that lacked either the chemokine CCR2 or one of its ligands CCL2 were shown to be relatively resistant to experimental autoimmune encephalomyelitis (EAE), the animal model of MS. These mice lacked monocytes, but had a T-cell response equivalent to wild type mice in the CNS lesions (Fife et al., 2000; Izikson et al., 2000; Huang et al., 2001). Similarly, mice that lacked CCL1 showed reduced monocytes in the spinal cord lesions and thus developed a milder EAE than controls (Rottman et al., 2000).

Interestingly, during diapedesis across the inflamed BBB, leukocytes migrate via a transcellular pathway through the endothelial cells and leave the tight junctions intact (Engelhardt, 2004). Nevertheless, tight junction associated proteins might also be differentially expressed and provide a firmer physical barrier in the cortex than in the white 
matter. This would explain why grey matter BBB is not leaky for serum proteins such as IgG. Such candidate proteins might be the platelet-endothelial cell adhesion molecule-1 (PECAM1). PECAM-1 deficient mice with EAE have increased CNS infiltrates with prolonged vascular permeability (Graesser et al., 2002). Blocking another tight junction associated molecule, the junctional adhesion molecule-A (JAM-A) inhibits leukocyte diapedesis in vitro, and prevents leukocyte entry during meningitis in vivo (Del Maschio et al., 1999; Lechner et al., 2000). At last, astrocytes - as a third BBB component beside the endothelial cell and the basal membrane - might "sense" the grey matter milieu and display another phenotype (e.g. characterised by expression of different glutamate transporters) and exert different functions.

\subsubsection{Neurons may provide an “immunosuppressive” milieu}

Factors that may downregulate the inflammatory response in the cortex may involve also neuronal properties. Recent work demonstrated that neuronal FasL induced cell death of CD8+ encephalitogenic T-lymphocytes in vivo and in vitro (Flugel et al., 2000). However, we have not seen apoptotic lymphocytes in our samples in any of the early cortical plaques. We found a diffuse activation of microglia and astroglia in early cortical lesions. Processes of activated microglia embraced neuronal cell bodies. Both glial cells are known to be potent MHC II antigen presenting cells (Hirsch et al., 1983; Frei et al. 1987). Recent reports have shown that neurons keep microglia in a quiescent state by local interaction between the microglia receptor CD200 and its ligand in the intact CNS (Neumann, 2001; Hoek, 2000). Moreover, neurons suppressed IFN-gamma mediated induction of MHC II expression in surrounding glial cells, in particular microglia and astrocytes (Neumann, 1996). Paralysis of neuronal electric activity by the neurotoxin tetrodotoxin (TTX) (Neumann, 1998), by lysolecithin induced focal demyelination, by axonal transsection (Prof. Komoly- personal communication) or the administration of glutamate receptor antagonist (Neumann, 1998) restored the induction of MHC II molecules on microglia and astrocytes. However, injury to neurons was also shown to result in a prompt change in their gene expression pattern, in this way stimulating the neighbouring microglia and astroglia for protection and repair (Minghetti and Levi, 1998). Moreover, neurons might secrete protective neurotrophins, antiinflammatory cytokines and chemokines, which downregulate MHC II expression on microglia cells (Neumann et al., 1998). Therefore, the physiological properties and the function of neurons may provide an "immunosuppressive" milieu and thus protect the cortex from potentially severe inflammatory damage. 


\subsection{Cortical lesions show a high propensity for remyelination}

\subsubsection{Normal appearing cortical areas may in part be remyelinated}

We found cortical demyelinated lesions showing signs of remyelination in more than $95 \%$ (28/29) of patients with long standing MS. Remyelination was identified on the light microscopical level by MBP immunohistochemistry and visualization of thin, irregular myelin sheaths. However, the gold standard for the detection of remyelination is electron microscopy, where the thinner myelin sheath after remyelination is reflected in a higher g-ratio (axon/fiber diameter). Our results on the light microscopical level were confirmed by electron microscopy, where remyelinated cortical lesions showed a significantly higher g-ratio. Surprisingly, the g-ratio in areas of light microscopically normal appearing cortical grey matter was significantly higher than in control patients. This suggests that part of the normal appearing cortical grey matter in MS patients may in fact be remyelinated.

\subsubsection{Oligodendrocytes are present and express myelin proteins in the majority of cortical plaques}

In our sample, $23 / 28$ patients $(82 \%)$ with cortical remyelination showed increased numbers of MBP and CNP positive oligodendroglial cells at the lesional borders compared with normal appearing cortex and control cortex. MBP protein is normally not found in the perinuclear cytoplasm of adult, non myelinating oligodendrocytes, but is observed in early stages of myelination and remyelination (Ozawa et al., 1994). High numbers of CNP, but not MBP positive cells were observed at the border of demyelinated cortical lesions. This indicates that cells of the oligodendrocyte lineage are present, but apparently do not progress to remyelinate the plaque centre. Accordingly, only few CNP and MBP positive cells were observed in the centres of demyelinated cortical lesions, indicating a loss or lack of recruitment of oligodendroglial cells. PLP mRNA positive myelinating cells were predominantly found at the lesional borders of remyelinated cortical lesions.

\subsubsection{Cortical microenvironment is permissive for remyelination}

We studied more than 200 white matter and cortical lesions from 33 MS patients. We showed that the scores for remyelination are consistently higher in cortical grey matter. Remyelination as assessed by light microscopy was more extensive in the grey than in the white matter lesions. The reasons for the extensive cortical remyelination observed in our study are not clear so far. Around $40 \%$ of white matter lesions show signs of remyelination in a series of autopsy cases providing evidence for extensive endogenous remyelination (Barkhof et al., 
2003). However, incomplete remyelination restricted to the lesional edge is frequent, and considered to be due to a multitude of inhibitory soluble and tissue factors: a lack of appropriate growth factors, exhaustion of oligodendrocyte progenitors by repeated waves of demyelination, impaired progenitor differentiation, extensive gliosis, and a lack of axonal permissiveness have been put forward (Chang et al., 2002; Charles et al., 2002, Franklin, 2002).

In the grey matter, the distinct microenvironment could modulate the response of oligodendrocyte progenitors to demyelination (Baracskay et al., 2002). Alternatively, oligodendrocytes with distinct physiological properties may reside in the cortex (Noble et al., 2003). Neuronal activity has been reported to enhance oligodendrocyte precursor proliferation (Barres and Raff, 1993). The close neighbourhood to neurons might provide a different, favourable mixture of growth factors. Axons may be more permissive for remyelination close to the neuronal cell body. Furthermore, the less destructive tissue pathology observed in grey matter lesions could lead to better preserved axons, a higher number of preserved oligodendrocyte progenitors, and a greater propensity towards remyelination.

\subsection{Region specific remodelling of synaptic contacts in the dentate nucleus and in the pontine nuclei}

We found equal synaptophysin signal density in chronic cortical MS plaques and in cortex of non-MS control brains. This result suggests either preserved density of presynaptic boutons or reappeared boutons reinnervating the preserved postsynaptic partner neurons in the lesions. Furthermore, we extended our observation that frontal cortex is often involved in chronic MS by showing that remodelling of synaptic contacts may take place in motor relay stations, such as the dentate nucleus and the pontine nuclei. Rather than being induced by local (humoral) factors, MS-related forms of synaptic remodelling may - at least in part - be based on transsynaptic and transneuronal effects of focal demyelination (Blinzinger and Kreutzberg, 1968). The structural changes observed suggest that at least two different mechanisms may be involved: (i) the so-called "synaptic stripping" (Blinzinger and Kreutzberg, 1968), that has been shown to be selective and reversible during ontogenetic development of spinal motorneurons (Conradi and Ronnevi, 1975) and as a retrograde reaction to experimental injury of axons (Moran and Graeber, 2004; Olmos et al.; 1989) and (ii) autophagy and lysosomal degradation of synaptic elements (Wolff et al. 1981; Gallyas et al., 1980) and subsequent transport of residual bodies in intact axons. 


\subsubsection{Region specific synaptic remodelling in the dentate nucleus}

Our immunhistochemical studies showed that the characteristic axo-somatic innervation pattern was eliminated selectively in patients with chronic MS; i.e. the population of large GAD-positive boutons forming axo-somatic synapses were lost from a subpopulation of neurons, while GABAergic and non-GABAergic innervation of their dendrites was apparently preserved. These observations indicate that in MS patients, neurons of the dentate nucleus may selectively lose input from the inhibitory feedback-loop provided by Purkinje cell axons. Other synapses are apparently preserved, especially those that are located on peripheral dendrites and are preferentially composed of small GABAergic and non-GABAergic boutons. The conditions, which might induce axo-somatic denervation remain obscure. The fact that we haven't found cell death of Purkinje cells (not shown) fits to the concept that axo-somatic synapses in the dentate nucleus did not undergo anterograde (Wallerian) degeneration. Also, demyelination of the respective Purkinje cell axons is probably not the reason. Although dissociation of axo-somatic synapses (synaptic stripping) was regularly found in demyelinated parts of the dentate nucleus, it also occurred in periplaque regions and - most importantly also developed in cases without recognizable demyelination in the cerebellum. Thus, synaptic regression in the dentate nucleus might be induced by other conditions, which are determined by the disease itself. Humoral agents are not very likely inducers, because adjacent neurons would react differently. However, suspension of the cerebellar function is more likely. Alterations in connectivity may take place due to damage to any part of the cortico-pontocerebellar tracts. This may explain the consistent reduction of axo-somatic innervation in the dentate nucleus of every MS patients studied. On the other hand, many MS patients are immobilized for long periods of time, i.e. vestibular stimuli and cerebellar compensatory functions are reduced to a minimum. Unfortunately, there are no comparable studies available on effects of long-term immobilisation on cerebellar nuclei.

\subsubsection{Displacement of synapses upon postsynaptic induction in the dentate nucleus: synaptic stripping}

Four modes of synaptic regression have been reported so far. Two of them occur as an irreversible consequence of cell death of pre- and/or postsynaptic neurons and/or degeneration of cell processes. The other two mechanisms, i.e. synaptic stripping and lysosomal degradation of predominantly the presynaptic elements lead to reversible disconnection of synaptic junctions (Wolff et al.; 1995). By electron microscopy, we showed dissociation of the synaptic boutons from the soma membrane by processes of glial cells in the dentate 
nucleus. Dissociation of the pre- and post-synaptic structures is accompanied by several structural changes, such as local impairment of membrane adhesion, expansion of the intercellular space and insulation of the soma membrane with stacks of compacted astrocytic lamellae. This way of synaptic regression is reminiscent of the process that has been initially described on the soma of developing motoneurons (Conradi and Ronnevi, 1975) and experimentally induced by axotomy (Blinzinger and Kreutzberg, 1968). According to the latter authors, facial nerve transection leads to proliferation and activation of microglial cells near the cell bodies of motorneurons in the facial nucleus. Microglia cells seem to be involved in separating the axonal boutons from the soma membrane of the regenerating motoneurons. Intercellular clefts dilate following activation of extracellular proteases (e.g. tissue plasminogen activator) in this way providing space for astrocytic processes that take over the perineuronal positions previously occupied by presynaptic elements of axo-somatic synapses and microglial cells. Interestingly, the disconnection of axo-somatic synapses is selective, i.e. it is restricted to excitatory synapses on motorneurons and reversible when neuronal function in circuits is restituted. This mode of synaptic disconnection is not confined to pathological conditions, but may occur during development of spinal motoneurons (Conradi and Ronnevi, 1975) as well as on pyramidal neurons in the developing cerebral cortex (Bähr and Wolff, 1985). Synaptic stripping was also shown in the arcuate nucleus, were detachment and reappearance of the axo-somatic boutons select for GABA-ergic synapses. Nevertheless, conditions responsible for the synaptic stripping are obviously different. In the arcuate nucleus it is inducible by oestrogen in a concentration-dependent manner (Cardona-Gomez et al., 2000; Naftolin et al., 1996; Parducz et al., 1993; Olmos et al.; 1989), while in the dentate nucleus humoral induction is improbable (see above). Considerable differences that exist among various experimental models do not help in answering the question, how the detachment of boutons from soma membranes is induced in the dentate nucleus in MS. If it occurred 'on postsynaptic demand' (as it seems to be the case in a retrograde axotomy reaction) projections from the dentate nucleus to the thalamus might be disturbed. Unfortunately, we did not have the necessary tissue material available to describe synaptic contacts in ventrolateral thalamic nuclei to examine this possibility.

4.4.3. Displacement of synapses upon presynaptic induction in the dentate nucleus: autophagy and lysosomal degradation of synaptic components

The fourth and also reversible way of structural modifications of synaptic junctions is autophagy and lysosomal degradation of predominantly presynaptic elements (Wolff et al.; 
1989; Wolff et al.; 1981; Gallyas et al., 1980). We showed in the demyelinated dentate nucleus the selective fusion and autophagy of synaptic vesicles surrounded by voluminous astroglial processes that contained glycogen grains and bundles of astroglial intermediate filaments (GFAP-positive structures). Lysosomal degradation may be induced by invagination of parts of presynaptic elements, spinules from the postsynaptic dendrite or finger-like processes from astrocytes. This stage may be characterised by astrocytic swelling and increase in S100-immunreactivity. It is followed by the formation of autophagosomes including synaptic vesicles or mitochondria apparently leading to reduction in synaptic function. During this regressive process the surrounding glia is frequently characterised by increased GFAP immunreactivity and pools of glycogen grains (Wolff et al.; 1995). Lysosomal degradation may either reduce the transmitter content or the capacity of release by removing synaptic vesicles and/or parts of the presynaptic specialisations. It may lead to empty presynaptic elements, i.e. the transmitter release may be completely suspended. These changes are reversible as long as the interneuronal connection persists. However, lysosomal degradation may also include postsynaptic structures and, thus, can result in disconnection and removal of both, pre- and postsynaptic densities, thus elimination of whole synapses (Wolff et al.; 1995).

\subsubsection{Preserved synaptic density in the demyelinated pons}

Synaptic density was histologically characterised by the number of synaptophysinimmunoreactive puncta per area of tissue section. This was largely unaltered in the demyelinated zones of pons, though some structural changes were observed. Occasionally, rarefied and/or focally aggregated synaptophysin-positive material indicated that synaptic vesicles might be redistributed in subpopulations of axonal boutons. Such changes were not only seen in demyelinated plaques. It was also seen in periplaque zones and in the contralateral parts of the respective nucleus but not in the control cases. Thus, we did not find any consistent histological change that could be attributed to demyelination in the pontine nuclei. Nevertheless, it is possible that the reduced synaptic density and focal accumulation of synaptic signals in the nuclei contralateral to the lesion resulted from transsynaptic changes mediated by communicating fibres that are crossing the midline of the pons.

\subsubsection{Multicellular dynamic synaptic reorganisation in the demyelinated pons}

Despite the scarce histological findings, electron microscopy provided evidence for structural changes by which synaptic remodelling could be identified in the demyelinated pons. Numerous synaptic boutons contained large aggregates of vesicles that were dislocated from the active zones of the synaptic junctions. Such vesicle aggregates probably can not 
participate in synaptic transmission and reduce the probability of the quantal release in response to action potentials. In addition, numerous free/vacated postsynaptic densities were found in the demyelinated pons. Such vacant postsynaptic densities may either be formed, when pre-and postsynaptic elements of a synapse have been dissociated from each other or the presynaptic element underwent regression while the postsynaptic one persisted (synaptic regression 'upon presynaptic demand'). Alternatively, there is postsynaptic demand for formation of new synapses; and in this latter case the free/vacant paramembraneous densities may serve as target sites for the formation of new synapses, when compatible presynaptic offers are available. Such a situation occurs during ontogenesis, when formation of synaptic contacts depends on the spatio-temporal matching of the potential pre- and postsynaptic elements. Pre- and postsynaptic elements, however, may be formed independently or each in different numbers. In this case, vacant postsynaptic densities appear and axon varicosities are found without synaptic contacts (Wolff et al. 1995; Dammasch et al., 1986; Wolff and Wagner 1983). Astrocytes play an active role to match the pre- and the postsynaptic contact offerings forming new intercellular connections. From static electron microscopic pictures one can thus suspect that synaptic reorganisation is going on in the pons in MS, which is orchestrated and accompanied by astroglial cells, as suggested (according to the TripartiteSynapse Concept) by Haydon et al. (2001). Correspondingly, voluminous processes of astrocytes appeared nearby axonal varicosities and opposite to free/vacant paramembranous densities. On the one hand, intermittent astrocytes may prevent reinnervation on adjacent vacant postsynaptic densities but on the other hand, astrocytes match axonal varicosities and free postsynaptic densities and assist in forming new synaptic relationships via connecting the pre- and postsynaptic partner neurons. The presence of abundant primary lysosomes (e.g. multivesicular bodies) in pre- and postsynaptic elements and in the perisynaptic astroglia, however, indicate that all three partners may be involved in regulating synaptic reorganisation upon the functional demand of the neuronal network. 


\section{SUMMARY}

Multiple sclerosis (MS) is an inflammatory demyelinating disease of the central nervous system. MS has traditionally been considered a disease affecting the well myelinated white matter areas. Recent insights into axonal pathology in MS raised the attention to the significance of grey matter lesions, which have not been well characterised yet. Thus, the aim of our study was to delineate the fundamental histopathological aspects of MS lesions in the grey matter.

Our work identified extensive cortical demyelination associated with marginal inflammation in autopsy brain tissue of patients with chronic MS. In addition, we found evidence for Tcell/macrophage-mediated active inflammatory demyelination in cortex in biopsy brain tissue of patients with early MS. A direct comparison of the inflammatory activity in white matter and cortical lesions of the same patients revealed that the density and composition of $\mathrm{T}$ lymphocytes was similar in early grey and white matter lesions. Foamy macrophages were, however, essentially absent; the blood brain barrier appeared intact, acute axonal injury was less in the cortical in contrast to the white matter lesions. While acute neuronal injury was apparent in a proportion of early lesions, neurons with synaptic boutons were well preserved in the chronic grey matter plaques.

We examined the frequency and extent of remyelination in cortical and white matter lesions of patients with chronic MS. Cortical remyelination was identified light microscopically by the presence of irregularly arranged and less densely packed myelin sheaths, and confirmed by electron microscopy. A direct comparison of the extent of remyelination in white matter and cortical lesions of the same patients revealed that remyelination of cortical lesions was consistently more extensive. In addition, g-ratios of fibers in the "normal appearing cortex" yielded values consistent with remyelination.

Preserved neuronal cell bodies and synaptic boutons as well as the extensive remyelination in chronic MS cortex suggested efficient repair and adaptive mechanisms that may take place in the grey matter during the course of MS. Therefore, the density, topography and morphology of synapses were investigated in the cerebellar dentate nucleus and in the nuclei of the pons by light and electron microscopy. There was a substantial loss of axosomatic synaptic contacts in the dentate nucleus in all MS patients examined. Synapses on the stem and peripheral dendrites, however, appeared well preserved. Subpopulations of neurons were affected to a variable degree. Dissociation of boutons from the soma membrane occurred 
irrespective of the lesional border; moreover, it could be found in sections, where no demyelinated lesions were recognised. In the pontine nuclei the density of synapses appeared largely preserved. The structural changes observed suggested the mechanisms that may be involved: (i) "synaptic stripping" that has been shown in various experimental models to be selective and reversible, (ii) autophagy and lysosomal degradation of synaptic elements and subsequent transport of residual bodies in intact axons, which has been shown during ontogenetic development to be a mode of reorganisation of synaptic contacts.

Our data imply that inflammatory demyelination occurs in cortex even in early MS. Cortical de- and remyelination are frequent and the propensity to remyelinate is high in cortical MS lesions. Remodelling of synaptic contacts may take place even in late stages of the disease. Further studies are required to determine the conditions under which regeneration can be elicited and supported, thus providing functional improvement of patients suffering from MS. 


\section{REFERENCES}

Adams and Victor's Principles of Neurology. (Victor M and Ropper AH ed.) McGraw-Hill $7^{\text {th }}$ edition.

Aldskogius H. Indirect and direct Wallerian degeneration in the intramedullary root fibres of the hypoglossal nerve. An electron microscopical study in the kitten. Advan. Anat. Embryol. Cell Biol. 1974; 50, 1-78.

Allen IV, Glover G, Anderson R. Abnormalities in the macroscopically normal white matter in cases of mild or spinal multiple sclerosis. Acta Neuropathol. (Berlin) 1981; 7 (Suppl): 176178.

Allen IV, Glover G, McKeown SR, McCormick D. The cellular origin of lysosomal enzymes in the plaque in multiple sclerosis. A histochemical study with combined demonstration of myelin and acid phosphatase. Neuropathology and applied neurobiology. 1979; 5: 197-210.

Allen IV. Pathology of multiple sclerosis. In: Matthews WB, editor. McAlpine's Multiple Sclerosis. Edinburgh: Churchill Livingstone, 1991: 341-78.

Anthony DC, Ferguson B, Matyzak MK, Miller KM, Esiri MM, Perry VH. Differential matrix metalloproteinase expression in cases of multiple sclerosis and stroke. Neuropathol. Appl. Neurobiol. 1997 Oct; 23(5): 406-15.

Babinski J. Recherches sur l'anatomie pathologique de la sclerose en plaque et etude comperative des diverses varietes de la sclreoses de la moelle Archives Physiologie (Paris). 1885; 5-6: 186-207.

Bähr S and Wolff JR. Postnatal development of axosomatic synapses in the rat visual cortex: morphogenesis and quantitative evaluation. J. Comp. Neurol. 1985 Mar 15; 233 (3): 405-20.

Baracskay KL, Duchala CS, Miller RH, Macklin WB, Trapp BD. Oligodendrogenesis is differentially regulated in gray and white matter of jimpy mice. J. Neurosci. Res. 2002; 70: 645-654.

Barkhof F, Bruck W, De Groot CJ et al. Remyelinated lesions in multiple sclerosis: magnetic resonance image appearance. Arch.Neurol. 2003; 60: 1073-1081.

Barres BA, Raff MC. Proliferation of oligodendrocyte precursor cells depends on electrical activity in axons. Nature 1993; 361: 258-260. 
Bjartmar C and Trapp BD. Axonal and neuronal degeneration in multiple sclerosis: mechanisms and functional consequences. Curr. Opin. Neurol. 2001; Jun; 14(3): 271-8.

Bjartmar C, Kidd G, Mork S, Rudick R, Trapp BD. Neurological disability correlates with spinal cord axonal loss and reduced $\mathrm{N}$-acetyl aspartate inchronicmultiplesclerosispatients. Ann. Neurol. 2000; Dec;48 (6): 893-901.

Blakemore WF. Remyelination of the superior cerebellar peduncle in the mouse following demyelination induced by feeding cuprizone. J. Neurol. Sci. 1973; 20: 73-83.

Blinzinger $\mathrm{K}$ and Kreutzberg G. Displacement of synaptic terminals from regenerating motoneurons by microglial cells. Z. Zellforsch. Mikrosk. Anat. 1968; 85(2): 145-57.

Bo L, Vedeler CA, Nyland H, Trapp BD, Mork SJ. Intracortical multiple sclerosis lesions are not associated with increased lymphocyte infiltration. Mult.Scler. 2003a; 9: 323-331.

Bo L, Vedeler CA, Nyland HI, Trapp BD, Mork SJ. Subpial demyelination in the cerebral cortex of multiple sclerosis patients. J.Neuropathol.Exp.Neurol. 2003b; 62: 723-732.

Breitschopf H, Suchanek G, Gould RM, Colman DR, Lassmann H. In situ hybridization with digoxigenin-labeled probes: sensitive and reliable detection method applied to myelinating rat brain. Acta Neuropathol. 1992; 84: 581-587.

Brownell B, Hughes JT. Distribution of plaques in the cerebrum in multiple sclerosis. J.Neurol.Neurosurg.Psychiatry. 1962; 315-320.

Brück W and Stadelmann C. Inflammation and degeneration in multiple sclerosis. Neurol. Sci. 2003a; 24:265-267.

Brück W, Kuhlmann T, Stadelmann C. Remyelination in multiple sclerosis. J.Neurol.Sci. 2003b; 206: 181-185.

Brück W, Schmied M, Suchanek G, Bruck Y, Breitschopf H, Poser S, Piddlesden S, Lassmann H. Oligodendrocytes in the early course of multiple sclerosis. Ann. Neurol. 1994; 35(1):65-73.

Campbell JJ, Butcher EC. Chemokines in tissue-specific and microenviroment-specific lymphocyte homing. Curr. Opin. Immunol. 2000; 12: 336-341.

Capello et al. Multiple-sclerosis: re-expression of a developmental gene in chronic lesions correlates with remyelination. Ann. Neurol. 1997; 41: 797-805.

Cardona-Gomez GP, DonCarlos R, Garcia-Segura LM. Insulin-like growth factor I receptors and estrogen receptors colocalize in female rat brain. Neuroscience. 2000; 99(4):751-60. 
Carroll WM and Jennings AR. Early recruitment of oligodendrocyte precursors in CNS demyelination. Brain. 1994 Jun;117( Pt 3): 563-78.

Carswell R. Pathological anatomy: Illustration of the Elementary Forms of Disease. 1838; London, Orme, Brown, Green and Longmann.

Catalaa I, Fulton JC, Zhang X et al. MR imaging quantitation of gray matter involvement in multiple sclerosis and its correlation with disability measures and neurocognitive testing. AJNR Am.J.Neuroradiol. 1999; 20: 1613-1618.

Chang A, Tourtellotte WW, Rudick R, Trapp BD. Premyelinating oligodendrocytes in chronic lesions of multiple sclerosis. N. Engl. J. Med. 2002; 346. 165-173.

Charles P, Reynolds R, Seilhean D, Rougon G, Aigrot MS, Niezgoda A, Zalc B, Lubetzki S. Re-expression of PSA-NCAM by demyelinated axons: an inhibitor of remyelination in multiple sclerosis? Brain. 2002 Sep; 125(Pt 9):1972-9.

Chao CC, Hu S, Ehrlich L, Peterson PK. Interleukin-1 and tumor necrosis factor alfa synergistically mediate neurotoxicity: involvement of nitric oxide and of N-methyl-Daspartate receptors. Brain. Behav. Immunol. 1995; 9: 355-365.

Chen JT, Narayanan S, Collins DL, Smith SM, Matthews PM, Arnold DL. Relating neocortical pathology to disability progression in multiple sclerosis using MRI. Neuroimage. 2004; 23: 1168-1175.

Coetzee T, Fujita N, Dupree J et al. Myelination in the absence of galactocerebroside and sulfatide: normal structure with abnormal function and regional instability. Cell. 1996; 86: 209-219.

Colonnier M and Gray EG. Degeneration in the cerebral cortex. In Electron microscopy. Fifth International Congress for Electron Microscopy, 1962; Vol. 2 U-3 (S.S. Breese Jr. ed.) Acad. Press NewYork.

Compston A. The pathogenesis and basis for treatment in multiple sclerosis. Clin. Neurol. and Nerosurg. 2004; 106: 246-248.

Conradi S and Ronnevi LO. Spontaneous elimination of synapses on cat spinal motoneurons after birth: do half of the synapses on the cell bodies disappear? Brain Res. 1975 Jul 18; 92 (3): 505-10. 
Corcione A, Casazza S, Ferretti E, Giunti D, Zappia E, Pistorio A, Gambini C, Mancardi GL, Uccelli A, Pistoia V. Recapitulation of B cell differentiation in the central nervous system of patients with multiple sclerosis. Proc. Natl. Acad. Sci. U S A. 2004 Jul 27;101(30): 11064-9.

Cowan WM. Anterograde and retrograde transneuronal degeneration in the central and peripheral nervous system. In Contemporary Research Methods in Neuroanatomy (W.J.H. Nauta and S.O.E. Ebbensson eds.). 1970; pp. 217-249. Springer Verlag, Berlin.

Dammasch IE, Wagner GP, Wolff JR. Self-stabilization of neuronal networks. I. The compensation algorithm for synaptogenesis. Biol Cybern. 1986; 54(4-5): 211-22.

Dawson JW. The histology of multiple sclerosis. Trans. R. Soc. Edinburgh. 1916; 517-740.

De Stefano N, Matthews PM, Fu L, Narayanan S, Stanley J, Francis GS, Antel J Arnold DL. Axonal damage correlates with disability in patients with relapsing-remitting multiple sclerosis. Results of a longitudinal magnetic resonance spectroscopy study. Brain. 1998 Aug; 121 ( Pt 8):1469-77.

Del Maschio A et al. Leukocyte recruitment in the cerebrospinal fluid of mice with experimental meningitis is inhibited by an antibody to junctional adhesion molecule (JAM) J. Exp. Med. 1999; 190:1351-1356.

Dinkler. Zur Kasuistik der multiplen Herdsklerose des Gehirns und Rückenmarks. Deutsche Zeitschrift für Nervenheilkunde 1904; 3: 233-247.

Engelhardt B and Wolburg H. Transendothelial migration of leukocytes: through the front door or around the side of the house? Eur. J. Immunol. 2004; 34, 2955-2963.

Engelhardt B et al. Adhesion molecule phenotype of T lymphocytes in inflamed CSF. J Neuroimmunol. 1998; 84: 92-104.

Estes ML, Rudick RA, Barnett GH, Ransohoff RM. Stereotactic biopsy of an active multiple sclerosis lesion. Immuncytochemical analysis and neuropathologic correlation with magnetic resonance imaging. Archives of Neurology. 1990; 47: 1299-1303.

Ferguson B, Matyszak MK, Esiri MM, Perry VH. Axonal damage in acute multiple sclerosis lesions. Brain. 1997 Mar;120 ( Pt 3): 393-9.

Fife BT, Huffnagle GB, Kuziel WA, Karpus WJ. CC chemokine receptor 2 is critical for induction of experimental autoimmune encephalomyelitis. J. Exp. Med. 2000;192: 899-905.

Flugel A, Schwaiger FW, Neumann H, Medana I et al. Neuronal FasL induces cell death of encephalitogenic T lymphocytes. Brain Pathol. 2000 Jul;10(3): 353-64. 
Fontana A, Grieder A, Arrenbrecht S, Grob P. In vitro stimulation of glia cells by a lymphocyte-produced factor. J. Neurol. Sci. 1980 Apr; 46(1): 55-62.

Foot AK and Blakemore WF. Inflammation stimulates remyelination in areas of chronic demyelination. Brain, 2005; 128: 528-539.

Foxman EF, Campbell JJ, Butcher EC. Multistep navigation and the combinatorial control of leukocyte chemotaxis. J. Cell Biol. 1997;139: 1349-1360.

Franklin RJ. Why does remyelination fail in multiple sclerosis? Nat. Rev. Neurosci. 2002; 3: 705-714.

Frei K, Siepl C, Groscurth P, Bodmer S, Schwerdel C, Fontana A. Antigen presentation and tumor cytotoxicity by interferon-gamma treated microglial cells. Eur. J. Immunol. 1987; 17: 1271-1275.

Friede RL, Beuche W. A new approach toward analyzing peripheral nerve fiber populations. I. Variance in sheath thickness corresponds to different geometric proportions of the internodes. J. Neuropathol. Exp.Neurol. 1985a; 44: 60-72.

Friede RL, Beuche W. Combined scatter diagrams of sheath thickness and fibre calibre in human sural nerves: changes with age and neuropathy. J.Neurol.Neurosurg.Psychiatry 1985b; 48: 749-756.

Gallyas F, Wolff JR, Bottcher H, Zaborszky L. A reliable and sensitive method to localize terminal degeneration and lysosomes in the central nervous system. Stain Technol. 1980 Sep; 55(5): 299-306.

Gay FW, Drye TJ, Dick GW, Esiri MM. The application of multifactorial cluster analysis in the staging of plaques in early multiple sclerosis. Identification and characterization of the primary demyelinating lesion. Brain. 1997 Aug;120 ( Pt 8):1461-83.

Gledhill RF, Harrison BM, McDonald WI. Pattern of remyelination in the CNS. Nature 1973; 244: 443-444.

Goebeler M. Roth J, Henseleit U, Sunderkotter C, Sorg C. Expression and complex assembly of calcium-binding proteins MRP8 and MRP14 during differentiation of murine myelomonocytic cells. J. Leukoc. Biol. 1993 Jan;53 (1): 11-8.

Graesser D et al. Changes in vascular permeability and early onset of experimental autoimmune encephalomyelitis in PECAM-1 (CD31) deficient mice. J. Clin. Invest. 2002; 109 383-392. 
Grant G and Walberg F. The light and electron microscopical appearance of anterograde and retrograde neuronal degeneration In Dynamics of Degeneration and Growth in Neurons. 1974; pp 5-18 (K. Fuxe, L. Olson, Y. Zotterman, eds.) Pergamon Press.

Gray EG. Axo-somatic and axo-dendritic synapses of the cerebral cortex: An electron microscope study. J. Anat. (London); 1959, 93: 420-433.

Gray EG and Hamlyn LH. Electron microscopy of experimental degeneration in the avian optic tectum. J. Anat. 1962; (London) 96 309-316.

Greter M, Heppner FL, Lemos MP, Odermatt BM, Goebels N et al. Dendritic cells permit immune invasion of the CNS in an animal model of multiple sclerosis. Nat. Med. 2005 Mar;11(3): 328-34.

Grossman RI, Braffman BH, Brorson JR, Golgberg HI, Silbenberg DH, Gonzales-Scarano F. Multiple sclerosis: serial study of gadolinium enhanced MR imaging. Radiology. 1988; 169: 117-122.

Hallpike JF, Adams CW, Bayliss OB. Histochemistry of myelin. 8. Proteolytic activity around multiple sclerosis plaques. Histochem J. 1970 May; 2(3):199-208.

Haydon PG. GLIA: listening and talking to the synapse. Nat. Rev. Neurosci. 2001 Mar; 2(3):185-93.

Hemmer B, Archelos JJ, Hartung HP. New concepts in the immunpathogenesis of multiple sclerosis. Nat. Rev. Neurosci. 2002, 3: 291-301.

Hessian PA, Edgeworth J, Hogg N. MRP-8 and MRP-14, two abundant Ca(2+)-binding proteins of neutrophils and monocytes. J. Leukoc. Biol. 1993 Feb;53(2): 197-204.

Hildebrand C, Remahl S, Persson H, Bjartmar C. Myelinated nerve fibres in the CNS. Prog. Neurobiol. 1993; 40: 319-384.

Hill KE, Zollinger LV, Watt HE et al. Inducible nitric oxide synthase in chronic active multiple sclerosis plaques: distribution, cellular expression and association with myelin damage. J. Neuroimmunol. 2004; 151: 71-179.

Hirsch M-A, Wietzerbin J, Pierres M, Goridis C. Expression of Ia antigens by cultured astrocytes treated with gamma-interferon. Neurosci. Lett. 1983; 41:199-204.

Hoek RM, Ruuls SR, Murphy CA, Wright GJ, Goddard R, Zurawski SM, Blom B, Homola ME, Streit WJ, Brown MJ, Barclay AN, Sedgwick JD. Down-regulation of the macrophage lineage through interaction with OX2 (CD200). Science. 2000; 290: 1768-1771. 
Höftberger R, Aboul-Enein F, Brück W et al. Expression of major histocompatibility complex class I molecules on the different cell types in multiple sclerosis lesions. Brain Pathol. 2004; 14: 43-50.

Huang DR, Wang J, Kivisäkk P, Rollins BJ, Ransohoff RM. Absence of monocyte chemoattractant protein 1 in mice leads to decreased local macrophage recruitment and antigen specific $\mathrm{T}$ helper cell type 1 immune response in experimental autoimmune encephalomyelitis. J. Exp. Med. 2001; 193: 713-726.

Issazadeh S, Mustafa M, Ljungdahl A, Hojeberg B, Dagerlind A, et al. Interferon- $\gamma$, interleukin-4 and transforming growth factor $\beta$ in experimental autoimmune encephalomyelitis in Lewis rats: dynamics of cellular mRNA expression in the central nervous system and lymphoid cells. J. Neurosci. Res. 1995; 40:579-90.

Izikson L, Klein RS, Charo IF, Weiner HL, Luster AD. Resistance to experimental autoimmune encephalomyelitis in mice lacking the CC chemokine receptor (CCR)2. J. Exp. Med. 2000; 192: 1075-1080.

Jacobs KM, Donoghue JP. Reshaping the cortical motor map by unmasking latent intracortical connections. Science. 1991; 251: 944-7.

Jones J, Frith S, Piddlesden S, Morgan BP, Compston DA, Campbell AK, Hallett MB. Imaging $\mathrm{Ca} 2+$ changes in individual oligodendrocytes attacked by $\mathrm{T}$-cell perforin. Immunology. 1991 Dec;74 (4): 572-7.

John R et al. Multiple sclerosis: Re-expression of a developmental pathway that restricts oligodendrocyte maturation. Nature Med. 2002; 8, 1115-1121.

Kalled SL. The role of BAFF in immune function and implications for autoimmunity. Immunol. Rev. 2005 Apr;204:43-54.

Kerschensteiner M, Bareyre FM; Buddenberg BS, Merkler D, Stadelmann C, Bruck W; Misgeld T, Schwab ME. Remodeling of axonal connections contributes to recovery in an animal model of multiple sclerosis. J. Exp. Med. 2004 Oct 18; 200(8):1027-38.

Kidd D, Barkhof F, McConnell R, Algra PR, Allen IV, Revesz T. Cortical lesions in multiple sclerosis. Brain 1999; 122 ( Pt 1): 17-26.

Kirk J, Plumb J, Mirakhur M, McQuaid S. Tight junction abnormality in multiple sclerosis white matter affects all calibres of vessel and is associated with blood brain barrier leakage and active demyelination. J. Pathol. 2003; 201:319-327. 
Kornek B, Storch MK, Weissert R, Wallstroem E, et al. Multiple sclerosis and chronic autoimmune encephalomyelitis: a comparative quantitative study of axonal injury in active, inactive, and remyelinated lesions. Am. J. Pathol. 2000 Jul; 157(1):267-76.

Krumbholz M, Theil D, Derfuss T, Rosenwald A, Schrader F, Monoranu C -M, Kalled S L, Hess D M, Serafini B, Aloisi F, Wekerle H, Hohlfeld R, Meinl E. BAFF is produced by astrocytes and upregulated in multiple sclerosis lesions and primary central nervous system lymphoma. J. Exp. Med. 2005; 201: 195-200.

Lassmann H, Bruck W, Lucchinetti C, Rodriguez M. Remyelination in multiple sclerosis. Mult.Scler. 1997; 3: 133-136.

Lassmann H, Bruck W, Lucchinetti C. Heterogeneity of multiple sclerosis pathogenesis: implications for diagnosis and therapy. Trends Mol.Med. 2001; 7: 115-121.

Lassmann H. Comparative neuropathology of chronic experimental autoimmune encephalomyelitis and multiple sclerosis. Schriftenreihe Neurologie 1983; 25: 1-135.

Lassmann H. Neuropathology in multiple sclerosis: new concepts. Mult. Scler. 1998; 4: 9398.

Lassmann H. Recent neuropathological findings in MS-implications for diagnosis and therapy J. Neurol. 2004; 251 Suppl. 4: IV2-IV5.

Lechner $\mathrm{F}$ et al. Antibodies to the junctional adhesion molecule cause disruption of endothelial cells and do not prevent leukocyte influx into the meninges after viral or bacterial infection. J. Infect. Dis. 2000; 182, 978-982.

Lee SC, Moore GR, Golensky G, Raine CS. Multiple sclerosis: a role of astroglia in active demyelination suggested by class II MHC expression and ultrastructural study. J. Neuropathol. Exp. Neurol. 1990; 49 122-136.

Lovas G, Szilagyi N, Palkovits M, Komoly S. Axonal changes in chronic demyelinated cervical spinal cord plaques. Brain 2000; 123:308-317.

Lucchinetti C, Bruck W, Parisi J, Scheithauer B, Rodriguez M, Lassmann H. A quantitative analysis of oligodendrocytes in multiple sclerosis lesions. A study of 113 cases. Brain 1999; 122 ( Pt 12): 2279-2295.

Lucchinetti C, Brück W, Parisi J, Scheithauer B, Rodriguez M, Lassmann H. Heterogeneity of multiple sclerosis lesions: implications for the pathogenesis of demyelination. Ann. Neurol. 2000 Jun; 47(6): 707-17. 
Lucchinetti CF, Bruck W, Rodriguez M, Lassmann H. Distinct patterns of multiple sclerosis pathology indicates heterogeneity on pathogenesis. Brain Pathol. 1996; 6: 259-274.

Ludwin SK, Sternberger NH. An immunohistochemical study of myelin proteins during remyelination in the central nervous system. Acta Neuropathol. 1984; 63: 240-248.

Lumsden CE. The neuropathology of multiple sclerosis. In: Vinken PJ, Bruyn GW, editors. Multiple sclerosis and other demyelinating diseases. Amsterdam: North-Holland Publishing Company, 1970: 217-309.

Mackay F and Tangye SG. The role of the BAFF/APRIL system in B-cell homeostasis and lymphoid cancers. Curr. Oppin. Pharmacol. 2004; 4: 347-354.

Marburg O. Die sogenannte "akute multiple sklerose". Jahrbücher für Psychiatrie und Neurologie 1906; 27:211-312.

Martin R, McFarland HF, McFarlin DE. Immunological aspects of demyelinating diseases. Annu. Rev. Immunol. 1992; 10: 153-87.

Medana IM, Gallimore A, Oxenius A, Martinic MM, Wekerle H, Neumann H. MHC class Irestricted killing of neurons by virus-specific CD8+ T-lymphocytes is effected through the Fas/FasL, but not the perforin pathway. Eur. J. Immunol. 2000; 30: 3623-33.

Mews I, Bergmann M, Bunkowski S, Gullotta F, Brück W. Oligodendrocyte and axon pathology in clinically silent multiple sclerosis. Mult. Scler. 1998; 4: 55-62.

Miller DH, Rudge P, Johnson G et al. Serial gadolinium enhanced magnetic resonance imaging in multiple sclerosis. Brain. 1988; 111: 927-939.

Minghetti L and Levi G. Microglia as effector cells in brain damage and repair: focus on prostanoids and nitric oxide. Prog. Neurobiol. 1998; 54:99-125.

Monson NL, Brezinschek HP, Brezinschek I, Mobley A, Vaughan GK, Frohman EM, Racke MK, Lipsky PE. Receptor revision and atypical mutational characteristics in clonally expanded B cells from the cerebrospinal fluid of recently diagnosed multiple sclerosis patients. J. Neuroimmunol. 2005 Jan;158 (1-2):170-81.

Moran LB and Graeber MB. The facial nerve axotomy model. Brain Res. Brain Res. Rev. 2004 Mar; 44(2-3): 154-78.

Morell $\mathrm{P}$ et al. Gene expression in brain during cuprozone-induced demyelination and remyelination. Mol. Cell. Neurosci. 2000; 12. 220-227. 
Morgen K, Kadom N, Sawaki L, Tessitore A et al. Training-dependent plasticity in patients with multiple sclerosis. Brain. 2004 Nov; 127(Pt 11): 2506-17.

Naftolin F, Mor G, Horvath TL, Luquin S, Fajer AB, Kohen F, Garcia-Segura LM. Synaptic remodeling in the arcuate nucleus during the estrous cycle is induced by estrogen and precedes the preovulatory gonadotropin surge. Endocrinology. 1996 Dec; 137(12): 5576-80.

Neumann H, Boucraut J, Hahnel C, Misgeld T, Wekerle H. Neuronal control of MHC II inducibility in rat astrocytes und microglia. Eur. J. Neurosci. 1996; 8: 2582-2590.

Neumann H, Cavalie A, Jenne DE, Wekerle H. Induction of MHC I genes in neurons. Science. 1995 Jul 28; 269(5223): 549-52.

Neumann H, Misgeld T, Matsumuro K, Wekerle H. Neurotrophins inhibit major histocompatibility class II inducibility of microglia: involvement of the p75 nerurotrophin receptor. Proc. Natl. Acad. Sci. USA. 1998; 95: 5779-5784.

Neumann H. Control of glial immune function by neurons. Glia. 2001; 36:191-199.

Newcombe J, Hawkins CP, Henderson CL et al. Histopathology of multiple sclerosis lesions detected by magnetic resonance imaging in unfixed postmortem central nervous system tissue. Brain 1991; 114 (Pt 2): 1013-1023.

Newman TA, Woolley ST, Hughes PM, Sibson NR, Anthony DC, Perry VH. T-cell and macrophage-mediated axonal damage in the absence of the CNS specific-immune response: involvement of metallopreteinases. Brain 2001; 124 2203-2214.

Nissl, F. Über die Veränderungen der Ganglienzellen am Facialiskern des Kaninchens nach Ausreissung der Nerven. Allg. Z. Psyichiat. 1892; 48, 197-198.

Noble M, Arhin A, Gass D, Mayer-Proschel M. The cortical ancestry of oligodendrocytes: common principles and novel features. Dev.Neurosci. 2003; 25: 217-233.

Olmos G, Naftolin F, Perez J, Tranque PA, Garcia-Segura LM. Synaptic remodeling in the rat arcuate nucleus during the estrous cycle. Neuroscience. 1989;32(3):663-7.

Owens GP, Ritchie AM, Burgoon MP, Williamson RA, Corboy JR, Gilden DH. Single-cell repertoire analysis demonstrates that clonal expansion is a prominent feature of the $\mathrm{B}$ cell response in multiple sclerosis cerebrospinal fluid. J. Immunol. 2003 Sep 1; 171(5): 2725-33.

Ozawa K, Suchanek G, Breitschopf H et al. Patterns of oligodendroglia pathology in multiple sclerosis. Brain 1994; 117 ( Pt 6): 1311-1322. 
Pantano P, Iannetti GD, Caramia F, Mainero C, Di Legge S, Bozzao L et al. Cortical motor reorganization after a single clinical attack of multiple sclerosis. Brain 2002; 125: 1607-15.

Parducz A, Perez J, Garcia-Segura LM. Estradiol induces plasticity of gabaergic synapses in the hypothalamus. Neuroscience. 1993 Mar; 53(2): 395-401.

Peterson JW, Bo L, Mork S, Chang A, Trapp BD. Transected neurites, apoptotic neurons, and reduced inflammation in cortical multiple sclerosis lesions. Ann.Neurol. 2001; 50: 389-400.

Piani D, Frei K, Do K Q, Cuenod M, Fontana M. Murine brain macrophages induced NMDA receptor mediated neurotoxicity in vitro by secreting glutamate. Neurosci. Lett. 1991; 159162.

Plumb J, McQuaid S, Mirakhur M, Kirk J. Abnormal endothelial tight junctions in active lesions and normal-appearing white matter in multiple sclerosis. Brain Pathol. 2002; Apr; 12(2): 154-69.

Powell T, Sussman JG, Davies-Jones GA. MR imaging in acute multiple sclerosis: ringlike appearance in plaques suggesting the presence of paramagnetic free radicals. American Journal of Neuroradiology. 1992; 13: 1544-1546.

Prineas J. Pathology of the early lesion in multiple sclerosis. Hum. Pathol. 1975; 6: 531.

Prineas JW and Wright RG. Macrophages, lymphocytes and plasma cells in the perivascular compartment in chronic multiple sclerosis. Laboratory Investigation, 1978; 38: 409-421.

Prineas JW, Barnard RO, Kwon EE, Sharer LR, Cho ES. Multiple sclerosis: remyelination of nascent lesions. Ann. Neurol. 1993; 33: 137-151.

Prineas JW, Connell F. Remyelination in multiple sclerosis. Ann. Neurol. 1979; 5: 22-31.

Prineas JW, Kwon EE, Goldenberg PZ, Ilyas AA, Quarles RH et al. Multiple sclerosis. Oligodendrocyte proliferation and differentiation in fresh lesions. Lab. Invest. 1989 Nov; 61(5): 489-503.

Prineas JW. The neuropathology of multiple sclerosis. In: Koetsier, editor. Demyelinating Diseases. Amsterdam: 1985: 337-98.

Raine CS, Scheinberg LC. On the immunopathology of plaque development and repair in multiple sclerosis. J. Neuroimmunol. 1988; 20:189-201.

Reddy H, Narayanan S, Arnoutelis R, Jenkinson M, Antel J, Matthews PM, et al. Evidence for adaptive functional changes in the cerebral cortex with axonal injury from multiple sclerosis. Brain 2000; 123: 2314-20. 
Rindfleisch E. Histologisches Detail zur grauen Degeneration von Gehirn und Rückenmark. Archiv für Pathologische Anatomie und Physiologie und fur Klinische Medizin (Virchow). 1863; 26: 474-483.

Ritchie AM, Gilden DH, Williamson RA, Burgoon MP, Yu X, Helm K, Corboy JR, Owens GP. Comparative analysis of the CD19+ and CD138+ cell antibody repertoires in the cerebrospinal fluid of patients with multiple sclerosis. J. Immunol. 2004 Jul 1;173(1):649-56.

Rocca MA, Pagani E, Ghezzi A, Falini A, Zaffaroni M, Colombo B, et al. Functional cortical changes in patients with multiple sclerosis and non- specific findings on conventional magnetic resonance imaging scans of the brain. Neuroimage 2003; 19: 826-36.

Rodriguez $M$ and Lennon VA. Immunoglobulins promote remyelination in the central nervous system. Ann. Neurol. 1990 Jan;27(1): 12-7.

Rose JW, Hill KE, Watt HE, Carlson NG. Inflammatory cell expression of cyclooxigenase-2 in the multiple sclerosis lesion. J. Neuroimmunol. 2004; 149: 40-49.

Rossolimo G. Zur Frage über die Multiple Sklerose und Gliose. Deutsche Zeitschrift für Nervenheilkunde 1897; 88-121.

Roth J, Goebeler M, Wrocklage V, van den Bos C, Sorg C. Expression of the calcium-binding proteins MRP8 and MRP14 in monocytes is regulated by a calcium-induced suppressor mechanism. Biochem. J. 1994 Aug 1; 301 ( Pt 3): 655-60.

Rottman JB et al. Leukocyte recruitment during onset of experimental autoimmune encephalomyelitis is CCR1 dependent. Eur. J. Immunol. 2000; 30: 2372-2377.

Sailer M, Fischl B, Salat D, Tempelmann C, Schonfeld MA, Busa E et al. Focal thinning of the cerebral cortex in multiple sclerosis. Brain. 2003 Aug;126 (Pt 8): 1734-44.

Saini S, DeStefano N, Smith S, Guidi L, Amato MP, Federico A, Matthews PM. Altered cerebellar functional connectivity mediates potential adaptive plasticity in patients with multiple sclerosis. J. Neurol. Neurosurg. Psychiatry. 2004 Jun;75(6):840-6.

Sander M. Hirnrindenbefunde bei multipler Sklerose. Monatsschr. Psych. Neurol. 1898; IV: 429-436.

Schmitt FO, Bear RS. The optical properties of vertebrate nerve axons as related to fibre size. J. Cell. Comp. Physiol. 1937; 9: 261-273.

Schwab C, McGeer PL. Complement activated C4d immunoreactive oligodendrocytes delineate small cortical plaques in multiple sclerosis. Exp.Neurol. 2002; 174: 81-88. 
Scolding NJ, Jones J, Compston DA, Morgan BP. Oligodendrocyte susceptibility to injury by T-cell perforin. Immunology. 1990 May;70 (1): 6-10.

Selmaj KW, Farooq M, Norton WT, Raine CS, Brosnan CF. Proliferation of astrocytes in vitro in response to cytokines. A primary role for tumor necrosis factor. J Immunol. 1990; 144: 129-135.

Serafini B, Rosicarelli B, Magliozzi R, Stigliano E, Aloisi F. Detection of ectopic B-cell follicles with germinal centres in the meninges of patients with secondary progressive multiple sclerosis. Brain Pathol. 2004; Apr;14(2):164-74.

Sewell WA, Jolles S. Immunomodulatory action of intravenous immunoglobulin. Immunology. 2002; 107:387-93.

Sim FJ, Hinks GL, Franklin RJ. The re-expression of the homeodomain transcription factor Gtx during remyelination of experimantally-induced demyelinating lesions in young and oldrat brain. Neuroscience. 2000;100: 131-139.

Smith JK and McDonald WI. The pathophysiology of multiple sclerosis: the mechanisms underlying the production of symptoms and the natural history of the disease. Phil. Trans. R. Soc. Lond. B. 1999; 354: 1649-1673.

Soffer D and Raine CS. Morphologic analysis of axo-glial membrane specializations in the demyelinated central nervous system. Brain Res.1980 Mar 31; 186(2): 301-13.

Stadelmann C, Kerschensteiner M, Misgeld T, Bruck W, Hohlfeld R, Lassmann H. BDNF and gp145trkB in multiple sclerosis brain lesions: neuroprotective interactions between immune and neuronal cells? Brain 2002; 125: 75-85.

Taylor EW. Zur pathologischen Anatomie der multiplen Sklerose. Deutsche Zeitschrift für Nervenheilkunde 1892; 1-26.

Trapp BC, Peterson J, Ransohoff RM, Rudick R, Mork S, Bö L. Axonal transection in the lesions of multiple sclerosis. N. Engl. J. Med. 1998 Jan 29;338 (5): 278-85.

Trapp BC. Pathogenesis of multiple sclerosis: the eyes only see what the mind is prepared to comprehend. Ann. Neurol. 2004 April; 55 (4): 455-7.

Uccelli A, Aloisi F, Pistoia V. Unveiling the enigma of the CNS as a B-cell fostering environment. Trends Immunol. 2005 May; 26 (5): 254-9. 
Vos CM, van Haastert ES, De Groot CJ, et al. Matrix metalloproteinase-12 is expressed in phagocytic macrophages in active multiple sclerosis lesions. J. Neuroimmunol. 2003; 138:106-114.

Werner P, Pitt D, Raine CS. Multiple sclerosis: altered glutamate homeostasis in lesions correlates with oligodendrocyte and axonal damage. Ann. Neurol. 2001; 50:169-180.

Wolff JR, Holzgraefe M, Eins S, Eulner S, Zaborszky L. The temporo-spatial course of degeneration after cutting cortico-cortical connections in adult rats. Cell Tissue Res. 1981; 214(2): 303-21.

Wolff JR, Laskawi R, Spatz WB, Missler M. Structural dynamics of synapses and synaptic components. Behav. Brain Res. 1995 Jan 23; 66(1-2): 13-20.

Wolff JR, Leutgeb M; Holzgraefe M, Teuchert G. Synaptic remodelling during primary and reactive synaptogenesis. In H Rahmann (ed.), Fundamentals of memory formation: Neuronal plasticity and brain functions. Gustav Fisher Stuttgart, 1989, pp. 68-82.

Wollf JR and Wagner GP. Self-organisation in synaptogenesis: interaction between the formation of excitatory and inhibitory synapses. In E. Basar et al. (Eds.) Synergetics of the Brain, Springer, Berlin, 1983, pp. 50-59.

Wolswijk G. Oligodendrocyte precursor cells in the demyelinated spinal cord. Brain. 2002; 125: $338-49$.

Wolswijk G. Oligodendrocyte survival, loss and birth in lesions of chronic-stage multiple sclerosis.Brain. 2000 Jan;123 ( Pt 1):105-15.

Woodroofe MN and Cuzner ML. Cytokine mRNA expression in inflammatory multiple sclerosis lesions: detection by non-radioactive in situ hybridization. Cytokine. 1993 Nov; $5(6): 583-8$.

Zeine $\mathrm{R}$ and Owens T. Direct demonstration of the infiltration of murine central nervous system by Pgp-1/CD44 ${ }^{\text {high }}$ CD $45 \mathrm{RB}^{\text {low }} \mathrm{CD} 4+\mathrm{T}$ cells that induce experimental autoimmune encephalomyelitis. J Neuroimmunol. 1992; 40: 57-70. 
CURRICULUM VITAE

Name

Date of birth

Nationality

1994-2001

2001

MD thesis

2001-2005

$\mathrm{PhD}$ thesis
Monika ALBERT

22. July 1974

Hungarian

University of Semmelweis, Faculty of Medicine, Budapest, Hungary

Doctor of medicine (MD)

University of Semmelweis, Budapest, Hungary

Apoptosis-inducing effect of receptor tyrosin-kinase inhibitors

Prof. Bela Szende, $1^{\text {st }}$ Department of Pathology and Experimental Cancer Research, University of Semmelweis, Budapest, Hungary

Dr. György Keri, Department of Biochemistry, University of Semmelweis, Budapest, Hungary

International Max Planck Research School for Neurosciences, MSc/PhD Program, Göttingen, Germany

Grey matter pathology in multiple sclerosis

Prof. Wolfgang Brück, Institute of Neuropathology, University of Göttingen, Germany 


\section{PUBLICATIONS}

\section{Published abstracts}

Chronic psychosocial stress down-regulates the GluR2 subunits in the prefrontal cortex

Albert M, Flugge G, Fuchs E, Hesselink MB, Michael GJ, Michael-Titus AT

Br. J. Pharmacol., 1(4), 124P (2004)

Extensive remyelination in cortex of patients with long-standing multiple sclerosis

Albert M, Stadelmann C, Antel J, Brück W

Multiple Sclerosis, 10(2), 8 (2004)

Extensive remyelination in cortex of patients with long-standing multiple sclerosis

Albert M, Stadelmann C, Antel J, Brück W

Acta Neuropathol., 108(4), 364 (2004)

Regression of synapses in the cerebellar dentate nucleus of patients with multiple sclerosis

Albert M, Antel J, Prineas JW, Palkovits M, Wolff JR, Brück W, Stadelmann C

Multiple Sclerosis, submitted

\section{Research articles}

Extensive cortical remyelination in patients with chronic multiple sclerosis

Albert M, Antel J, Brück W, Stadelmann C - submitted

Remodelling of synapses in the cerebellar and pontine nuclei of patients with multiple sclerosis

Albert M, Antel J, Prineas JW, Palkovits M, Wolff JR, Brück W, Stadelmann C - submitted

Inflammation in cortex of patients with early multiple sclerosis

Albert M, Brück W, Stadelmann C - submitted 